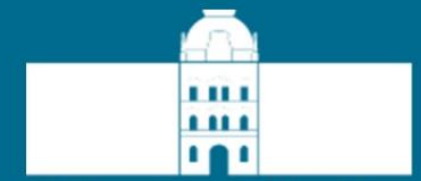

University of Maribor

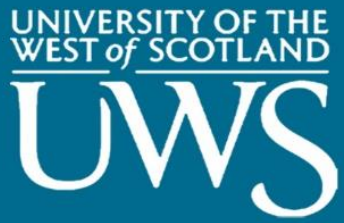

\title{
$10^{\mathrm{TH}}$ International Conference on Sustainable Energy and Environmental Protection:
}

\section{Mechanical Engineering}

(June 27 ${ }^{T H}-30^{T H}, 2017$, Bled, Slovenia)

(Conference Proceedings)

\section{Editors:}

Emeritus Prof. dr. Jurij Krope Prof. dr. Abdul Ghani Olabi Prof. dr. Darko Goričanec Prof. dr. Stanislav Božičnik 
University of Maribor Press 


\title{
$10^{\mathrm{TH}}$ International Conference on Sustainable Energy and Environmental Protection
}

\author{
Mechanical Engineering \\ (June 27 ${ }^{\mathrm{TH}}-30^{\mathrm{TH}}, 2017$, Bled, Slovenia) \\ (Conference Proceedings)
}

Editors:

Emeritus Prof. dr. Jurij Krope

Prof. dr. Abdul Ghani Olabi

Prof. dr. Darko Goričanec

Prof. dr. Stanislav Božičnik 
Title: $\quad 10^{\mathrm{TH}}$ International Conference on Sustainable Energy and Environmental Protection (June $27^{\mathrm{TH}}-30^{\mathrm{TH}}, 2017$, Bled, Slovenia) (Conference Proceedings)

Subtitle: Mechanical Engineering

Editors: Emeritus Prof. Jurij Krope, Ph.D. (University of Maribor, Slovenia), Prof. Abdul Ghani Olabi, Ph.D. (University of the West of Scotland, UK), Asso. Prof. Darko Goričanec, Ph.D. (University of Maribor, Slovenia), Asso. Prof. Stanislav Božičnik (University of Maribor, Slovenia).

Review: Prof. Željko Knez, Ph.D. (University of Maribor, Slovenia), Prof. Niko Samec, Ph.D. (University of Maribor, Slovenia).

Tehnical editors : Jan Perša (University of Maribor Press), Armin Turanović (University of Maribor Press).

Design and layout: University of Maribor Press

Conference: $\quad 10^{\mathrm{TH}}$ International Conference on Sustainable Energy and Environmental Protection

Honorary Committee:

Abdul Ghani Olabi, Ph.D. (Honorary President, University of the West of Scotland, United Kingdom), Igor Tičar, Ph.D (Rector of the University of Maribor, Slovenia), Niko Samec Ph.D. (Pro-rector of University of Maribor, Slovenia), Zdravko Kravanja, Ph-D. (Dean of the Faculty of Chemistry and Chemical Engineering, University of Maribor, Slovenia).

Organising Committee:

Jurij Krope, Ph.D. (University of Maribor, Slovenia), Darko Goričanec, Ph.D. (University of Maribor, Slovenia), Stane Božičnik, Ph.D. (University of Maribor, Slovenia), Peter Trop, Ph.D. (University of Maribor, Slovenia), Danijela Urbancl, Ph.D. (University of Maribor, Slovenia), Sonja Roj (University of Maribor, Slovenia), Željko Knez, Ph.D. (University of Maribor, Slovenia), Bojan Štumberger, Ph.D. (University of Maribor, Slovenia), Franci Čuš, Ph.D. (University of Maribor, Slovenia), Miloš Bogataj, Ph.D. (University of Maribor, Slovenia), Janez Žlak, Ph.D (Mine Trbovlje Hrastnik, Slovenia), LL. M. Tina Žagar (Ministry of Economic Development and Technology), Igor Ivanovski, MSc. (IVD Maribor, Slovenia), Nuša Hojnik, Ph.D. (Health Center Maribor).

Programme Committee:

Prof. Abdul Ghani Olabi (UK), Emeritus Prof. Jurij Krope (Slovenia), Prof. Henrik Lund (Denmark), Prof. Brian Norton (Ireland), Prof. Noam Lior (USA), Prof. Zdravko Kravanja (Slovenia), Prof. Jirí Jaromír Klemeš (Hungary), Prof. Stane Božičnik (Slovenia), Prof. Bojan Štumberger (Slovenia), Prof. Soteris Kalogirou (Cyprus), Prof. Stefano Cordiner (Italy), Prof. Jinyue Yan (Sweden), Prof. Umberto Desideri (Italy), Prof. M.S.J. Hashmi (Ireland), Prof. Michele Dassisti (Italy), Prof. Michele Gambino (Italy), Prof. S. Orhan Akansu (Turkey), Dr. David Timoney (Ireland), Prof. David Kennedy (Ireland), Prof. Bekir Sami Yilbas (Saudi Arabia), Dr. Brid Quilty (Ireland), Prof. B. AbuHijleh (UAE), Prof. Vincenc Butala (Slovenia), Prof. Jim McGovern (Ireland), Prof. Socrates Kaplanis (Greece), Dr. Hussam Jouhara (UK), Prof. Igor Tičar (Slovenia), Prof. Darko Goričanec (Slovenia), Dr. Joseph Stokes (Ireland), Prof. Antonio Valero (Spain), Prof. Aristide F. Massardo (Italy), Prof. Ashwani Gupta (USA), Dr. Aoife Foley (UK), Dr. Athanasios Megartis (UK), Prof. Francesco Di Maria (Italy), Prof. George Tsatsaronis (Germany), Prof. Luis M. Serra (Spain), Prof. Savvas Tassou (UK), Prof. Luigi Alloca (Italy), Prof. Faek Diko (Germany), Dr. F. Al-Mansour (Slovenia), Dr. Artur Grunwald (Germany), Dr. Peter Trop (Slovenia), Prof. Philippe Knauth (France), Prof. Paul Borza (Romania), Prof. Roy Douglas (UK), Prof. Dieter Meissner (Austria), Dr. Danijela Urbancl (Slovenia), Prof. Daniel Favrat (Switzerland), Prof. Erik Dahlquist (Sweden), Prof. Eric Leonhardt (USA), Prof. GianLuca Rospi (Italy), Prof. Giuseppe Casalino (Italy), Prof. J. Dawson (USA), Dr. Josè Simoes (Portugal), Prof. Kadir Aydin (Turkey), Dr. Khaled Benyounis (Ireland), Prof. Laszlo Garbai (Hungary), Prof. Mariano Martin (Spain), Prof. Masahiro Ishida (Japan), Prof. Michael Seal (USA), Prof. Marco Spinedi (Italy), Prof. Michio Kitano (Japan), Prof. Milovan Jotanović (BiH), Prof. Nafiz Kahraman (Turkey), Prof. Na Zhang (China), Prof. Naotake Fujita (Japan), Prof. Niko Samec (Slovenia), Prof. Oleksandr Zaporozhets (Ukraine), Prof. Osama Al-Hawaj (Kuwait), Prof. Petar Varbanov (Hungary), Prof. Peter Goethals (Belgium), Prof. Qi Zhang (China), Prof. Rik Baert (The Netherlands), Prof. Rolf Ritz (USA), Dr. Stephen Glover (UK), Prof. Signe Kjelstrup (Norway), Dr. Sumsun Naher (UK), Prof. Sven Andersson (Sweden), Dr. Salah Ibrahim (UK), Prof. Sebahattin Unalan (Turkey), Prof. Sabah Abdul-Wahab Sulaiman (Oman), Prof. Somrat Kerdsuwan (Thailand), Prof. T. Hikmet Karakoç (Turkey), Prof. Tahir Yavuz (Turkey), Prof. Hon Loong Lam (Thailand), LL.M. Tina Žagar (Slovenia), Prof. A.M.Hamoda (Qatar), Prof. Gu Hongchen (China), Prof. Haşmet Turkoglu (Turkey), Dr. Hussam Achour (Ireland), Dr. James Carton (Ireland), Dr. Eivind Johannes (Norway), Prof. Elvis Ahmetović (BiH), Prof. 
D.G.Simeonov (Bulgaria), Prof. Abdelakder Outzourhit (Morocco), Prof. Bilge Albayrak Çeper (Turkey), Prof. Bekir Zühtü Uysal (Turkey), Prof. D. Bradley (UK), Dr. Silvia Tedesco (UK), Dr. Valentin Ivanov (Germany), Dr. Vincent Lawlor (Austria), Prof. Yonghua Cheng (Belgium), Prof. Yasufumi Yoshimoto (Japan), Prof. Yahya Erkan Akansu (Turkey), Prof. Yunus Ali Çengel (Turkey), Prof. Zeljko Knez (Slovenia), Prof. Zoltan Magyar (Hungary), Dr. William Smith (Ireland), Dr. Abed Alaswad (UK).

First published in 2017 by

University of Maribor Press

Slomškov trg 15, 2000 Maribor, Slovenia

tel. +386225042 42, fax +38622523245

http://press.um.si, zalozba@um.si

\section{Co-published by}

University of Maribor, Faculty of Chemistry and Chemical Engineering

Smetanova ulica 17,2000 Maribor, Slovenia

tel. +386 (0)2 2294 400, faks + $386(0) 22527774$

http://www.fkkt.um.si, fkkt@um.si

Published: 5. July 2017

\section{(C) University of Maribor Press}

All rights reserved. No part of this book may be reprinted or reproduced or utilized in any form or by any electronic, mechanical, or other means, now known or hereafter invented, including photocopying and recording, or in any information storage or retrieval system, without permission in writing from the publisher.

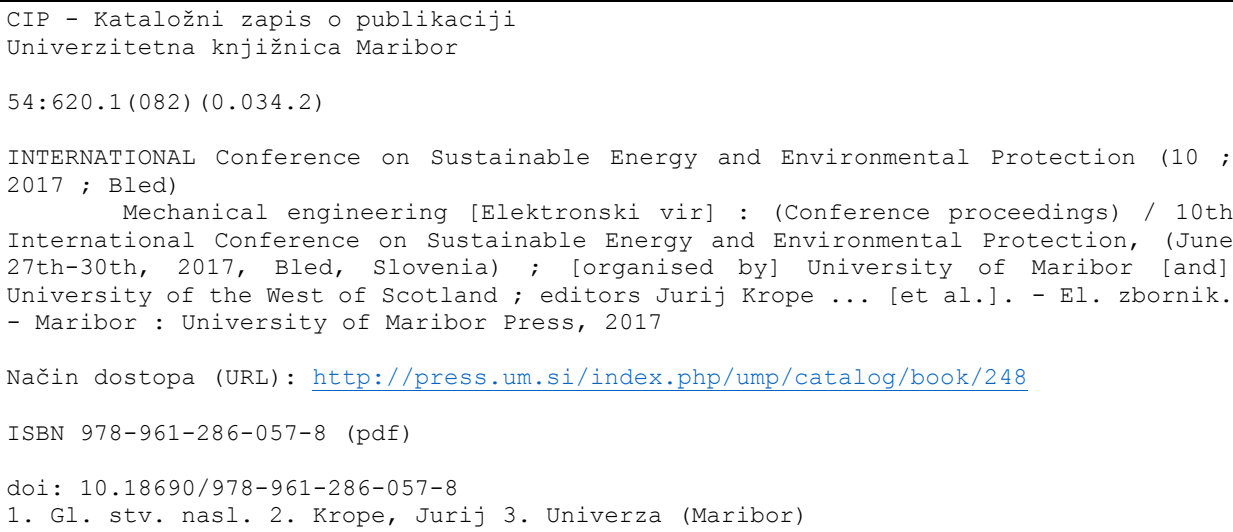

ISBN 978-961-286-057-8

DOI: https://doi.org/10.18690/978-961-286-057-8

Price: Free copy

For publisher: $\quad$ Prof. Igor Tičar, Ph.D., rector (University of Maribor) 
$10^{\mathrm{TH}}$ InTERNATIONAL CONFERENCE ON Sustainable ENERGy AND Environmental Protection (June 27 $7^{\mathrm{TH}}-30^{\mathrm{TH}}$, 2017, BLed, Slovenia), Mechanical ENGINEERING

J. Krope, A.Ghani Olabi, D. Goričanec \& S. Božičnik

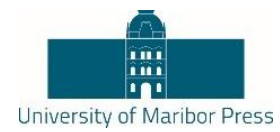

\section{Preface}

The $10^{\text {th }}$ International Conference on Sustainable Energy and environmental Protection SEEP 2017 was organised on June $27^{\text {th }}-30^{\text {th }} 2017$ in Bled, Slovenia, by:

- Faculty of Chemistry and Chemical Engineering, University of Maribor, Slovenia,

- University of the West of Scotland, School of Engineering and

The aim of SEEP2017 is to bring together the researches within the field of sustainable energy and environmental protection from all over the world.

The contributed papers are grouped in 18 sessions in order to provide access to readers out of 300 contributions prepared by authors from 52 countries.

We thank the distinguished plenary and keynote speakers and chairs who have kindly consented to participate at this conference. We are also grateful to all the authors for their papers and to all committee members.

We believe that scientific results and professional debates shall not only be an incentive for development, but also for making new friendships and possible future scientific development projects.

General chair

Emeritus Prof. dr. Jurij Krope
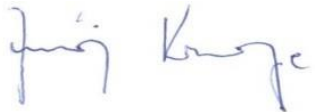
$10^{\mathrm{TH}}$ International CONFERENCE ON Sustainable ENERGY AND Environmental Protection (June $27^{\mathrm{TH}}-30^{\mathrm{TH}}$, 2017, BLed, Slovenia), Mechanical ENGINEERING

J. Krope, A.Ghani Olabi, D. Goričanec \& S. Božičnik

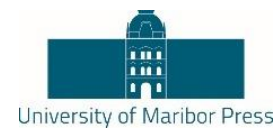

\title{
Plenary Talk on \\ The Relation between Renewable Energy and Circular Economy
}

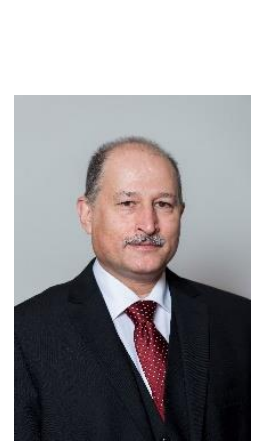

\author{
ABDUL GHANI OLABI - BIBLIOGRAPHY
}

Prof Olabi is director and founding member of the Institute of Engineering and Energy Technologies (www.uws.ac.uklieet) at the University of the West of Scotland. He received his M.Eng and Ph.D. from Dublin City University, since 1984 he worked at SSRC, HIAST, CNR, CRF, DCU and UWS. Prof Olabi has supervised postgraduate research students (10 M.Eng and 30PhD) to successful completion. Prof Olabi has edited 12 proceedings, and has published more than 135 papers in peer-reviewed international journals and about 135 papers in international conferences, in addition to 30 book chapters. In the last 12 months Prof Olabi has patented 2 innovative projects. Prof Olabi is the founder of the International Conference on Sustainable Energy and Environmental Protection SEEP, www.seepconference.co.uk

$\mathrm{He}$ is the Subject Editor of the Elsevier Energy Journal https://www.journals.elsevier.com/energy/editorial-board/abdul-ghani-olabi, also Subject editor of the Reference Module in Materials Science and Materials Engineering http://scitechconnect.elsevier.com/reference-module-material-science/ and board member of a few other journals. Prof Olabi has coordinated different National, EU and International Projects. He has produced different reports to the Irish Gov. regarding: Hydrogen and Fuel Cells and Solar Energy.

Correspondence AdDress: Abdul Ghani Olabi, Ph.D., Professor, University of the West of Scotland, School of Engineering and Computing, D163a, McLachlan Building, Paisley, United Kingdom, e-mail: Abdul.Olabi@uws.ac.uk. 
$10^{\mathrm{TH}}$ InTERNATIONAL CONFERENCE ON Sustainable ENERGy AND

Environmental Protection (June 27 $7^{\mathrm{TH}}-30^{\mathrm{TH}}$, 2017, Bled,

SLOVENia), Mechanical ENGINEERING

J. Krope, A.Ghani Olabi, D. Goričanec \& S. Božičnik

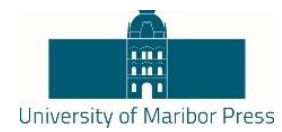

\title{
Plenary Talk on \\ Energy Footprints Reduction and Virtual Footprints Interactions
}

\author{
JIŘí JAROMÍR KLEMEŠ \& PETAR SABEV VARBANOV
}

Increasing efforts and resources have been devoted to research during environmental studies, including the assessment of various harmful impacts from industrial, civic, business, transportation and other economy activities. Environmental impacts are usually quantified through Life Cycle Assessment (LCA). In recent years, footprints have emerged as efficient and useful indicators to use within LCA. The footprint assessment techniques has provided a set of tools enabling the evaluation of Greenhouse Gas (GHG) - including $\mathrm{CO}_{2}$, emissions and the corresponding effective flows on the world scale. From all such indicators, the energy footprint represents the area of forest that would be required to absorb the GHG emissions resulting from the energy consumption required for a certain activity, excluding the proportion absorbed by the oceans, and the area occupied by hydroelectric dams and reservoirs for hydropower.

An overview of the virtual GHG flow trends in the international trade, associating the GHG and water footprints with the consumption of goods and services is performed. Several important indications have been obtained: (a) There are significant GHG gaps between producer's and consumer's emissions - US and EU have high absolute net imports GHG budget. (b) China is an exporting country and increasingly carries a load of GHG emission and virtual water export associated with consumption in the relevant importing countries. (c) International trade can reduce global environmental pressure by redirecting import to products produced with lower intensity of GHG emissions and lower water footprints, or producing them domestically.

To develop self-sufficient regions based on more efficient processes by combining neighbouring countries can be a promising development. A future direction should be focused on two main areas: (1) To provide the self-sufficient regions based on more efficient processes by combining production of surrounding countries. (2) To develop the shared mechanism and market share of virtual carbon between trading partners regionally and internationally.

CORRESPONDENCE AdDRESS: Jiř́i Jaromír Klemeš, DSc, Professor, Brno University of Technology - VUT Brno, Faculty of Mechanical Engineering, NETME Centre, Sustainable Process Integration Laboratory - SPIL, Technická 2896/2, 61669 Brno, Czech Republic, e-mail: klemes@fme.vutbr.cz. Petar Sabev Varbanov, Ph.D., Associate Professor, Brno University of Technology - VUT Brno, Faculty of Mechanical Engineering, NETME Centre, Sustainable Process Integration Laboratory - SPIL, Technická 2896/2, 61669 Brno, Czech Republic, e-mail: varbanov@fme.vutbr.cz. 
$10^{\mathrm{TH}}$ International CONFERENCE ON Sustainable ENERGY AND EnVironmental Protection (June $27^{\mathrm{TH}}-30^{\mathrm{TH}}$, 2017, Bled, SLOVENia), Mechanical ENGINEERING

J. Krope, A.Ghani Olabi, D. Goričanec \& S. Božičnik

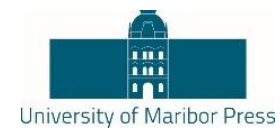

\section{JIŘÍ JAROMÍR KLEMEŠ - BIBLIOGRAPHY}

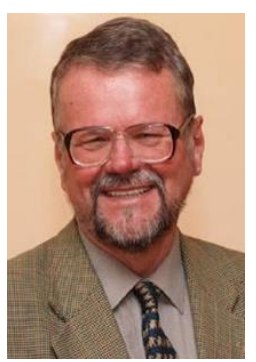

Head of "Sustainable Process Integration Laboratory - SPIL", NETME Centre, Faculty of Mechanical Engineering, Brno University of Technology - VUT Brno, Czech Republic and Emeritus Professor at "Centre for Process Systems Engineering and Sustainability", Pázmány Péter Catholic University, Budapest, Hungary.

Previously the Project Director, Senior Project Officer and Hon Reader at Department of Process Integration at UMIST, The University of Manchester and University of Edinburgh, UK. Founder and a long term Head of the Centre for Process Integration and Intensification - CPI2, University of Pannonia, Veszprém, Hungary. Awarded by the EC with Marie Curies Chair of Excellence (EXC). Track record of managing and coordinating 91 major EC, NATO and UK Know-How projects. Research funding attracted over $21 \mathrm{M€}$.

Co-Editor-in-Chief of Journal of Cleaner Production ( $\mathrm{IF}=4.959)$. The founder and President for 20 $\mathrm{y}$ of PRES (Process Integration for Energy Saving and Pollution Reduction) conferences. Chairperson of CAPE Working Party of EFCE, a member of WP on Process Intensification and of the EFCE Sustainability platform.

He authored nearly 400 papers, h-index 40. A number of books published by McGraw-Hill; Woodhead; Elsevier; Ashgate Publishing Cambridge; Springer; WILEY-VCH; Taylor \& Francis).

Several times Distinguished Visiting Professor for Universiti Teknologi Malaysia, Xi'an Jiaotong University; South China University of Technology, Guangzhou; Tianjin University in China; University of Maribor, Slovenia; University Technology Petronas, Malaysia; Brno University of Technology and the Russian Mendeleev University of Chemical Technology, Moscow. Doctor Honoris Causa of Kharkiv National University "Kharkiv Polytechnic Institute" in Ukraine, the University of Maribor in Slovenia, University POLITEHNICA Bucharest, Romania. "Honorary Doctor of Engineering Universiti Teknologi Malaysia", "Honorary Membership of Czech Society of Chemical Engineering", "European Federation of Chemical Engineering (EFCE) Life-Time Achievements Award" and "Pro Universitaire Pannonica" Gold Medal.

CORRESPONDENCE AdDRESS: Jiří Jaromír Klemeš, DSc, Professor, Brno University of Technology - VUT Brno, Faculty of Mechanical Engineering, NETME Centre, Sustainable Process Integration Laboratory - SPIL, Technická 2896/2, 61669 Brno, Czech Republic, e-mail: klemes@fme.vutbr.cz. 
$10^{\mathrm{TH}}$ InTERNATIONAL CONFERENCE ON Sustainable ENERGy AND Environmental Protection (June 27 $7^{\mathrm{TH}}-30^{\mathrm{TH}}$, 2017, Bled, Slovenia), Mechanical ENGINEERING

J. Krope, A.Ghani Olabi, D. Goričanec \& S. Božičnik

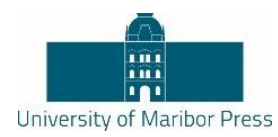

\title{
Plenary Talk on \\ Renewable energy sources for environmental protection
}

\author{
HAKAN SERHAD SOYHAN
}

Development in energy sector, technological advancements, production and consumption amounts in the countries and environmental awareness give shape to industry of energy. When the dependency is taken into account in terms of natural resources and energy, there are many risks for countries having no fossil energy sources. Renewable and clean sources of energy and optimal use of these resources minimize environmental impacts, produce minimum secondary wastes and are sustainable based on current and future economic and social societal needs. Sun is one of the main energy sources in recent years. Light and heat of sun are used in many ways to renewable energy. Other commonly used are biomass and wind energy. To be able to use these sources efficiently national energy and natural resources policies should be evaluated together with the global developments and they should be compatible with technological improvements. Strategic plans with regard to energy are needed more intensively and they must be in the qualification of a road map, taking into account the developments related to natural resources and energy, its specific needs and defining the sources owned by countries. In this presentation, the role of supply security was evaluated in term of energy policies. In this talk, new technologies in renewable energy production will be shown and the importance of supply security in strategic energy plan will be explained.

Correspondence Address: Hakan Serhad Soyhan, Ph.D., Professor, Sakarya University, Engineering Faculty, Esentepe Campus, M7 Building, 54187 - Esentepe /Sakarya, Turkey, e-mail: hsoyhan@sakarya.edu.tr. 
$10^{\mathrm{TH}}$ InTERNATIONAL CONFERENCE ON Sustainable ENERGY AND Environmental Protection (June 27 $7^{\mathrm{TH}}-30^{\mathrm{TH}}$, 2017, Bled, SLOVEnia), MechanicAl ENGINEERING

J. Krope, A.Ghani Olabi, D. Goričanec \& S. Božičnik

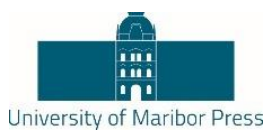

\section{HAKAN SERHAD SOYHAN - BIBLIOGRAPHY}

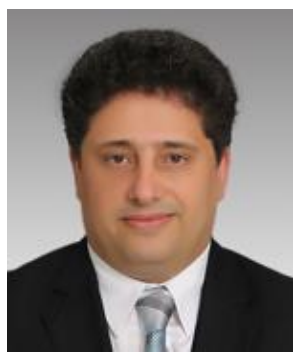

Professor at Sakarya University, Engineering Faculty. $50 \%$ fot teaching and the rest for reasearch activities.

Teaching, courses taught:

Graduate courses:

- Combustion technology;

- Modelling techniques;

Undergraduate courses:

- Combustion techniques;

- Internal combustion engines;

- Fire safety.

Tehnical skills and competences professional societies:

- 25 jurnal papers in SCI Index. 23 conference papers;

- $\quad$ Editor at FCE journal. Co-editor at J of Sakarya University;

- Head of Local Energy Research Society (YETA);

- Member od American Society of Mechanical engineers (ASME);

- Member of Turkish Society of Mechanical Engineers (TSME).

Correspondence AdDress: Hakan Serhad Soyhan, Ph.D., Professor, Sakarya University, Engineering Faculty, Esentepe Campus, M7 Building, 54187 - Esentepe /Sakarya, Turkey, e-mail: hsoyhan@sakarya.edu.tr. 

$10^{\mathrm{TH}}$ InTERnAtional CONFERENCE ON Sustainable ENERGy AND Environmental Protection (June $27^{\mathrm{TH}}-30^{\mathrm{TH}}$, 2017, Bled, Slovenia), MechaniCAL ENGINEERING

J. Krope, A.Ghani Olabi, D. Goričanec \& S. Božičnik

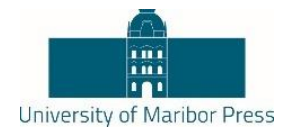

\section{Table of Contents}

\section{CONFERENCE PROCEEDINGS}

Assesment of Plasma Actuator's Position on Stall Angle for an Airfoil

Hürrem Akbıyık, Hakan Yavuz \& Yahya Erkan Akansu

Investigation of the Electrode Geometry Configurations of Plasma Actuators

Hürrem Akbıyık, Hakan Yavuz \& Yahya Erkan Akansu

Inertial Envirolment Small Alloy Welding Equipment

I. R. Fermo, V. R. R. V. Da Silva, M. Y. G. De Giovanni, R. L. Acorsi,

R. Z. Sakiyama \& C. M. G. Andrade

Industrial Processes of Sucrose Crystallization: A Brief

Review

Paulo Eduardo de Morais Gonzales, Igor Rossi Fermo, Eugênia Leandro Almeida \& Cid Marcos Gonçalves Andrade

Optimisation of Wire Electro Discharge Machining Parameter Using Desirability Based Multi Objective RSM While Machining of Al6061-Cenosphere AMCs Abhijit Dey, Krishna Murari Pandey \& Biplab Das

A Parametric Thermal Analysis of Triangular Fins for Improved Heat Transfer in Forced Convection

Saroj Yadav \& Krishna M Pandey

Modeling and Simulating a Water Distribution Network Using the Epanet Software. Case Study

Pedro Faria de Carvalho, Lucas Bonfim, Eugênia Leandro Almeida, Mauro Antônio da Silva Sá Ravagnani \& Cid Marcos Gonçalves Andrade

Hydrodynamic Vibratory Filtration as a Method Removing of Mechanical Impurities in Regeneration Systems of Highly Viscous Working Fluids

Vladimir Devisilov, Elena Sharai \& Anatoly Aleksandrov 


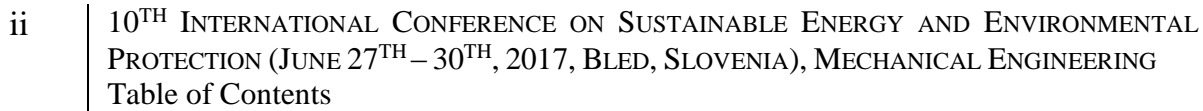

Numerical Investigation of the Separation of Two-Phase

Media With Complex Power Effects in Order to Reduce Energy Consumption for Cleaning

Vladimir Devisilov \& Elena Sharai

Assessment of Optimal Drilling Parameter for Bamboo Filler Reinforced Epoxy Composite

Chaiki Malakar \& Sumit Bhowmik

Domestic Hot Water Consumption in District Heating in 113 Hungary

László Garbai, Andor Jasper \& Zoltán Magyar 
$10^{\mathrm{TH}}$ InTERnational CONFERENCE ON Sustainable ENERgy AND EnVironmental Protection (June $27^{\mathrm{TH}}-30^{\mathrm{TH}}$, 2017, Bled, SLOVENIA), MECHANICAL ENGINEERING

J. Krope, A.Ghani Olabi, D. Goričanec \& S. Božičnik

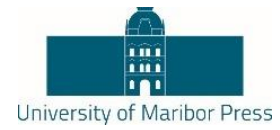

\title{
Assesment of Plasma Actuator's Position on Stall Angle for an Airfoil
}

\author{
HÜRREM AKBIYIK, HAKAN YAVUZ \& YAHYA ERKAN AKANSU
}

\begin{abstract}
In recent years, there has been an increase in the number of research papers on plasma and its use in flow control. The main objective of this study is to improve the performance of the airfoil by shifting the stall angle. In addition, optimization of the plasma actuator position and configuration is to be studied to identify the optimum configuration for maximum stall angle shift. These flow control study is performed for a NACA0015 airfoil. The experiments were conducted in a wind tunnel at Reynolds number of $4.8 \times 104$. The plasma actuators are mounted on various positions $(\mathrm{x} / \mathrm{C})$ starting from the leading edge to trailing edge of the airfoil. The electrical parameters used for the plasma generating device are set to constant values of $7 \mathrm{kV}_{\mathrm{pp}}$ applied voltage and $3.5 \mathrm{kHz}$ excitation frequency. The experimental results on force measurement is presented to illustrate the effect of the generated plasma on shift of the stall angle. The results of the study suggest that the energy efficiency of airborne systems can be improved with the use of plasma actuators due to its increasing lift and decreasing drag coefficient effects. This result becomes a vital finding considering that same flight can be achieved with less fuel and less amount of environmental pollution for the same distance of journey.
\end{abstract}

Keywords: • plasma actuator $\bullet$ airfoil $\bullet$ stall angle $\bullet$ drag coefficient lift coefficient $\bullet$ Reynolds number •

CORRESPONDENCE ADDRESS: Hürrem Akbıyık, Ph.D., Assistant, Çukurova University, Engineering and Architecture Faculty, Sarıçam, Adana, Turkey, e-mail: hakbiyik@cu.edu.tr. Hakan Yavuz, Ph.D., Professor, Çukurova University, Engineering and Architecture Faculty, Sarıçam, Adana, Turkey, e-mail: dr.hakanyavuz@gmail.com. Yahya Erkan Akansu, Ph.D., Associate Professor, Ömer Halisdemir University, Engineering Faculty, Bor, Niğde, Turkey, e-mail: akansu@nigde.edu.tr. 
$10^{\mathrm{TH}}$ InTERnATIONAL CONFERENCE ON Sustainable ENERgy AND ENVIRONMENTAL Protection (June 27 $7^{\mathrm{TH}}-30^{\mathrm{TH}}, 2017$, Bled, Slovenia), Mechanical EngineERING H. Akbıyı, H. Yavuz \& Y. Erkan Akansu: Assesment of Plasma Actuator's Position on Stall Angle for an Airfoil

The dielectric barrier discharge (DBD) plasma actuators are one of the most common aerodynamic active flow control techniques of the recent years. They are constructed using two conducting electrodes and a dielectrics material placed between them. Typically, the DBD plasma actuators can be mounted on leading edge, trailing edge, and/or mid-chord of an airfoil for improving the aerodynamic efficiency. They generate the plasma on the surface of the electrodes. The plasma generated by the actuator leads to an induced flow around the airfoil. The DBD plasma actuators have very high potential for improvement of the aerodynamic performances of the airfoils in terms of efficiency as well as lift, drag and stall-shifting properties. Moreau et al. (2016) studied about the delaying flow separation from leading edge to trailing edge of a NACA0015 airfoil at Re $=1.33 \times 10^{6}$. They used three single DBD plasma actuators in the experiments and activated them separately in order to see the effect of varying actuator location. The separation delay is improved $14 \%$ for the single DBD plasma actuator located at $\mathrm{x}_{\mathrm{c}} / \mathrm{C}=$ $18 \%$ compared to the baseline flow. Also, this actuator $\left(\mathrm{x}_{\mathrm{c}} / \mathrm{C}=18 \%\right)$ has been reported to be more effective than the other actuators located at $27 \%$ and $37 \%$ of the chord in their presented study [1]. In a numerical study of Rhoskhoo and Jahangirian (2016), the effect of the unsteady plasma body force is compared with steady force over a stalled NACA0015 airfoil at $\operatorname{Re}=4.5 \times 10^{4}$. Their numerical results indicate that for both situations (steady and unsteady cases), the flow separation from the leading edge area of the airfoil is prevented. It has also been reported that the DBD plasma actuator with steady mode has stronger prevention of flow separation effect than that of unsteady mode. However, the DBD plasma actuator with unsteady mode has been reported to have consumed $20 \%$ less energy compared with steady mode. Also, it is concluded in their results that the increase in duty cycle gives rise to the change of attachment of the flow separation [2]. Zhang et al. (2016) placed a symmetrical plasma actuators on SC (2)-0714 supercritical airfoil model to show the effect of the plasma actuators for controlling the turbulent boundary layer separation at high Reynolds numbers. They have reported that they have successfully suppressed the turbulent boundary separation. In addition, they concluded that the increase in the maximum lift coefficient is around $8.89 \%$ and the stall angle of attack is delayed by 2 degrees [3]. It is also reported that using the duty cycle approach leads to significant reduction in the power consumption of the plasma actuators. The Duty cycle rates between 10-90\% comparing via steady actuation gave rise to \%25 increment in lift coefficient of the NACA0015 airfoil. Also, using duty cycle approach on activation of the plasma actuators have been reported to have consumed less power [4]. Besides, an experimental study on NLF0414 airfoil has shown that the duty cycle approach helps to change the separation point at $18^{\circ}$ angle of attack and $50 \mathrm{~Hz}$ excitation frequency. However, it has also been reported that the effect of plasma via various duty cycles has no effect on pressure distribution at $16^{\circ}$ angle of attack and $100 \mathrm{~Hz}$ excitation frequency [5].

The main objective of this study is to investigate the ways improve the performance of the airfoil with the aim of shifting the stall angle. In addition, optimization of the plasma actuator position and configuration is to be studied to identify the optimum configuration 
for maximum stall angle shift. These active flow control approaches are tested to control the flow around a NACA0015 airfoil.

\section{$2 \quad$ Experimental setup}

Experiments are conducted on a wind tunnel with a test section of $570 \mathrm{~mm}$ x $570 \mathrm{~mm}$ x $1000 \mathrm{~mm}$. In Figure 1., the test model and experimental setup of plasma actuator are illustrated. The NACA0015 airfoil is used as a test model in the experiments. The chord length and spanwise length of the airfoil are $150 \mathrm{~mm}$ and $540 \mathrm{~mm}$, respectively.

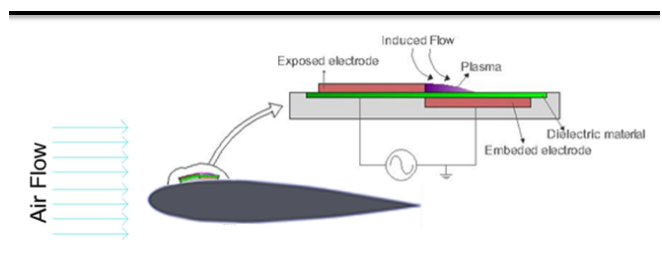

Figure 1. The Test Model And Experimental Setup Of Plasma Actuator

As it is seen in Figure 2., four different plasma actuator positions and configurations are considered. The plasma actuators are mounted horizontally on the NACA0015 airfoil at $\mathrm{x} / \mathrm{C}=0.1,0.2,0.5$, and 1.0 where " $\mathrm{x}$ and $\mathrm{C}$ " denotes direction and chord length, respectively. Each plasma actuator consists of embedded and exposed electrodes. The dielectric material, Kapton, is a dielectric tape with thicknesses of $0.07 \mathrm{~mm}$ and it is placed between the plasma electrodes.

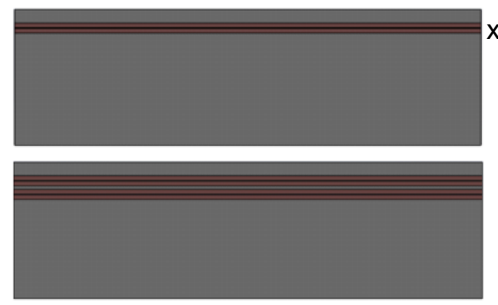

$\mathrm{x} / \mathrm{C}=0.1$

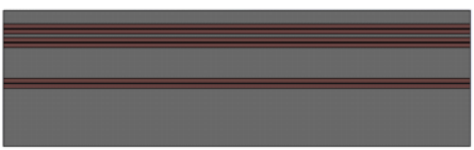

$\mathrm{x} / \mathrm{C}=0.1$

$\mathrm{x} / \mathrm{C}=0.2$

$\mathrm{x} / \mathrm{C}=0.5$

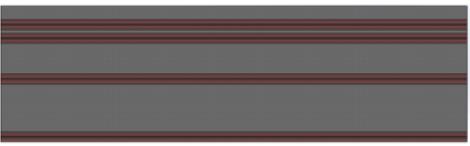

$\mathrm{x} / \mathrm{C}=0.1$

$\mathrm{x} / \mathrm{C}=0.2$

$\mathrm{x} / \mathrm{C}=0.5$

$\mathrm{x} / \mathrm{C}=1$

Figure 2. The Electrode Geometry Configurations 

Protection (June $27^{\mathrm{TH}}-30^{\mathrm{TH}}, 2017$, Bled, Slovenia), Mechanical ENGineERING

H. Akbıyı, H. Yavuz \& Y. Erkan Akansu: Assesment of Plasma Actuator's Position on Stall Angle for an Airfoil

In Figure 3, the force measurement system devices and plasma production system devices are illustrated. A custom-made power amplifier is used in order to produce the voltage required for plasma generation. The applied plasma voltage and frequency are set to 7 $\mathrm{kV}_{\mathrm{pp}}$ and $3.5 \mathrm{kHz}$, respectively. The sinusoidal signal waveform is measured by using Tektronix TDS2012B model oscilloscope. The applied voltage is monitored by use of Tektronix P6015A model voltage probe connected to the oscilloscope.

In order to measure drag and lift forces, ATI Gamma model six axes load cell is used. Test model mounted on a rotary unit to measure the attack angle of the model. Measurements are taken at $1000 \mathrm{~Hz}$ sampling frequency during 10 second period. Therefore, 10000 sampled values are taken for each measurement and it is repeated twice for each experimental testing session.

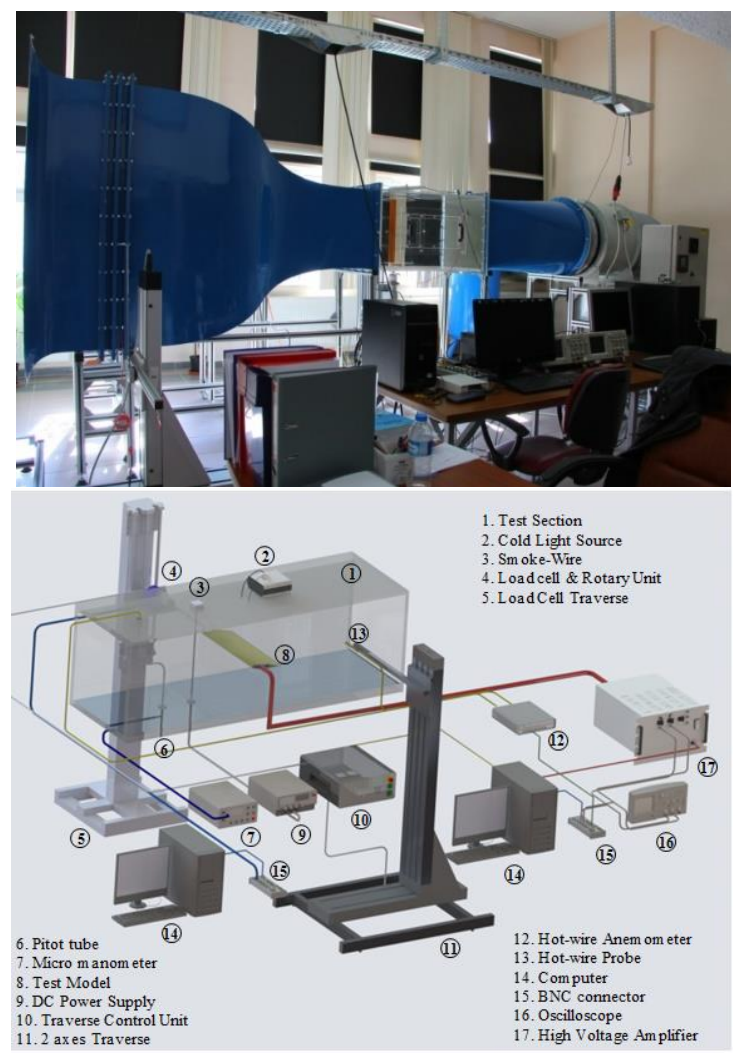

Figure 3. General and Schematic View of the Test Setup

In order to calculate the net drag forces acting on the airfoil, drag of endplates, holder rod, connector between model and holder rod are exiled from total drag forces. 
$10^{\mathrm{TH}}$ INTERNATIONAL CONFERENCE ON SUSTAINABLE ENERGY AND ENVIRONMENTAL

\section{$3 \quad$ Results}

The optimization of the plasma actuator position and configuration is studied to identify the optimum configuration for maximum stall angle shift. These flow control approaches are used to control the flow around a NACA0015 airfoil. The plasma actuators were activated at $3.5 \mathrm{kHz}$ excitation frequency and $7 \mathrm{kV}_{\mathrm{pp}}$ applied voltage. As it is seen from Fig. 4 , the stall angle is shifted from $8^{\circ}$ to $10^{\circ}$ by all plasma actuator configurations. This is due to the configurations of the activation of plasma actuators. Also, the shifting of the stall angle means that the separation point slightly shifted from the leading edge to the mid chord. However, the flow visualization is necessary to calculate how much the separation point is delayed. It is seen that a single pair of plasma actuators is sufficient to shift the stall angle and this enables more efficient usage of the energy. For this study, the use of other plasma actuators appears to be only contributing to the increases in the lift coefficient. In first step, one plasma actuator placed at $\mathrm{x} / \mathrm{C}=0.1$ is activated. At this point, the value of the lift coefficient is observed to be increased from 0.49 to 0.83 . This is the minimum enhancement in lift coefficient in comparison with other configurations. In the next stage, the plasma actuators placed at $\mathrm{x} / \mathrm{C}=0.1$ and 0.2 are activated together. For this configuration, the improvement in the lift coefficient is measured to be about $77 \%$. The reason for this configuration being more effective than first one is mainly due to the position of the second plasma actuator. The study of Jolibois et al. (2008) has shown that the placement of the plasma actuators leads to more effective separation control when it is mounted on the upstream separation point [6].

In the following stage, one more plasma actuator, placed $\mathrm{x} / \mathrm{C}=0.5$, is added to previous configuration and all plasma actuators are activated all together. The induced flow appears to add momentum to the separated flow, and then the separated flow becomes closer to the surface of the airfoil.

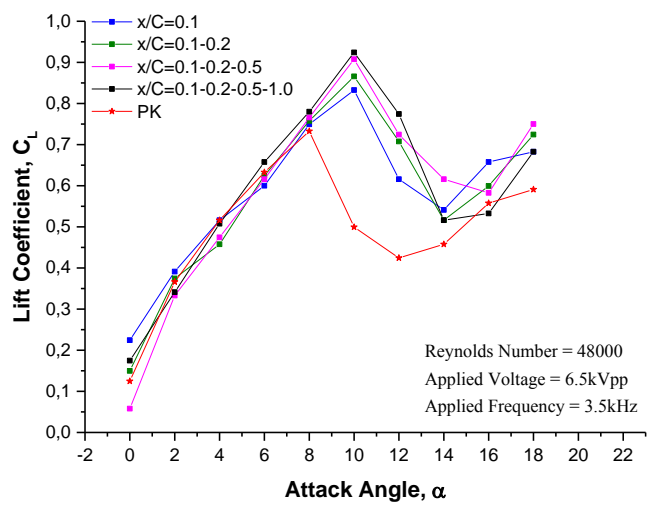

Figure 4. Effect of the Plasma Actuator Positions on Lift Coefficient of the NACA0015 Airfoil 
$10^{\text {TH }}$ International Conference on Sustainable Energy and Environmental Protection (June 27 $7^{\mathrm{TH}}-30^{\mathrm{TH}}, 2017$, Bled, Slovenia), Mechanical Engineering

H. Akbıyık, H. Yavuz \& Y. Erkan Akansu: Assesment of Plasma Actuator's Position on Stall Angle for an Airfoil

The last experimental configuration consists of four plasma actuators that are positioned at $\mathrm{x} / \mathrm{C}=0.1,0.2,0.5$ and 1 . The maximum increase in the lift coefficient is observed in this configuration. The lift coefficient value is observed to be increased from 0.49 to 0.92 (approximately 88\%) at the stall angle.

\section{Conclusion}

The main objective of this study is to improve the performance of the airfoil with the aim of shifting the stall angle. In addition, optimization of the plasma actuator position and configuration is being studied to identify the optimum actuator configuration for maximum stall angle shift. The plasma actuators were mounted horizontally on the NACA0015 airfoil (at $\mathrm{x} / \mathrm{C}=0.1,0.2,0.5$, and 1.0 ) for $\mathrm{Re}=4.8 \times 10^{4}$. The applied plasma voltage and frequency are set to $7 \mathrm{kV}_{\mathrm{pp}}$ and $3.5 \mathrm{kHz}$, respectively. The effect of plasma on lift coefficient of the airfoil is examined by varying the attack angle. It is shown that the stall angle is shifted from $8^{\circ}$ to $10^{\circ}$ by all plasma actuator configurations. The actuation of one or multiple plasma actuators gives rise to same shifting stall angle value. Therefore, the shifting stall angle can be provided by using lowest energy consumption levels. The lift coefficient value is observed to be increased from 0.49 to 0.83 at $\mathrm{x} / \mathrm{C}=0.1$. This is the minimum enhancement in lift comparison with other configurations as only one plasma actuator is used. The last configuration is consist of four plasma actuators that are positioned at $\mathrm{x} / \mathrm{C}=0.1,0.2,0.5$ and 1 . The maximum increase in lift is observed in this configuration. The observed increase in lift coefficient value is approximately $88 \%$ at the stall angle.

\section{Nomanclature}

$\mathrm{C}_{\mathrm{L}} \quad$ : Lift coefficient based on $D, F_{L} / 0.5 \rho L D U_{\infty}^{2}$

C : Chord length (mm)

PK : Plasma Off

Re $\quad$ : Reynolds number based on $\mathrm{D}, \rho \mathrm{U} \infty \mathrm{D} / \mu$

$\alpha \quad$ : Attack angle

Vpp : Peak to peak applied voltage

$\mathrm{x} \quad$ : Direction

\section{References}

[1] M. Moreau, A. Debien, J. M. Breux, and N. Benard, "Control of a turbulent flow separated at mid-chord along an airfoil with DBD plasma actuators," Journal of Electrostatics, vol. 83, pp. 78-87, 2016.

[2] R. Khoshkoo and A. Jahangirian, "Numerical simulation of stall flow control using a DBD plasma actuator in pulse mode," Plasma Science and Technology, no:9, 2016.

[3] X. Zhang, Y. Huang, X. Wang, W. Wang, K. Tang, and H. Li, "Turbulent boundary layer separation control using plasma actuator at Reynolds number 2000000," Chinese Journal of Aeronautics, vol. 29, pp. 1237-1246, 2016.

[4] Y. E. Akansu, F. Karakaya, A. Şanlısoy, "Active control of flow around NACA0015 airfoil by using DBD plasma actuator," EPJ Web of Conferences, vol. 45, no:01008, 2016. 
$10^{\text {TH }}$ INTERNATIONAL CONFERENCE ON SUSTAINABLE ENERGY AND ENVIRONMENTAL

Protection (June $27^{\mathrm{TH}}-30^{\mathrm{TH}}, 2017$, Bled, Slovenia), Mechanical ENGineERING

H. Akbıyık, H. Yavuz \& Y. Erkan Akansu: Assesment of Plasma Actuator's Position on

Stall Angle for an Airfoil

[5] A. S. Taleghani, A. Shadaram, and M. Mirzaei, "Effects of duty cycles of the plasma actuators on improvement of pressure distribution above a NLF0414 airfoil," IEEE Transactions on Plasma Science, vol. 40, pp. 1434-1440, 2012.

[6] J. Jolibois, M. Forte, and E. Moreau, "Application of an ac barrier discharge actuator to control airflow separation above a NACA0015 airfoil: optimization of the actuation location along the chord," Journal of Electrostatics, vol. 66, pp. 496-503, 2008. 
\begin{tabular}{l|l}
8 & $10^{\mathrm{TH}}$ International CONFERENCE on Sustainable EnERgy AND ENVIRONMENTAL
\end{tabular} Protection (June $27^{\mathrm{TH}}-30^{\mathrm{TH}}, 2017$, BLed, Slovenia), Mechanical ENGineERING 
$10^{\mathrm{TH}}$ InTERnAtional CONFERENCE ON Sustainable ENERgy AND EnVironmental Protection (June $27^{\mathrm{TH}}-30^{\mathrm{TH}}$, 2017, Bled, SLOVENIA), MECHANICAL ENGINEERING

J. Krope, A.Ghani Olabi, D. Goričanec \& S. Božičnik

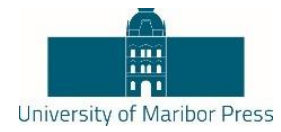

\title{
Investigation of the Electrode Geometry Configurations of Plasma Actuators
}

\author{
HÜRREM AKBIYIK, HAKAN YAVUZ \& YAHYA ERKAN AKANSU
}

\begin{abstract}
In this study, the induced flow effects of plasma generated by various types of electrode geometry configurations are presented. The model chosen for the study is a NACA0015 airfoil. The experiments are conducted in a wind tunnel at Reynolds number of $4.8 \times 104$. The plasma actuators mounted on the leading edge of the airfoil at chord position of 0.1 (x/C). The plasma actuators consist of an embedded and exposed electrode between which a dielectric material is placed. The applied voltage is set to $7 \mathrm{kVpp}$. The excitation frequency is also set to $3.5 \mathrm{kHz}$. Three different electrode geometry configurations, namely as Linear, Sawtooth and Square, are considered for the study. As a part of the experimental study, the $2 \mathrm{D}$ and $3 \mathrm{D}$ flow structures generated by the plasma actuators and related analysis results are presented. In addition, necessary measurements are also made to determine drag and lift forces.
\end{abstract}

Keywords: • NACA0015 airfoil $\bullet$ lift and drag coefficients $\bullet$ square plasma actuator $\bullet$ sawtooth plasma actuator $\bullet$ linear plasma actuator $\bullet$

CORRESPONDENCE AdDRESS: Hürrem Akbıyık, Ph.D., Assistant, Çukurova University, Engineering and Architecture Faculty, Sarıçam, Adana, Turkey, e-mail: hakbiyik@cu.edu.tr. Hakan Yavuz, Ph.D., Professor, Çukurova University, Engineering and Architecture Faculty, Sarıçam, Adana, Turkey, e-mail: dr.hakanyavuz@gmail.com. Yahya Erkan Akansu, Ph.D., Associate Professor, Ömer Halisdemir University, Engineering Faculty, Bor, Niğde, Turkey, e-mail: akansu@nigde.edu.tr. 
$10^{\mathrm{TH}}$ INTERNATIONAL CONFERENCE ON SUSTAINABLE ENERGY AND ENVIRONMENTAL Protection (June $27^{\mathrm{TH}}-30^{\mathrm{TH}}, 2017$, Bled, Slovenia), Mechanical ENGineERING H. Akbiyık, H. Yavuz \& Y. Erkan Akansu: Investigation of the Electrode Geometry Configurations of Plasma Actuators

\section{Introduction}

In recent years, plasma actuators have become an important tool in flow control applications. The plasma actuators basically maintain a surface discharge that starts with delaying flow separation on airplane wings. Besides, it becomes more effective with control applications. It is well-known that the generated plasma contributes to the flow around the bodies. In terms of flow control efficiency, parameters such as thickness of the dielectric material, dielectric constant of the dielectric material, the distance between electrodes, the electrode lengths, applied voltage level, applied voltage signal properties, electrode geometry and the number of electrodes appear to play an important role in the prosess.

Erfani et al. (2013) conducted a study in which the plasma structures formed by placing a plasma actuator having a multiple encapsulate electrode structure with an electrode in contact with air on a flat plate. The induced flow velocity is increased and more momentum is provided by using multiple-encapsulate electrodes. Also, the most effective electrode structure is identified in their study [1]. Hale et al. (2010) reported that the multiple encapsulate electrode structure effects the induced jet structure. Their results revealed that the generated induced jet positions have influence on the jet length. Also, the jet velocity appears to increase linearly along the embedded electrodes. In their experiments, all multiple-encapsuled electrode geometries provide higher velocity values than the classical models [2]. Wang et al. (2011) placed four electrode geometries on a flat plate and produced three dimensional vortex structures in their numerical study. Three dimensional effects such as compression and expansion were observed by using square and serpentine plasma actuators in the flow over the electrode. Numerical results have shown that the linear actuator is less effective in creating the vortex structure in the flow direction than the other designed models [3]. Roy and Wang (2009) used serpentine and horseshoe shaped plasma actuators in order to change boundary layer's thickness. They investigated that the serpentine and horseshoe shaped plasma actuators lead to three dimensional flow structures. Not only these actuators help to reattach the flow on model surfaces but also with momentum transfer they convert the flow type from two dimensional flow to a three dimensional volume flow [4]. Akbiyık et al. (2017) reported that intermittent plasma actuators give rise to reduction in drag coefficient of a bluff body and lead to changes in wake width of the bluff body. Two dimensional flow structure around the bluff bodies is converted into a three dimensional flow structure by intermittent plasma actuators [5]. Akansu et al. (2013) placed plasma actuators at different positions $(\mathrm{x} / \mathrm{C}=0.1,0.3,0.5,0.9)$ in order to control flow around a NACA0015 airfoil. The plasma actuators led to reattach flow over the airfoil and also lift coefficients was increased [6]. In their numerical study, of Zhang et al. (2009) reported that the lift effect is increased when the plasma actuators are placed on the Gurney flaps [7]. Lu et al. (2016) reported results of an experimental work based on sawtooth plasma actuators mounted on the NACA0015 airfoil at $\mathrm{Re}=7.7 \times 10^{4}$. In this study, with the help of sawtooth plasma actuators, success in delaying the attack angle of the airfoil by $5^{\circ}$ and achieving $\% 9$ increases in maximum lift force is reported. Compared to standard type linear plasma actuators with sawtooth plasma actuators at the same input power, the attack angle shift is about $3^{\circ}$ and increase in lift force 
is about 3\% [8]. All these studies on plasma actuators have been carried out in order to improve the efficiency in flow control.

The aim of this study is to present the results for flow separation control and increase in lift force by placing plasma actuators in different electrode structures on the aerodynamic body of NACA0015 aircraft wing. In addition, it is aimed at studying the different electrode geometries that are used most effectively in aerodynamic applications.

\section{$2 \quad$ Experımental setup}

Experiments are conducted on a wind tunnel with a test section of $570 \mathrm{~mm} \times 570 \mathrm{~mm} \times$ $1000 \mathrm{~mm}$. In Figure 1., the test model and experimental setup of plasma actuator are illustrated. The NACA0015 airfoil is used as a test model in the experiments. The chord length and spanwise length of the airfoil are $150 \mathrm{~mm}$ and $540 \mathrm{~mm}$, respectively.

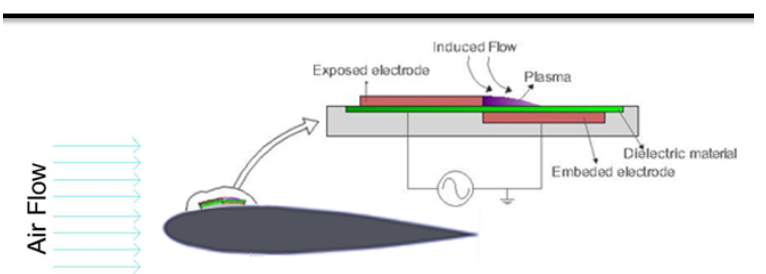

Figure 1. The Test Model and Experimental Setup of Plasma Actuator

As it is seen in Figure 2., three different electrode geometry configurations namely as linear, sawtooth and square types are used. The plasma actuators were mounted horizontally on the NACA0015 airfoil at $\mathrm{x} / \mathrm{C}=0.1$ where " $\mathrm{x}$ and $\mathrm{C}$ " denotes direction and chord length, respectively. Each plasma actuator consists of embedded and exposed electrodes. The dielectric material, Kapton, is a dielectric tape with thicknesses of $0.07 \mathrm{~mm}$ and it is placed between plasma electrodes.

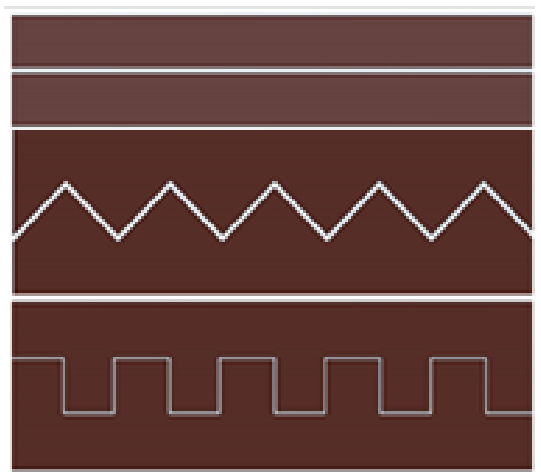

Figure 2. The Electrode Geometry Configurations 

Protection (June $27^{\mathrm{TH}}-30^{\mathrm{TH}}, 2017$, Bled, Slovenia), Mechanical ENGineERING H. Akbıyık, H. Yavuz \& Y. Erkan Akansu: Investigation of the Electrode Geometry Configurations of Plasma Actuators

In Figure 3, the force measurement system devices and plasma production system devices are illustrated. A custom-made power amplifier is used in order to produce the voltage required for plasma generation. The applied plasma voltage and frequency are set to $7 \mathrm{kV}_{\mathrm{pp}}$ and $3.5 \mathrm{kHz}$, respectively. The sinusoidal signal waveform is measured by using Tektronix TDS2012B model oscilloscope. The applied voltage is monitored by use of Tektronix P6015A model voltage probe connected to the oscilloscope.

In order to measure drag and lift forces, ATI Gamma model six axes load cell is used. Test model mounted on a rotary unit to measure the attack angle of the model. Measurements are taken at $1000 \mathrm{~Hz}$ sampling frequency during 10 second period. Therefore, 10000 sampled values are taken for each measurement and it is repeated twice for each experimental testing session.

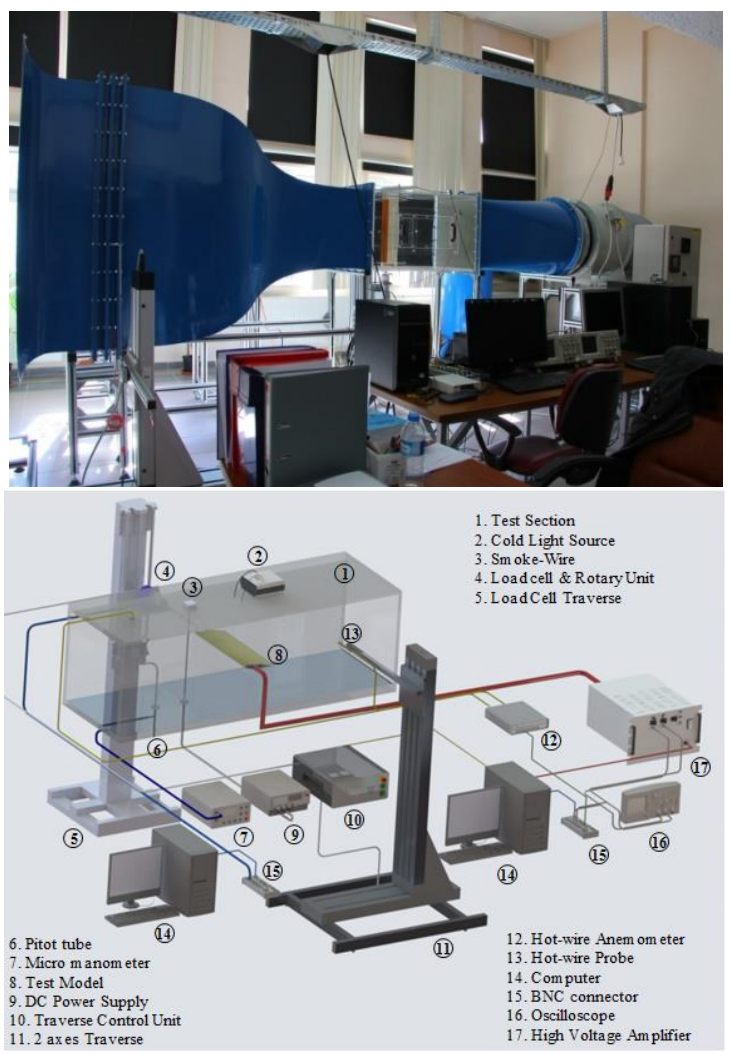

Figure 3. General and Schematic View of the Test Setup

In order to calculate the net drag forces acting on the airfoil, drag of endplates, holder rod, connector between model and holder rod are exiled from total drag forces. 


\section{$3 \quad$ Results}

The effects of the plasma actuators shapes placed along the chord length of the NACA0015 airfoil are investigated. Three different electrode geometry configurations, linear, sawtooth and square, are used for the experiments. The plasma actuators were activated at $3.5 \mathrm{kHz}$ excitation frequency and $7 \mathrm{kV}_{\mathrm{pp}}$ applied voltage. As it is seen from Figure 4, the stall angle is shifted from $8^{\circ}$ to $10^{\circ}$ by using linear and sawtooth plasma actuators compared with the no plasma condition on the airfoil at $\operatorname{Re}=4.8 \times 10^{4}$. The square shaped plasma actuator is not effective for delaying stall angle for the same experimental parameters. On the one hand, for the attack angle of $10^{\circ}$, the lift coefficient value is observed to be increasing from 0.70 to 0.80 (approximately $\% 15$ increase) when sawtooth shaped plasma actuators is activated. The linear plasma actuator leads to increase approximately $\% 8$ at the same attack angle. On the other hand, the square shaped plasma actuators give rise to reduction in lift coefficient of the airfoil. For the attack angle of $12^{\circ}$, the lift coefficient was increased from 0.49 to 0.94 (approximately $91 \%$ ) by sawtooth shaped plasma actuators. The lift coefficient has nearly the same enhancement performance for the linear plasma actuators.

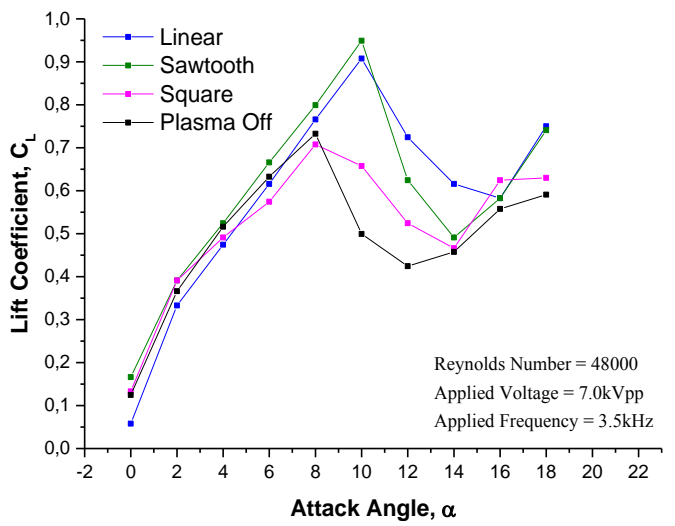

Figure 4. Effect of the Electrode Geometry on Lift Coefficient of the NACA0015 airfoil

As it is seen from Figure 5, the reduction in drag coefficient was observed by square shaped and linear plasma actuators. However, there is no significant effect in reduction of the drag coefficient for the sawtooth shaped plasma actuators. The maximum reduction in drag is $31 \%$ at the attack angle of $10^{\circ}$ for the square shaped plasma actuators. For the same plasma actuator, the drag coefficient is decreased $34 \%$ at the attack angle of $12^{\circ}$. 


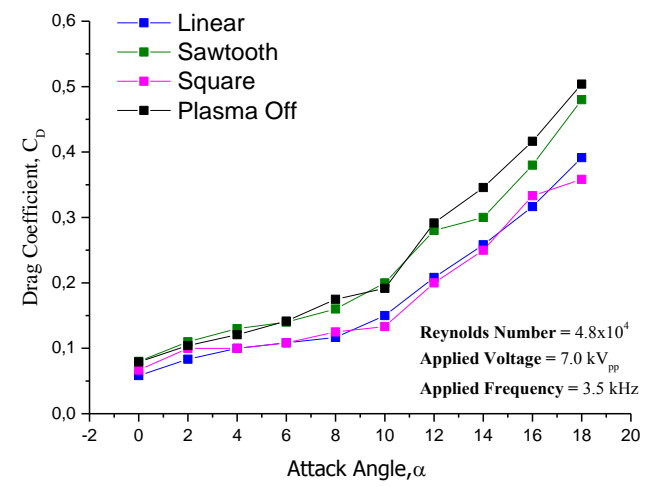

Figure 5. Effect of the Electrode Geometry on Drag Coefficient of the NACA0015 airfoil

The sawtooth plasma actuators appear to be more suitable for obtaining more lift force on take-off and reducing fuel consumption. However, it seems to be more convenient to use a square-shaped plasma actuator to reduce the drag force acting on the airfoil when there is no need for extra lifting force. This experimental study contributed to the determination of the plasma actuator geometry to be used according to the necessary conditions of the aircraft. In addition, the use of other models in comparison to conventional (linear) plasma actuators appears to reduce fuel consumption due to enhancement in aerodynamic efficiency.

\section{Conclusion}

In this study, the effects of the plasma actuator shapes placed along the chord length of the NACA0015 airfoil are investigated at $\operatorname{Re}=4.8 \times 10^{4}$. Three different electrode geometry configurations as linear, sawtooth and square are used for the experiments. The plasma actuators are activated at $3.5 \mathrm{kHz}$ excitation frequency and $7 \mathrm{kV}_{\mathrm{pp}}$ applied voltage. The lift and drag coefficient of the airfoil are examined by varying the attack angle. The following list of conclusions achieved,

- For the attack angle of $12^{\circ}$, the lift coefficient is increased approximately $91 \%$ by sawtooth shaped plasma actuators. Also, the linear plasma actuator enhanced the lift coefficient significantly.

- The stall angle is shifted from $8^{\circ}$ to $10^{\circ}$ by using linear and sawtooth plasma actuators.

- The linear and square shaped plasma actuators also lead to more reduction in the drag than no plasma and sawtooth shaped plasma actuators cases.

- The maximum reduction in drag is $31 \%$ at the attack angle of $10^{\circ}$ for the square shaped plasma actuators. For the same plasma actuator, the drag coefficient is decreased $34 \%$ at the attack angle of $12^{\circ}$. 
$10^{\mathrm{TH}}$ INTERNATIONAL CONFERENCE ON SUSTAINABLE ENERGY AND ENVIRONMENTAL 15 Protection (June $27^{\mathrm{TH}}-30^{\mathrm{TH}}, 2017$, Bled, Slovenia), MeChaniCAl ENGINEERING H. Akbiyık, H. Yavuz \& Y. Erkan Akansu: Investigation of the Electrode Geometry Configurations of Plasma Actuators

\section{Acknowledgements}

The authors would like to acknowledge the financial support of this work by the Scientific Research Projects (BAP) of the Çukurova University under the Contact Number of FBA-2017-7111.

\section{Nomanclature}

$\mathrm{C}_{\mathrm{D}} \quad$ : Drag coefficient based on $D, F_{D} / 0.5 \rho L D U_{\infty}^{2}$

$\mathrm{C}_{\mathrm{L}} \quad$ : Lift coefficient based on $D, F_{L} / 0.5 \rho L D U_{\infty}^{2}$

C : Chord length ( $\mathrm{mm})$

Re $\quad$ : Reynolds number based on $\mathrm{D}, \rho \mathrm{U} \infty \mathrm{D} / \mu$

$\alpha \quad$ : Attack angle

Vpp : Peak to peak applied voltage

\section{References}

[1] R. Erfani, T. Erfani, S. V. Utyuznikov, and K. Kontis, "Optimisation of multiple encapsuled electrode plasma actuator,” Aerospace Science and Technology, vol. 26, pp. 120-127, 2013.

[2] C. Hale, R. Erfani, and K. Kontis, "Plasma actuators with multiple encapsuled electrodes to influence the induced velocity," presented at the $48^{\text {th }}$ AIAA Aerospace Sciences Meeting Including the New Horizons Forum and Aerospace Exposition, Orlando, Florida, 2010.

[3] C. C. Wang, R. Dursher, and S. Roy, "Three-dimensional effects of curved plasma actuators in quiescent air," Journal of Applied Physics, vol. 109, no:083305, 2011.

[4] S. Roy and C. C. Wang, "Bulk flow modification with horseshoe and serpentine plasma actuators," Journal of Physics D:Applied Physics, vol. 42, no:032004, 2016.

[5] H. Akbiyı, Y. E. Akansu, and H. Yavuz, "Active control of flow around a circular cylinder by using intermittent DBD plasma actuators," Flow Measurement and Instrumentation, vol. 53, pp. 215-220, 2017.

[6] Y. E. Akansu, F. Karakaya, and A. Şanlısoy, "Active control of flow around NACA0015 airfoil by using DBD plasma actuator," EPJ Web of Conferences, vol. 45, no:01008, 2013.

[7] P. F. Zhang, A. B. Liu, and J. J. Wang, "Aerodynamic modification of a NACA0012 Airfoil by trailing-edge plasma Gurney flap,” AIAA, vol. 47, no:10, 2009.

[8] Z. Lu, C. W. Wong, L. Wang, M. M. Alam, and Y. Zhou, "Separation control on a NACA0015 airfoil with plasma-actuator-generated disturbance," presented at the $8^{\text {th }}$ AIAA Flow Control Conference, Washington, 2016. 
16 10 $10^{\text {TH }}$ International Conference on Sustainable EnERgy AND ENVIRONMENTAL Protection (June $27^{\mathrm{TH}}-30^{\mathrm{TH}}, 2017$, Bled, Slovenia), Mechanical EngineERING 
$10^{\mathrm{TH}}$ InTERnational CONFERENCE ON Sustainable ENERgy AND EnVironmental Protection (June $27^{\mathrm{TH}}-30^{\mathrm{TH}}$, 2017, Bled, SLOVENIA), MECHANICAL ENGINEERING

J. Krope, A.Ghani Olabi, D. Goričanec \& S. Božičnik

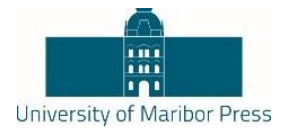

\title{
Inertial Envirolment Small Alloy Welding Equipment
}

\author{
I. R. FERmo, V. R. R. V. DA Silva, M. Y. G. DE GIOVAnNi, R. L. ACORSI, R. Z. \\ SAKIYAMA \& C. M. G. ANDRADE
}

\begin{abstract}
Welding is the most common process to join two types of metal. Capacitive welding is used in small alloys, jewelry and temperature sensors. A good quality welding is composed by a homogeneous distribution and uniformity of the material at welding point and a mass conservation, keeping the metal crystalline proprieties. Capacitive welding consists in submitting a metal to an electric arc, storing energy in capacitors, when released will melt alloy and creates a union. In an inertial chamber the atmosphere is controlled and Argon is injected by a solenoid valve, responsible to control Argon from a cylinder. Argon is an inertial gas responsible for the non-inclusion of external elements in the weld. This study develops equipment able to make capacitive welding using the principles mass and energy conservation in alloys and gauges preestablished, of different types of metals in an inertial environment, with the objective of create a good quality and efficient weld with low cost equipment with easy manipulation.
\end{abstract}

Keywords: • capacitive welding • thermocouples welding • Arduino • inertial environment welding $\bullet$ argon welding •

CORRESPONDENCE AdDRESS: I. R. Fermo, Master's degree students, State University of Maringá, Chemical Engineering Department, Technology Center, Av. Colombo, 5790 - Zona 7, Maringá PR, 87020-900, Paraná, Brazil, email: igor_fermo@hotmail.com. V. R. R. V. Da Silva, Master’s degree students, State University of Maringá, Chemical Engineering Department, Technology Center, Av. Colombo, 5790 - Zona 7, Maringá - PR, 87020-900, Paraná, Brazil, email: victor_ramom@hotmail.com. M. Y. G. De Giovanni, C. M. G. Andrade, Professor, State University of Maringa, Av. Colombo, 5790 - Zona 7, Maringá - PR, 87020-900, Paraná, Brazil, R. L. Acorsi, PhD's degree students, State University of Maringá, Mechanical Engineering Department, Technology Center, Av. Colombo, 5790 - Zona 7, Maringá - PR, 87020-900, Paraná, Brazil, R. Z. Sakiyama, PhD's degree students, State University of Maringá, Mechanical Engineering Department, Technology Center, Av. Colombo, 5790 - Zona 7, Maringá - PR, 87020900, Paraná, Brazil, C. M. G. Andrade, Professor, State University of Maringa, Av. Colombo, 5790 - Zona 7, Maringá - PR, 87020-900, Paraná, Brazil, email: rubens.uem@gmail.com.

https://doi.org/10.18690/978-961-286-057-8.3

ISBN 978-961-286-057-8

(C) 2017 University of Maribor Press

Available at: http://press.um.si. 
$10^{\mathrm{TH}}$ InTERnAtional CONFERENCE ON Sustainable ENERGy AND ENVIRONMENTAL Protection (June $27^{\mathrm{TH}}-30^{\mathrm{TH}}, 2017$, Bled, Slovenia), Mechanical ENGineERING

I. R. Fermo, V. R. R. V. Da Silva, M. Y. G. De Giovanni, R. L. Acorsi, R. Z. Sakiyama

\& C. M. G. Andrade: Inertial Envirolment Small Alloy Welding Equipment

\section{$1 \quad$ Introduction}

Capacitive welding is one of the most common methods to weld small alloys. One of main characteristics is the simplicity of the system. Welding by capacitive discharge consists the support of an electric arc by a small fissure between the conductive substrate that is keep in the neighbourhood of a wire, subject a high electrical potential. The high temperature produced melts part of the material near the outflow, what suddenly occupy the empty spaces and solidify, creating the union of the metal alloy involved [1].

A thermocouple is an example of capacitive welding application in small gauges. Thermocouples are composed by 2 wires of pure or homogeneous mixture alloys that need a resistant and almost perfectly homogeneous union, acquiring characteristics as a single metallic alloy, to obtain high levels of precision of temperature measurement.

The thermocouple measurement point can be made by a method that will keep the alloy proprieties and a good electrical conduction. The measurement point can be made of two types, twisted or top.

There are some thermocouples that are larger used in industrial process, usually metallic thermocouples, the thermocouples are divided in types, the most common are: type $\mathrm{T}$ (cupper-constantan; -180 to $370{ }^{\circ} \mathrm{C}$ ); type $\mathrm{E}$ (chromel- constantan; -200 to $900{ }^{\circ} \mathrm{C}$ ); type $\mathrm{J}$ (Iron-constantan; -40 to $750^{\circ} \mathrm{C}$ ); type $\mathrm{K}$ (Chromel-Alumel; -180 to $300^{\circ} \mathrm{C}$ ) [2].

The mass conservation of the alloys involved is important to assure the quality of the welding in a thermocouple, because there is no addition of a third alloy or element in the system. The inclusion of a third element between the pair of metallic in the welding process must be avoided what attribute a high efficiency and precision the measure equipment [3].

Similar equipment was developed by Zanstra [1] and G. Orr and M. Roth [3]. In a market research, we found these welding equipment [4], [5] and [6], in this equipment there is just a voltage regulator and there is no way of automation of the amount of energy to be used, depending of the thermocouple or alloy gage. In this work, we propose a piece of equipment that can be pre-programed to weld small metal alloys, to minimize the energy consumption and provide a high-quality welding.

Capacitive welding equipment create an electric arc thought the energy stored in a capacitor bank. This system intends to avoid unnecessary use of energy during the process, which can lead a low-quality final product. An Arduino microcontroller controls the charge of the capacitor bank according to the type of alloys and metal gages used in the welding. 
$10^{\mathrm{TH}}$ INTERNATIONAL CONFERENCE ON SUSTAINABLE ENERGY AND ENVIRONMENTAL Protection (June $27^{\mathrm{TH}}-30^{\mathrm{TH}}, 2017$, Bled, SLOvenia), MeChanical ENGINEERING I. R. Fermo, V. R. R. V. Da Silva, M. Y. G. De Giovanni, R. L. Acorsi, R. Z. Sakiyama \& C. M. G. Andrade: Inertial Envirolment Small Alloy Welding Equipment

\section{Methodology}

\subsection{Developing the equipment}

The developed equipment of capacitive welding is able to weld metallic wires, commonly find in jewellery and thermocouple. The equipment is composed of a symmetrical direct voltage source of $31 \mathrm{~V}$ associated to a capacitive bank of $37600 \mu \mathrm{F}$, a microcontroller Arduino UNO, 2 relay, one that will be used as a switch between the capacitive bank and the voltage source, and the other that will be used to control the argon gas valve.

The process of the capacitive relies on direct voltage source is monitored by microcontroller Arduino though the measurement of the voltage of the capacitive bank. Arduino's compatible levels of voltage are achieved through a tension division in order to calculate the energy stored in the capacitors.

The microcontroller Arduino controls the charge stored in the capacitor bank according to its voltage levels. The Arduino is also responsible for determining the charge level of the bank considering the material used in the alloys. To control the charge circuit of the capacitive bank it was used a relay which is responsible by connecting and disconnecting the charging circuit of the source. It was necessary to use a relay for the bank voltage level is not compatible with the tension level supported by the Arduino. Therefore, it was necessary an isolated circuit Fig. 1 illustrates a diagram of the welding process.

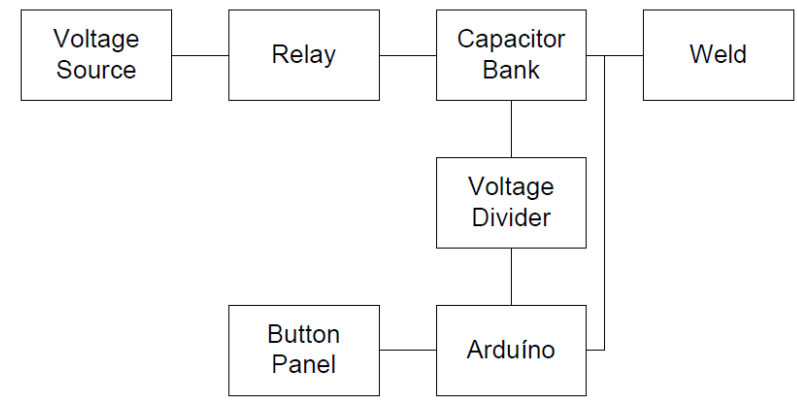

Figure 1. Welding process diagram

The capacitor bank is composed of an association of 8 capacitors in parallel, so that the resulting capacitance is summed and the necessary charge is obtained. For this circuit, it was chosen 8 electrolytic capacitors of $4700 \mu \mathrm{F}$ and $63 \mathrm{~V}$, connected by a $2.5 \mathrm{~mm}^{2}$ wire of cupper. Under its max load, the capacitive bank provides an energy od $74.62 \mathrm{~J}$ approximately. The energy stored it's enough to weld the pre-established gauges and types of thermocouple and there is an energy over to future new gauges and alloys.

It was necessary the development of a circuit called Shield (Hardware circuit able to extra activities for Arduino) to make the connection between the capacitive bank and the charge 
$10^{\mathrm{TH}}$ INTERNATIONAL CONFERENCE ON SUSTAINABLE ENERGy AND ENVIRONMENTAL Protection (June $27^{\mathrm{TH}}-30^{\mathrm{TH}}, 2017$, Bled, Slovenia), Mechanical ENGineERING

I. R. Fermo, V. R. R. V. Da Silva, M. Y. G. De Giovanni, R. L. Acorsi, R. Z. Sakiyama \& C. M. G. Andrade: Inertial Envirolment Small Alloy Welding Equipment

circuit and the connection between the Arduino and the solenoid valve. The Arduino microcontroller cannot operate the relay of load circuit and the valve directly through its digital gate, so it was necessary to develop a circuit able to activate the relay and promote electric isolation between the microcontroller Arduino and the load circuit. The chosen relay has a coil with working voltage of $5 \mathrm{~V}$ and current of $25 \mathrm{~mA}$ model SRD-05VDCSL-C. The relay contacts are able to operate up to $10 \mathrm{~A}$. The digital gate chosen does not supports the necessary current, was necessary to develop an auxiliary circuit to amplify the circuit current.

It was used a BJT (Bipolar Junction Transistor) from the type NPN model BC548 in common emitter to develop the voltage amplifier. In this configuration, the transistor emitter is connected to ground, the collector is connected at one side of coil relay and the other to a $5 \mathrm{~V}$ voltage. The digital gate of the microcontroller Arduino is connected at the transistor base in series with a $1 \mathrm{k} \Omega$ resistor. A high-level logic in the digital output causes a base-emitter polarization and saturate the transition and turns the relay active. A diode 1N4007 was added in parallel with the coil to avoid voltage spikes. Fig 2 illustrates the Shield schematic diagram.

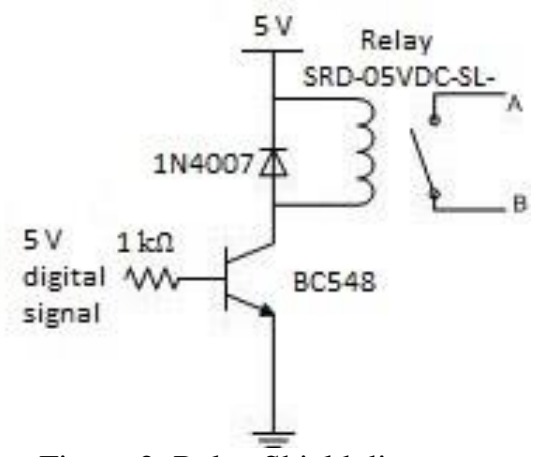

Figure 2. Relay $\overline{\text { Shield diagram }}$

The voltage source responsible for feeding the capacitive bank is formed by a transformer that lowers the voltage from $127 / 220 \mathrm{~V}$ to $24 \mathrm{~V} \mathrm{AC}$. Then a diode rectifies the signal provided by the transformer, the rectification is made by a diode bridge, composed by 4 diodes $1 \mathrm{~N} 4007$. After the rectification, there will still an oscillatory characteristic at the signal and a filter made by $4700 \mu \mathrm{F}$ electrolytic capacitor is used to solve this issue.

After the grid voltage is lowered and filtered is necessary adjust it using the dispositive LM317 from positive and LM337 from negative side, since there is a symmetric power source. With the regulator, it was added potentiometers, that are responsible to create a voltage division, generating a controlled output to the source. Before the final output, it is necessary a new filter, that is made by a pair of $10 \mathrm{nF}$ and $100 \mathrm{nF}$ ceramic capacitors, respectively. The final result is a DC symmetrical voltage source with positive amplitude of $31 \mathrm{~V}$, able to obtain $62 \mathrm{~V}$ of amplitude in DC current. The symmetrical characteristic was chosen because the available components at the market by a low-coast, if necessary 
the components can be changed and a simple source can be produced. Figure 3 illustrates the steps of signal conversion.

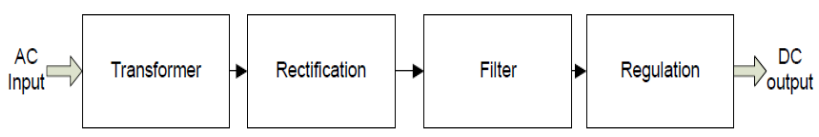

Figure 3. Steps of signal conversion

\subsection{Energy consumption estimations}

Conservation mass and energy balances were done to calculate the necessary energy used in each metallic alloy. A good welding makes a perfect union between both the materials, keeping their physical and chemical proprieties. Therefore, it is necessary to provide enough energy to melt the metallic alloys involved. The variables involved in the calculation of heat transfer process were: specific heat, density and melting temperature of the metallic alloys.

The equipment was developed by 3 gauges of metallic alloys to be welded, 24, 26 and 32 AWG. Reference values of satisfactory radius to weld metallic alloys were established though practical experiments. They were considered to be 2.4 times the diameter for 32 AWG, 1.9 times the diameter for $26 \mathrm{AWG}$ and $24 \mathrm{AWG}$. With the reference values for the generated weld sphere, it was calculated the weld sphere volume to be generated and that would be used to energy calculation. Table 1 presents the theoretical calculation for the energy needed to melt metallic alloys.

Table 1. Melt Energy (J)

\begin{tabular}{|c|c|c|c|}
\hline \multirow{2}{*}{ Element } & \multicolumn{3}{|c|}{ Gauge (AWG) } \\
\cline { 2 - 4 } & 32 & 26 & 24 \\
\hline Iron & 3,535 & 14,136 & 24,120 \\
\hline Cupper & 2,615 & 10,464 & 17,842 \\
\hline Platinum & 3,408 & 13,637 & 23,253 \\
\hline Constantan & 3,037 & 12,154 & 20,725 \\
\hline Alumel & 4,164 & 16,662 & 28,411 \\
\hline Chromel & 3,815 & 15,266 & 26,020 \\
\hline
\end{tabular}

It was calculated the energy stored by the capacitive bank according to the voltage, to control the stored energy in the capacitor bank and assure that the right values are used in different gauges and alloys by the microcontroller Arduino. The composition of each thermocouple type is shown at Table 2 and the results of energy mensuration are shown in table 2 . 

Protection (June $27^{\mathrm{TH}}-30^{\mathrm{TH}}, 2017$, Bled, Slovenia), Mechanical ENGineERING I. R. Fermo, V. R. R. V. Da Silva, M. Y. G. De Giovanni, R. L. Acorsi, R. Z. Sakiyama \& C. M. G. Andrade: Inertial Envirolment Small Alloy Welding Equipment

Table 2. Thermocouple Composition

\begin{tabular}{|c|c|}
\hline Thermocouple & Alloy composition \\
\hline E & Chromel and Constantan \\
\hline J & Iron and Constantan \\
\hline K & Alumel and Chromel \\
\hline T & Cupper and Constantan \\
\hline
\end{tabular}

Table 3. Necessary Melt Voltage (V)

\begin{tabular}{|c|c|c|c|}
\hline \multirow{2}{*}{ Thermocouple } & \multicolumn{3}{|c|}{ Thermocouple Gauge (AWG) } \\
\cline { 2 - 4 } & 24 & 26 & 32 \\
\hline E & 49.869 & 38.191 & 19.091 \\
\hline J & 50.198 & 38.442 & 19.217 \\
\hline K & 53.813 & 41.210 & 20.6 \\
\hline T & 49.293 & 34.686 & 17.339 \\
\hline
\end{tabular}

\subsection{Arduino programming and welding}

In this part values, theoretical calculated will be converted to values that are compatible with the Arduino.

The voltage values that will be monitored by microcontroller Arduino are not compatible with the microcontroller scale. Therefore, it is necessary a circuit to do the voltage conversion from capacitive bank to values between $0 \mathrm{~V}$ and $5 \mathrm{~V}$. To obtain this conversion it was developed a circuit known as voltage divider, that use 2 resistors to create a proportional voltage, a resistor of $1 \mathrm{M} 5 \Omega$ and another of $100 \mathrm{k} \Omega$, as illustrated at Figure 4 .

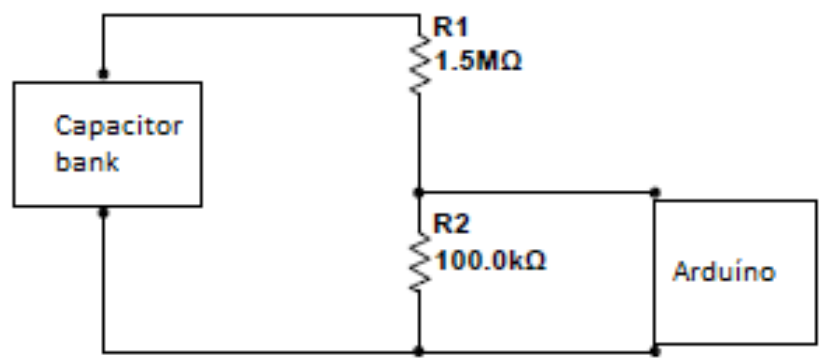

Figure 4. Conversion circuit for Arduino.

Voltage values from the capacitive bank to the $0 \mathrm{~V}$ to $5 \mathrm{~V}$ scale we obtain the values shown in table 4. 
Table 4. Capacitive Bank Voltages at divider (V)

\begin{tabular}{|c|c|c|c|}
\hline \multirow{2}{*}{ Thermocouple } & \multicolumn{3}{|c|}{ Thermocouple Gauge } \\
\cline { 2 - 4 } & 24 AWG & 26 AWG & 32 AWG \\
\hline E & 3.059 & 2.343 & 1.171 \\
\hline J & 3.080 & 2.358 & 1.179 \\
\hline K & 3.301 & 2.528 & 1.264 \\
\hline T & 2.779 & 2.128 & 1.064 \\
\hline
\end{tabular}

The microcontroller Arduino make an analogic conversion to values between 0 and 1023, being 0 to $0 \mathrm{~V}$ and 1023 to $5 \mathrm{~V}$, in a linear scale. So, it is necessary to create a conversion constant to these units, that will be $4.8828 \times 10^{-3}$. Thus, we can program the equipment using a button panel. The result conversion is shown at Table 5 .

Table 5. Conversion variables for Arduino

\begin{tabular}{|c|c|c|c|}
\hline \multirow{2}{*}{ Thermocouple } & \multicolumn{3}{|c|}{ Thermocouple Gauge } \\
\cline { 2 - 4 } & 24 AWG & 26 AWG & 32 AWG \\
\hline E & 627 & 480 & 240 \\
\hline J & 631 & 483 & 241 \\
\hline K & 679 & 518 & 259 \\
\hline T & 569 & 436 & 218 \\
\hline
\end{tabular}

The coupling of the welding terminals will be made of an object with conduction characteristics. To make the conduction from the capacitive bank to metallic alloy $6.0 \mathrm{~mm}^{2}$ wire was been chosen.

An efficient welding connection depends on a good metallic alloy to the welding terminal where it was used an orthodontic forceps to keep the alloys together during the welding process. The forceps were connected to a positive terminal and for the negative terminal it was used a coal brush, usually used in induction motor. The coal was chosen given it is low electrical resistance and high fusion point, important characteristics for a non-inclusive element in the welding.

The weld will be done inside an inertial chamber, the chamber is made of glass and has a cylindrical form, in one side it's opened and in the other there is a connection with a Argon tube, which is responsible for inject the gas during the welding.

The chamber was developed by use in 2 different kinds of weld, twisted and top. The glass chamber is shown at figure 5 . 
$24 \quad 10^{\text {TH }}$ INTERNATIONAL CONFERENCE ON Sustainable ENERGy AND ENVIRONMENTAL Protection (June $27^{\mathrm{TH}}-30^{\mathrm{TH}}, 2017$, Bled, Slovenia), Mechanical ENGineERING

I. R. Fermo, V. R. R. V. Da Silva, M. Y. G. De Giovanni, R. L. Acorsi, R. Z. Sakiyama \& C. M. G. Andrade: Inertial Envirolment Small Alloy Welding Equipment

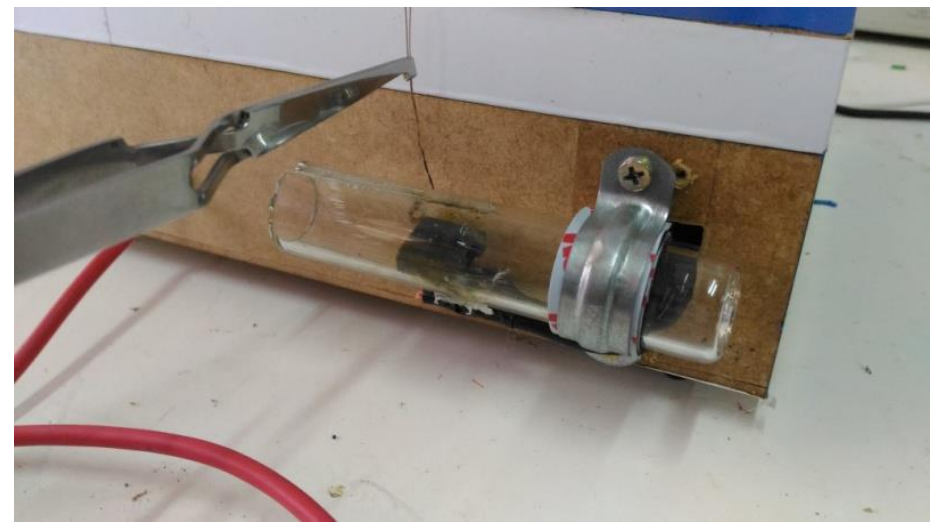

Figure 5. Glass chamber at weld equipment.

The equipment is illustrated in Figure 6.

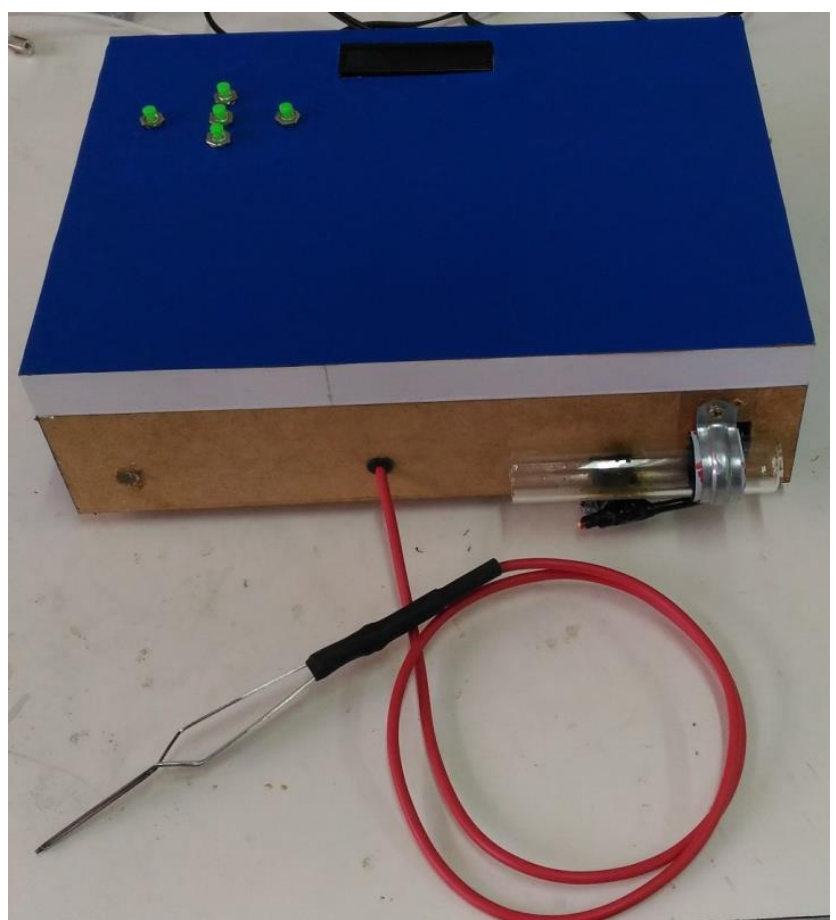

Figure 6. Equipment layout 
$10^{\text {TH }}$ INTERNATIONAL CONFERENCE ON SUSTAINABLE ENERGY AND ENVIRONMENTAL 25 Protection (June $27^{\mathrm{TH}}-30^{\mathrm{TH}}, 2017$, Bled, SLOVENia), MeChanical ENGINEERING I. R. Fermo, V. R. R. V. Da Silva, M. Y. G. De Giovanni, R. L. Acorsi, R. Z. Sakiyama \& C. M. G. Andrade: Inertial Envirolment Small Alloy Welding Equipment

\section{3}

\section{Results}

The experiments were made with thermocouples, type T with gauge 32 AWG. The welding was observed at microscope $260 x$ to verify the quality using the established parameters, such as: format, size, colour and homogeneity.

The Figure 6 show the comparison between the thermocouple weld with Argon (right) and without (left). As we can see the Argon avoid the oxidation, what can be inferred by the colour, the dark characteristic is common by oxidation, what we see in less frequency at the Argon weld experiment.

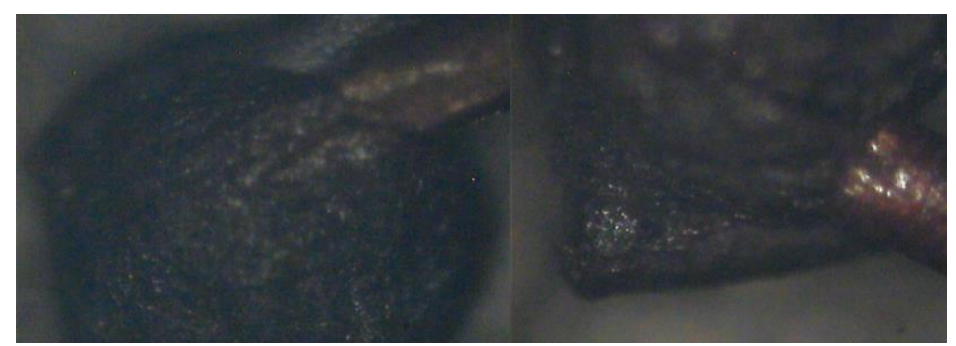

Figure 6. Thermocouple type T 32 AWG

Figure 7 shows a weld with a good appearance, the weld presents a spherical format, as we proposed in this work and with homogeneity at weld point. At the left side we can see a weld without use of Argon, and the right side the Argon use welding, as we saw at Figure 6 , the oxidation is clear at non-use Argon welding.

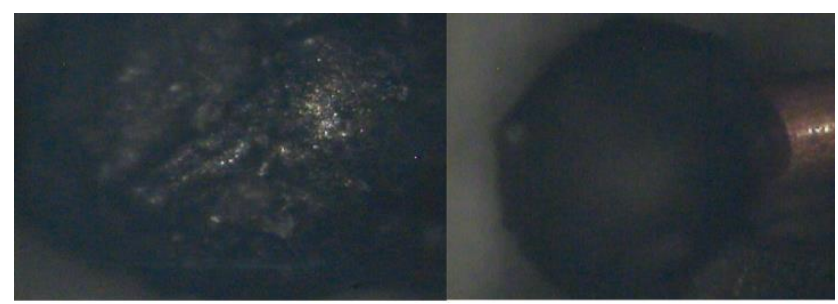

Figure 7. Thermocouple type T 32AWG with argon use (right) and without(left).

Figure 8 show a detail of a weld made without argon, as we can see there is dark points at sphere surface, what indicate the oxidation and the inclusion of external elements at the weld point, this will generate a non-good precision union. 

Protection (June $27^{\mathrm{TH}}-30^{\mathrm{TH}}, 2017$, Bled, SLOVENIA), MeChanical ENGinEERING I. R. Fermo, V. R. R. V. Da Silva, M. Y. G. De Giovanni, R. L. Acorsi, R. Z. Sakiyama \& C. M. G. Andrade: Inertial Envirolment Small Alloy Welding Equipment

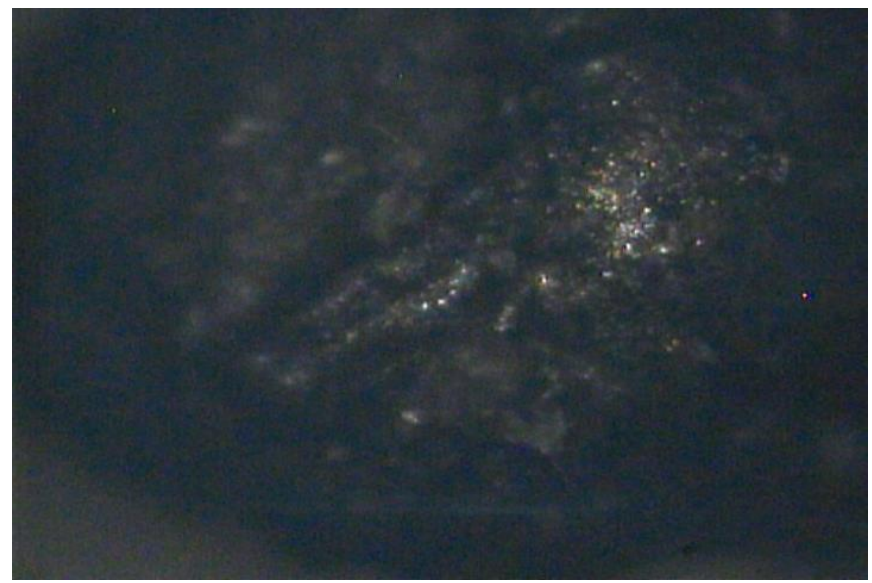

Figure 8. Spherical Weld in a Thermocouple type $\mathrm{T}$ in open atmosphere.

The Figure 9 presents a weld sphere made in an inertial atmosphere, the result is a fusion sphere without oxidation and non-inclusion of external elements, assuring a good union with the alloy fusion and presents a good format.

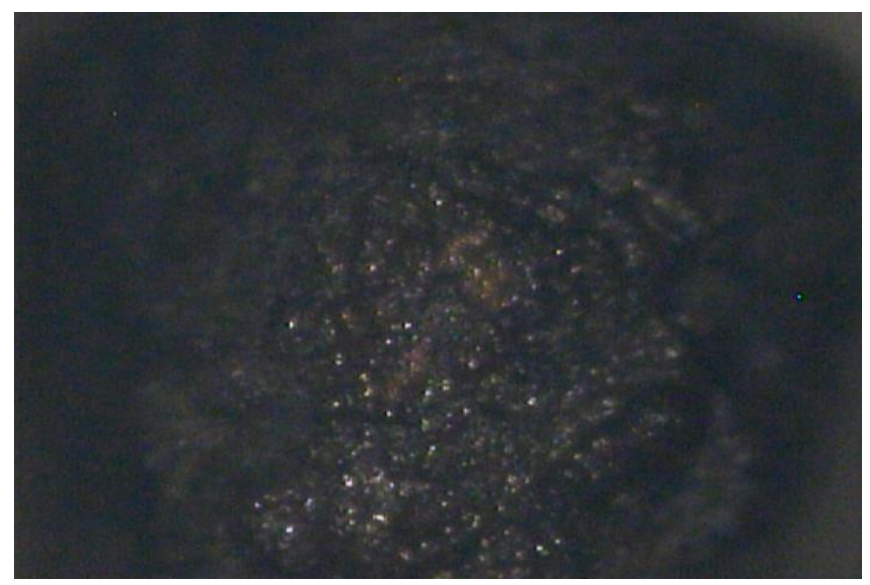

Figure 9. Spherical Weld in a Thermocouple made in an inertial atmosphere

\section{Conclusion}

It was shown a development and use of a piece of equipment to small alloy metallic welding. This equipment can be easily operated. The equipment was developed to use exactly the necessary amount of energy to weld each metallic alloy and gauge. The test objects had a high-level quality. 
$10^{\mathrm{TH}}$ INTERNATIONAL CONFERENCE ON SUSTAINABLE ENERGY AND ENVIRONMENTAL

Protection (June $27^{\mathrm{TH}}-30^{\mathrm{TH}}, 2017$, Bled, SLOvenia), MeChanical ENGiNEERING

I. R. Fermo, V. R. R. V. Da Silva, M. Y. G. De Giovanni, R. L. Acorsi, R. Z. Sakiyama \& C. M. G. Andrade: Inertial Envirolment Small Alloy Welding Equipment

\section{Acknowledgements}

This work has been realized with support of Coordenação de Aperfeiçoamento de Pessoal de Nível Superior (CAPES) - Brazil.

\section{References}

[1] P.E.Zanstra. "Welding Uniform Sized Thermocouple Junctions for thin Wires".1975.

[2] Wang, T. P. (1990) "Thermocouple Materials" in ASM Handbook, Vol. 2. ISBN:978-087170-378-1

[3] G. Orr, M. Roth "Safe and consistente method of spot-welding platinum thermocouple wires and foils for high temperature measurements", Scientific Instruments, Ago 2012.

[4] http://www.realtherm.com.br/prod-tau-interna.php. Acessado em 21/11/2016 as 10:00 horas.

[5] http://br.amadamiyachi.com/products/resistance-welding/rw-power-supplies/thermocouplewelder. Acessado em 21/11/2016 as 10:00 horas.

[6] http://vmvcosta.com.br/\#blog). Acessado em 21/11/2016 as 10:00 horas. 
$28 \quad 10^{\text {TH }}$ InTERnAtional CONFERENCE ON Sustainable ENERGy AND ENVIRONMENTAL Protection (June $27^{\mathrm{TH}}-30^{\mathrm{TH}}, 2017$, BLed, Slovenia), Mechanical ENGineERING 
$10^{\mathrm{TH}}$ INTERNATIONAL CONFERENCE ON Sustainable ENERgy AND EnVironmental Protection (June $27^{\mathrm{TH}}-30^{\mathrm{TH}}$, 2017, Bled, SLOVENIA), MeChaniCAL ENGINEERING

J. Krope, A.Ghani Olabi, D. Goričanec \& S. Božičnik

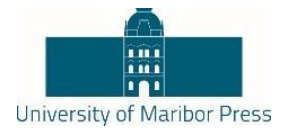

\title{
Industrial Processes of Sucrose Crystallization: A Brief Review
}

\author{
Paulo Eduardo de Morais GonZales, IGOR Rossi Fermo, EugÊNiA LEANDro \\ ALMEIDA \& CID MARCOS GONÇALVES ANDRADE
}

\begin{abstract}
The world is increasing the production of renewable fuels (bioethanol or biodiesel) in industries that can produce food (sugar or soybean oil). In the case of sugar factories, in addition to ethanol, electricity is generated by the combustion of sugarcane bagasse, which, after serving the plant, its surplus is exported to the grid. In this paper we will present a brief review of the process of crystallization of sucrose, which is one of the fundamental steps to obtain sugar with good yield and quality. It will also be shown the influence of the equipment and schemes used in this process in the energy balance of a mixed plant (which produces sugar, ethanol and electricity) and why the use of continuous equipment and the simplification of the crystallization step with the use of two massecuite scheme are the better choices (from the energy point of view) for this type of industry.
\end{abstract}

Keywords: • crystallization $\bullet$ sugar $\bullet$ sucrose $\bullet$ ethanol $\bullet$ electricity $\bullet$

CoRRESPONDENCE AdDRESS: Paulo Eduardo de Morais Gonzales, M.Sc, Universidade Estadual de Maringá, Chemical Engineering Department, Av. Colombo, 5790 - Vila Esperança, Maringá Paraná, Brasil, email: paulogonzales@outlook.com. Igor Rossi Fermo, M.Sc, Universidade Estadual de Maringá, Chemical Engineering Department, Av. Colombo, 5790 - Vila Esperanca, Maringá - Paraná, Brasil,email: igor fermo@hotmail.com. Eugenia Leandro Almeida, M.Sc, Universidade Estadual de Maringá, Chemical Engineering Department, Av. Colombo, 5790 - Vila Esperança, Maringá - Paraná, Brasil, email: eugenia-almeida@hotmail.com; Cid Marcos Gonçalves Andrade, Ph.D, Universidade Estadual de Maringá, Chemical Engineering Department, Av. Colombo, 5790 - Vila Esperanca, Maringá - Paraná, Brasil,email: cid@deq.uem.br.

https://doi.org/10.18690/978-961-286-057-8.4

ISBN 978-961-286-057-8

(C) 2017 University of Maribor Press

Available at: http://press.um.si. 
$10^{\mathrm{TH}}$ InTERnAtional CONFERENCE ON Sustainable EnERgy AND ENVIRONMENTAL Protection (June 27 ${ }^{\mathrm{TH}}-30^{\mathrm{TH}}, 2017$, Bled, Slovenia), Mechanical EngineERing P. Eduardo de Morais Gonzales, I. Rossi Fermo, E. Leandro Almeida \& C. Marcos Gonçalves Andrade: Industrial Processes of Sucrose Crystallization: A Brief Review

\section{$1 \quad$ Introduction}

The world is expanding the production of renewable fuels (bioethanol or biodiesel) in industries that can produce food (sugar or soybean oil). In the case of sugar factories, in addition to the production of ethanol, electricity is generated through the combustion of sugarcane bagasse, which after serving the plant its surplus is exported to the grid. There are several studies that, to increase energy efficiency, seek improvements that can be made in the sugar and ethanol production process in order to reduce the vapor consumption of these stages.

Modifications in the juice extraction system are presented in [1], [2]. Improvements in the evaporation step are [1], [3], [4]. Optimization proposals for the integration of heat sources are detailed in [3], [4]. The use of bagasse to obtain other sources of renewable energy is discussed in [5], [6].

Among the studies that detail the crystallization step, few present the reduction of steam consumption with the change of the scheme used [7]. This paper presents a review of this step, seeking to increase the efficiency of a sugarcane plant.

\section{$2 \quad$ Methodology}

This article uses an industry steam cycle consisting of a boiler that produces live steam at 65 bar and $510^{\circ} \mathrm{C}$ and an condensing-extraction turbine, which can supply the process with saturated exhaust steam at 2.5 bar and condense the remainder of the live steam for the production of electric energy, according to the flowchart shown in Figure 1.

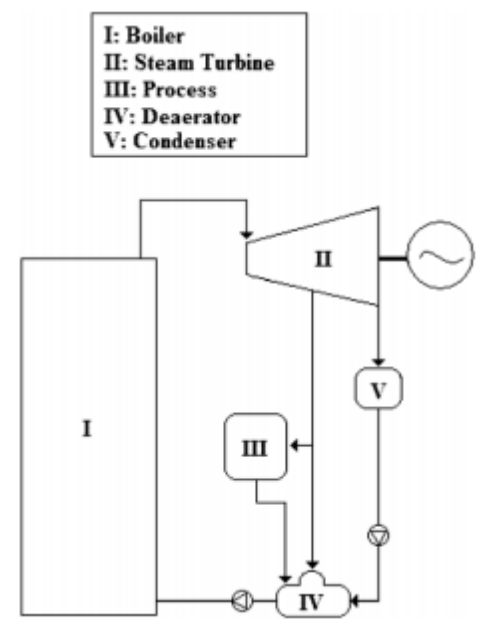

Figure 1: Flow diagram of cogeneration of electric energy with condensing-extraction turbine.[3] 
$10^{\mathrm{TH}}$ INTERNATIONAL CONFERENCE ON SUSTAINABLE ENERGy AND ENVIRONMENTAL Protection (June $27^{\mathrm{TH}}-30^{\mathrm{TH}}, 2017$, Bled, SLOVENIA), MECHANiCAl ENGINEERING

P. Eduardo de Morais Gonzales, I. Rossi Fermo, E. Leandro Almeida \& C. Marcos Gonçalves Andrade: Industrial Processes of Sucrose Crystallization: A Brief Review

Table 1 shows the $\mathrm{kWh}$ ratio generated for each ton of steam under the extraction and condensation conditions.

Table 1: Consumption of live steam at 65 bar and $510^{\circ} \mathrm{C}[8]$

\begin{tabular}{|l|c|}
\hline \multicolumn{1}{|c|}{ Conditions } & $\mathrm{kWh} /$ ton steam \\
\hline Extraction & 181.82 \\
\hline Condensation & 277.78 \\
\hline
\end{tabular}

How much less exhaust vapor at 2.5 bar is consumed by the process, the more electricity will be generated by the condensation of the steam, which has higher efficiency.

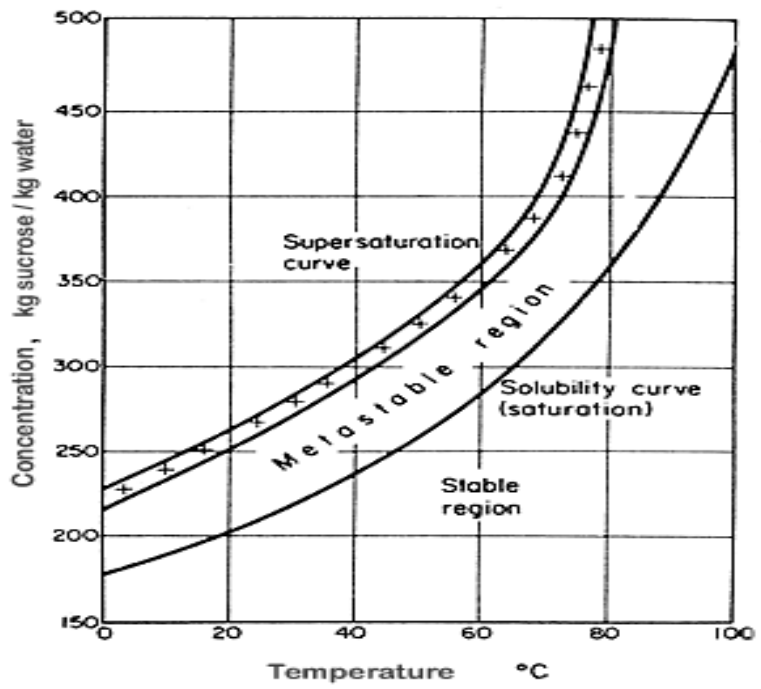

Figure 2: Supersaturation curves for pure sucrose.[9]

The sucrose crystallization step occurs after the juice concentration on evaporation. The syrup, then so-called, is fed into vacuum pans where the introduction and development of the sugar crystals will occur. These devices work under vacuum to reduce the boiling temperature of the massecuite, providing less inversion of the sucrose and saving in the consumption of steam. After the completion of this process the massecuite is sent to the crystallizers, where depending on the type of equipment used, the crystals can develop a little more. At the end of this stage the massecuite feeds centrifuges whose function is to separate the crystals formed from the exhausted mother liquor, which is now called molasses. 
The quality of the sugar may vary depending on the sequence of processes and equipment used. In this paper, we focus on the main processes of crystallization, with their respective yields and energy consumption.

The objective of this step is to obtain crystals of sucrose through the concentration of a sugar solution. For this, one must evaporate part of the water in order that the solution reaches supersaturation. In Figure 2 it is possible to see the supersaturation zones for a pure sucrose solution.

The sucrose crystals may be formed spontaneously if conducted above the metastable region. However, this practice is not recommended because of the irregularity of the size and quantity of crystals formed. Currently in the industry is carried out the total seeding of the pan, process in which is introduced selected crystals in the amount necessary to take advantage of the total capacity of the equipment. Thus, the crystallization is conducted in the metastable zone, where only the added crystals develop, guaranteeing the standardization of the sugar produced.

\subsection{Vacuum pans}

The principle of a vacuum pan is analogous to that of one of the bodies of a juice evaporator [10]. The pans can be operated in batch or continuous mode.

A batch pan has only one chamber where crystallization and crystal development takes place. In this way, in a well-designed equipment, the properties of cooked pasta at any point in the chamber are equivalent and vary with time. These devices follow the following steps during their operation:

- Suction of the sugary solution

- Concentration

- Seeding

- Growth of crystals

- Discharge

- Cleaning

Normally the agitation of the contents of these equipment's is natural, however they may have mechanical stirrers to increase the speed of recirculation and consequently reduce the batch time. Depending on the purity of the massecuite can reduce the batch time by up to $50 \%$ [10]. In addition, it significantly improves the quality of the crystals developed in each batch. 
$10^{\mathrm{TH}}$ InTERNATIONAL CONFERENCE ON SUSTAINABLE ENERGY AND ENVIRONMENTAL Protection (June $27^{\mathrm{TH}}-30^{\mathrm{TH}}, 2017$, Bled, SLOVENIA), MECHANiCAl ENGINEERING

P. Eduardo de Morais Gonzales, I. Rossi Fermo, E. Leandro Almeida \& C. Marcos Gonçalves Andrade: Industrial Processes of Sucrose Crystallization: A Brief Review

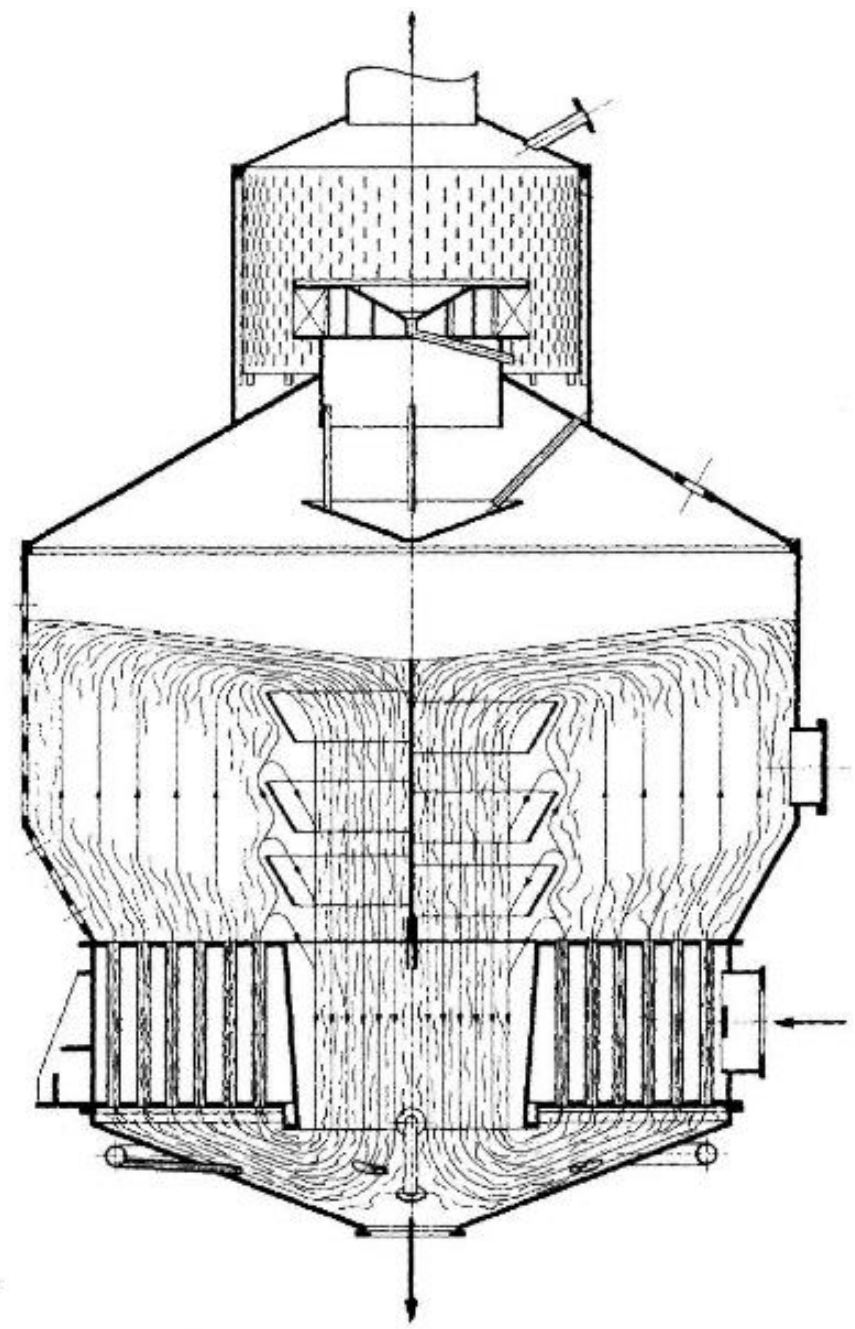

Figure 3: Batch vacuum pan. [10]

Continuous equipment has several chambers that allow the feeding in a uniform way. The size of the crystals varies between the chambers, but the cooked mass of each has properties that remain with the time. 
$10^{\mathrm{TH}}$ InTERnATIONAL CONFERENCE ON Sustainable ENERgy AND ENVIRONMENTAL Protection (June $27^{\mathrm{TH}}-30^{\mathrm{TH}}, 2017$, Bled, Slovenia), Mechanical ENGineERING P. Eduardo de Morais Gonzales, I. Rossi Fermo, E. Leandro Almeida \& C. Marcos Gonçalves Andrade: Industrial Processes of Sucrose Crystallization: A Brief Review

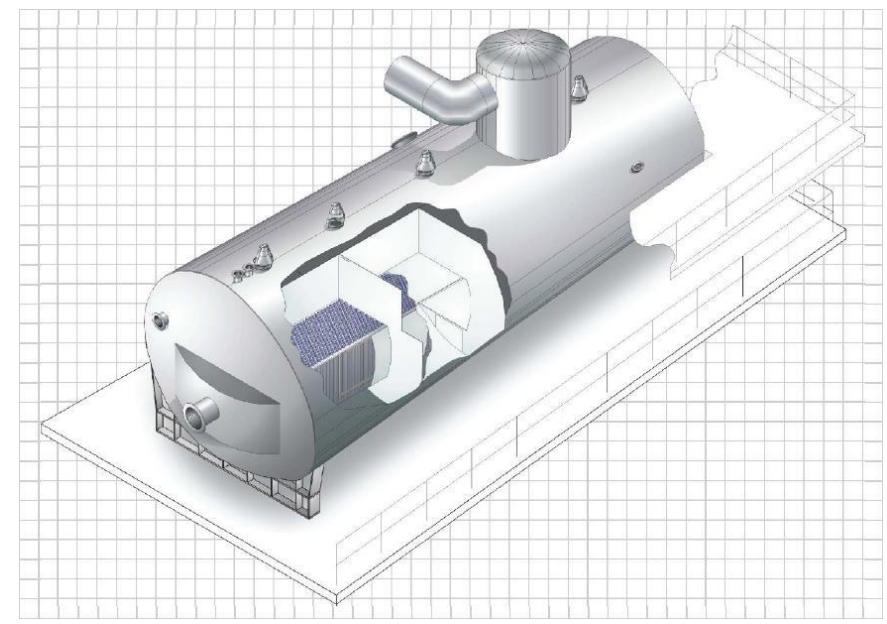

Figure 4: Continuous vacuum pan.

Batch equipment's are present in large numbers in industry, but gradually the continuous are taking up their space, as they have among their advantages the uniformity of steam consumption, eliminating the peaks and possibility of total automation. Among the disadvantages is the time required to start operations during its first operation and the additional care that must be taken during prolonged stops [11].

\subsection{Crystallizers}

When the cooked pasta leaves the vacuum pan it is in high supersaturation [10]. This means that if it rests, the diluted sugar in the mother liquor, which has not yet crystallized, may migrate to the existing crystals, increasing its size. However, to enable this, the massecuite must be in motion, because due to its high viscosity there is the formation of a film that prevents this transfer.

To ensure the massecuite mobility, U-shaped equipment called crystallizers are used which have mechanical stirrers that slowly stir their contents [12].

Currently most of the crystallizers have a cooling system, which reduces the size of the equipment and maximizes the depletion of the liquor. As the massecuite cools, it reduces the solubility of the sucrose in the solution by increasing the rate of deposition of this in the existing crystals. After cooling the mass should be reheated to reduce its viscosity and allow its introduction into the centrifuges.

In mixed plants, where there is the production of ethanol with the fermentation of the final molasses, this step can be simplified. In this way, it is used only as a lung between the pans and the centrifuges, since the uncrystallised sucrose can be used in the production of ethanol. 

Protection (June $27^{\mathrm{TH}}-30^{\mathrm{TH}}, 2017$, Bled, Slovenia), Mechanical ENGinEERING

P. Eduardo de Morais Gonzales, I. Rossi Fermo, E. Leandro Almeida \& C. Marcos Gonçalves Andrade: Industrial Processes of Sucrose Crystallization: A Brief Review

\subsection{Crystals separation}

The sucrose crystals separate from the depleted liquor with the force of gravity. However, the massecuite has very high viscosity, so that the sedimentation operation is not applied on an industrial scale. In this way, centrifuges are used to increase the $\mathrm{G}$ force and reduce the time for the separation of the crystals. Currently, 02 basic types of centrifuges stand out in the manufacturing units being the automatic intermittent ones, based on the machine of Weston [13], and the continuous ones, commonly used in low purity massecuites [14]. The depleted liquor, separated from the crystals, is now called molasses after this step. Figure 5 shows the operating curve of an automatic intermittent centrifuge.

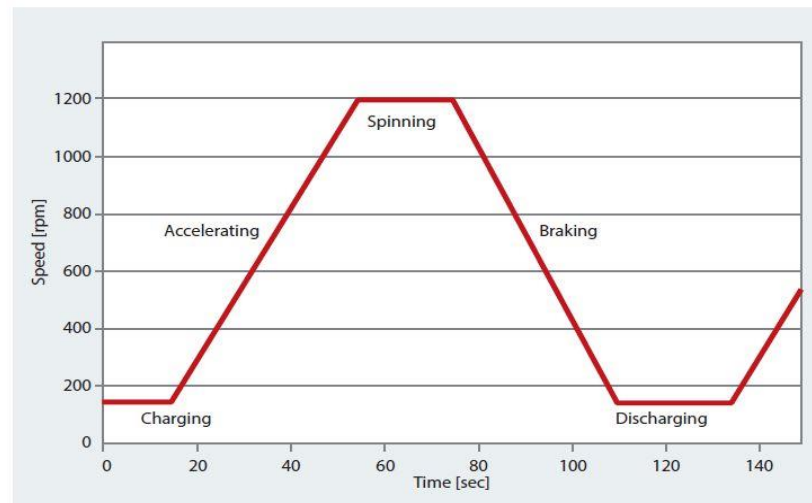

Figure 5: Operating curve of an automatic intermittent centrifuge. Adapted from [12]

\subsection{Cristallization schemes}

During the crystallization step about $50 \%$ of the sucrose contained in the massecuite is crystallized. That is, if only the steps described above were applied approximately half of the sucrose would be diluted in the molasses. To increase the yield of the sugar mill, crystallization schemes are used where molasses are recycled in the process.

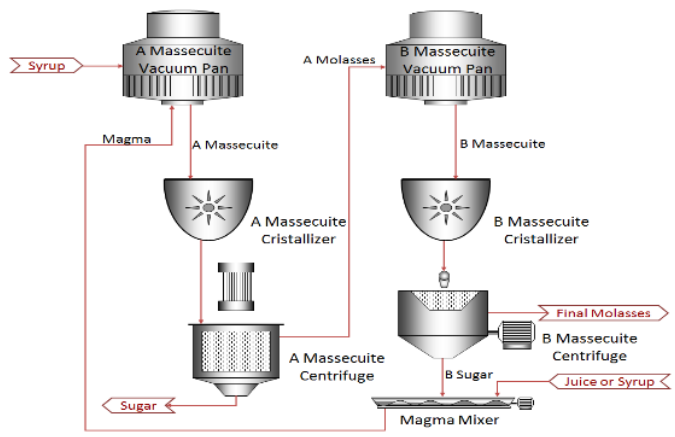

Figure 6: Flow diagram of two massecuites. Adapted from [10] 
$10^{\mathrm{TH}}$ InTERnAtional CONFERENCE ON Sustainable ENERgy AND ENVIRONMENTAL Protection (June 27 $7^{\mathrm{TH}}-30^{\mathrm{TH}}, 2017$, Bled, Slovenia), Mechanical Engineering P. Eduardo de Morais Gonzales, I. Rossi Fermo, E. Leandro Almeida \& C. Marcos Gonçalves Andrade: Industrial Processes of Sucrose Crystallization: A Brief Review

There are several configurations diffused in the industry, however the great majority is based on one of the following:

- Two massecuite scheme;

- Three massecuite scheme.

A flowchart of a two massecuite scheme is shown in figure 6. In this scheme, molasses generated in the centrifugation of the first massecuite, denominated A molasses, feed a vacuum pan where selected crystals will be added to produce B massecuite. This massecuite is centrifuged producing B molasses, which is the poorest in sucrose (in this scheme) and is denominated final molasses, and B sugar, with inferior quality to the sugar obtained in the first centrifugation. This is then mixed with the clarified juice or syrup and it is then called magma. The magma has the crystals that will develop in the crystallization of the A massecuite and composes a third of the work volume of the vacuum pan, the remainder of this volume being the syrup fed into the equipment. The A massecuite is centrifuged generating the sugar and A molasses, thus closing the cycle. This scheme is commonly used in mixed plants, where the sucrose diluted in the final molasses can be used in another process, or in the implantation of new factories, reducing the capital needed to start operations.

The three massecuite scheme has all of the steps of the previous one with the difference that $\mathrm{B}$ molasses is fed into another vacuum pan, where selected crystals producing the $\mathrm{C}$ massecuite will also be added. This is then centrifuged to generate $\mathrm{C}$ molasses, which in this scheme is called final molasses, and $\mathrm{C}$ sugar, which is diluted with clarified juice to be fed together with the syrup. In this way, this scheme generates a molasses with less diluted sucrose, increasing the efficiency of the sugar mill. But it requires a larger sector of crystallization.

\subsection{Mass and energy balances}

Mass balances were performed using the soluble solids content, the crystallization byproducts purity and the proportion of massecuites presented in [10]. For the energy balance, a factor $\mathrm{K}$ was considered equal to 1.5 and was used the Equation (1).

$S C=K x E W$

Where $S C$ is the vapor consumed by the vacuum cleaner and $E W$ is the evaporated water in the equipment. 
$10^{\mathrm{TH}}$ INTERNATIONAL CONFERENCE ON SUSTAINABLE ENERGY AND ENVIRONMENTAL Protection (June $27^{\mathrm{TH}}-30^{\mathrm{TH}}, 2017$, Bled, Slovenia), MeChanical ENGineERING

P. Eduardo de Morais Gonzales, I. Rossi Fermo, E. Leandro Almeida \& C. Marcos Gonçalves Andrade: Industrial Processes of Sucrose Crystallization: A Brief Review

Table 2: Crystallization by-products mass flow in the massecuite schemes (ton / $\mathrm{h}$ )

\begin{tabular}{|l|c|c|c|}
\hline \multicolumn{1}{|c|}{ By-product } & Two Mass. & $\begin{array}{c}\text { Three } \\
\text { Mass. }\end{array}$ & Dif. \% \\
\hline Syrup & 100.00 & 100.00 & 0.00 \\
\hline A Massecuite & 90.45 & 96.93 & 7.17 \\
\hline A Molasses & 82.18 & 84.11 & 2.35 \\
\hline B Massecuite & 49.72 & 48.47 & $-2,53$ \\
\hline B Molasses & 24.25 & 64.42 & 165.63 \\
\hline C Massecuite & - & 38.77 & \\
\hline C Molasses & - & 16.24 & \\
\hline A Sugar & 37.92 & 44.18 & 16.49 \\
\hline $\begin{array}{l}\text { Molasses } \\
\text { Ethanol }\end{array}$ & 6.17 & 3.09 & -50.00 \\
\hline
\end{tabular}

Table 2 shows the difference of the mass flow rates calculated for the two schemes considering the same amount of syrup fed with $60 \%$ soluble solids concentration and $83 \%$ purity (sucrose / soluble solids ratio). Analyzing Table 2, it can be observed that for the same syrup flow there is a $16.49 \%$ increase in sugar production, with a reduction of half the ethanol production from molasses. However, it is necessary A massecuite equipment's of $7.17 \%$ greater and $B$ massecuite section $2.35 \%$ higher, in addition of the equipment for $\mathrm{C}$ massecuite. The significant difference in the $\mathrm{B}$ molasses flow is due to the same being diluted with water in the three massecuite scheme, resulting in a larger flow rate. Performing the energy balance for these flows reaches the values shown in Table 3:

Table 3: Crystallization schemes vapor consumption (ton / h)

\begin{tabular}{|l|c|c|c|}
\hline \multicolumn{1}{|c|}{ Step } & Two Mass. & $\begin{array}{c}\text { Three } \\
\text { Mass. }\end{array}$ & Dif. \% \\
\hline A Massecuite & 57.13 & 62.23 & 16.19 \\
\hline B Massecuite & 48.69 & 53.46 & 44.36 \\
\hline C Massecuite & - & 38.48 & \\
\hline $\begin{array}{l}\text { Molasses } \\
\text { Distillation }\end{array}$ & 24.15 & 12.08 & -50.00 \\
\hline Total & 129.97 & 166.24 & 44.88 \\
\hline
\end{tabular}

The table 4 shows that the consumption of steam increases by $44.88 \%$. This means an increase in the V1 bleed from the evaporation (1.8 bar) and consequently the increase in the amount of exhaust steam (2.5 bar) required in the pre-evaporators. In this way, it decreases the electric energy production through condensation and increases it production through the extraction that as shown in table 1 is less efficient. 
$10^{\mathrm{TH}}$ INTERNATIONAL CONFERENCE ON Sustainable ENERGy AND ENVIRONMENTAL Protection (June $27^{\mathrm{TH}}-30^{\mathrm{TH}}, 2017$, Bled, Slovenia), Mechanical ENGineERING P. Eduardo de Morais Gonzales, I. Rossi Fermo, E. Leandro Almeida \& C. Marcos Gonçalves Andrade: Industrial Processes of Sucrose Crystallization: A Brief Review

Table 4: Electrical energy generation in the massecuite schemes (MWh / h)

\begin{tabular}{|l|c|c|c|}
\hline \multicolumn{1}{|c|}{ Step } & $\begin{array}{c}\text { Two } \\
\text { Mass. }\end{array}$ & $\begin{array}{c}\text { Three } \\
\text { Mass. }\end{array}$ & Dif. \% \\
\hline $\begin{array}{l}\text { Condensation } \\
\text { Generation }\end{array}$ & 12.97 & 2.90 & $-77.67 \%$ \\
\hline $\begin{array}{l}\text { Extraction } \\
\text { Generation }\end{array}$ & 25.43 & 32.02 & $25.94 \%$ \\
\hline $\begin{array}{l}\text { Plant } \\
\text { Consumption }\end{array}$ & 6,16 & 6,39 & $3.77 \%$ \\
\hline Energy Surplus & 32.24 & 28.53 & $-11.52 \%$ \\
\hline
\end{tabular}

Table 4 shows the variation in the amount of electric energy produced by each portion of the generator and the amount exported according to the scheme used. Therefore, it is verified that there is less electric energy sale when the three massecuite scheme is used. Together with lower production of bioethanol this scheme is less interesting from an energy point of view.

\section{$4 \quad$ Conclusion}

In this work, a brief review was presented on the processes involved in the sucrose crystallization stage. Although there are some modeling and simulation studies of this stage [15]-[17], there is not a deepening in the change of the consumption of steam according to the crystallization scheme or type of equipment used. For this, empirical correlations presented in [10].

It was demonstrated that the mixed plants do not seek the maximum exhaustion of their molasses not only due to the possibility of the use of this uncrystallized sucrose in the bioethanol process, but also due to the lower consumption of steam, which increase the quantity of electric energy surplus. This is also verified in [18] in a broader way, that is, without the focus on the crystallization step.

\section{Acknowledgements}

This work was supported by Chemical Engineering Department from State University of Maringá. The authors would like to thank Coordenação de Aperfeiçoamento de Pessoal de Nível Superior (CAPES) for the financial support.

\section{References}

[1] A. V. Ensinas, M. Modesto, S. A. Nebra, and L. Serra, "Reduction of irreversibility generation in sugar and ethanol production from sugarcane," Energy, vol. 34, no. 5, pp. 680-688, 2009.

[2] M. Modesto, R. J. Zemp, and S. A. Nebra, "Ethanol Production from Sugar Cane: Assessing the Possibilities of Improving Energy Efficiency through Exergetic Cost Analysis," Heat Transf. Eng., vol. 30, no. 4, pp. 272-281, 2009. 
$10^{\mathrm{TH}}$ INTERNATIONAL CONFERENCE ON SUSTAINABLE ENERGY AND ENVIRONMENTAL Protection (June $27^{\mathrm{TH}}-30^{\mathrm{TH}}, 2017$, Bled, Slovenia), MeChanical EngineERING

P. Eduardo de Morais Gonzales, I. Rossi Fermo, E. Leandro Almeida \& C. Marcos Gonçalves Andrade: Industrial Processes of Sucrose Crystallization: A Brief Review

[3] A. V. Ensinas, S. A. Nebra, M. A. Lozano, and L. M. Serra, "Analysis of process steam demand reduction and electricity generation in sugar and ethanol production from sugarcane," Energy Convers. Manag., vol. 48, no. 11, pp. 2978-2987, 2007.

[4] L. F. Pellegrini and S. de Oliveira Junior, "Combined production of sugar, ethanol and electricity: Thermoeconomic and environmental analysis and optimization," Energy, vol. 36, no. 6, pp. 3704 3715, 2011.

[5] M. Ioelovich, "Recent Findings and the Energetic Potential of Plant Biomass as a Renewable Source of Biofuels-A Review," BioResources, vol. 10, no. 1, pp. 1879-1914, 2015.

[6] L. Mesa- and E. Castro, "Revamping strategy of diversified industry of sugar cane for combined production of bioetanol and co-products," Rev. Fac. Ing., pp. 189-198, 2013.

[7] N. A. Filho, "Uma Análise Energética da Cristalização Por Resfriamento na Indústria da Cana-deaçúcar," Escola de Economia de São Paulo - FGV-EESP, 2012.

[8] T. D. Vecchia, "Curso de Tecnologia Sucroenergética - Módulo Balanço de Massa e Energia." Reunion Engenharia, Ribeirão Preto, p. 46, 2011.

[9] R. L. Earle, Unit operations in food processing, Second. Oxford: Pergamon Press.

[10] E. Hugot, Handbook of Cane Sugar Engineering, THIRD. New York: Elsevier Pub. Co, 1986.

[11] E. E. McDougall and G. A. Wallace, "The racecourse continuous vacuum pan," Proc. ASSCT, p. 383, 1982.

[12] G. P. Meade, Manual del Azúcar de Caña, 9a edición. Barcelona: Montaner y Simon, S. A., 1967.

[13] P. Honig, Principles of sugar technology. New York: Elsevier Pub. Co, 1953.

[14] G. F. EASTAUGHFFE, "An analysis of continuous centrifugation," in Proc. 39th Conf. QSSCT, 1972, p. 223.

[15] E. Bolaños-Reynoso, K. B. Sánchez-Sánchez, G. R. Urrea-García, and L. Ricardez-Sandoval, "Dynamic modeling and optimization of batch crystallization of sugar cane under uncertainty," Ind. Eng. Chem. Res., vol. 53, no. 33, pp. 13180-13194, 2014.

[16] M. J. da C. G. Meireles, "Modelização e Simulação Computacional de Uma Unidade Industrial de Cristalização de Açúcar," Faculdade de Engenharia da Universidade do Porto, 1996.

[17] N. C. M. Faria, "Quantificação da morfologia de cristais de açúcar e sua aplicação ao estudo das cinéticas de Cristalização," Faculdade de Engenharia na Universidade do Porto, 2001.

[18] E. F. Grisi, J. M. Yusta, and R. Dufo-López, "Opportunity costs for bioelectricity sales in Brazilian sucro-energetic industries,” Appl. Energy, vol. 92, pp. 860-867, 2012. 
\begin{tabular}{l|l}
40 & $10^{\mathrm{TH}}$ International CONFEREnce on Sustainable EnERgy and ENVIRONMENTAL
\end{tabular} Protection (June $27^{\mathrm{TH}}-30^{\mathrm{TH}}, 2017$, Bled, Slovenia), Mechanical EngineERING 
$10^{\mathrm{TH}}$ InTERnational CONFERENCE ON Sustainable ENERgy AND EnVironmental Protection (June $27^{\mathrm{TH}}-30^{\mathrm{TH}}$, 2017, Bled, SLOVEnia), Mechanical ENGINEERING

J. Krope, A.Ghani Olabi, D. Goričanec \& S. Božičnik

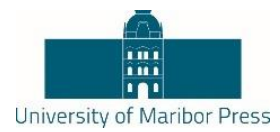

\title{
Optimisation of Wire Electro Discharge Machining Parameter Using Desirability Based Multi Objective RSM While Machining of Al6061-Cenosphere AMCs
}

\author{
ABHIJT DEY, KRISHNA MURARI PANDEY \& BIPLAB DAS
}

\begin{abstract}
WEDM has tremendous potential in its applicability in the present day metal cutting industry for achieving a considerable dimensional accuracy, surface finish and contour generation features of products or parts. But the influence properties that associated with the matel matrix composites (MMCs) confronted a lot of challenges while machining through WEDM. Hence, the present study focussed to investigate the wire electro discharge machining behaviour of cenosphere fly ash reinforced Al6061 alloys. An economic and modified stir casting method has been implemented to synthesize the AMCs known as compo casting process to improve the wettability of casting. Wire electrical discharge machining (WEDM) was employed for cutting the prepared MMCs implementing face centered central composite design (CCD) of response surface methodology. ANOVA analysis was imposed to investigate the influence of process variables and their interactions. Further, a second order quadratic mathematical model has been developed in order to estimate the performance characteristics. It has been observed that pulse-on-time and pulse-off-time were found to be the most significant factors affecting all the three responses. Finally, desirability function approach was employed to optimize the parameters for maximizing the $\mathrm{CR}$ and minimizing $\mathrm{KW}$ and SR.
\end{abstract}

Keywords: • Compocasting method $\bullet$ WEDM $・$ RSM $・$ ANOVA analysis

- Desirability functions •

CorResPondence AdDRESS: Abhijit Dey, Ph.D., National Institute of Technology Silchar, Department of Mechanical Engineering, Assam-788010, India,. e-mail: abhijit14302110@gmail.com. Krishna Murari Pandey, Ph.D., National Institute of Technology Silchar, Department of Mechanical Engineering, , Assam-788010, India, e-mail: kmpandey2001@yahoo.com. Biplab Das, Ph.D., National Institute of Technology Silchar, Department of Mechanical Engineering, Assam-788010, India. e-mail: bpd@ mech.nits.ac.in. 
$10^{\mathrm{TH}}$ InTERnAtional CONFERENCE ON Sustainable EnERgy AND ENVIRONMENTAL Protection (June $27^{\mathrm{TH}}-30^{\mathrm{TH}}, 2017$, Bled, Slovenia), Mechanical ENGineERING

A. Dey, Krishna M. Pandey \& B. Das: Optimisation of Wire Electro Discharge Machining Parameter Using Desirability Based Multi Objective RSM While Machining of Al6061-Cenosphere AMCs

The applications of existing MMCs are limited whereas the machinability is the major concerned. Poor machinability of the material results in poor surface finish and excessive tool wear. Most of the time the MMC's are difficult to be machined by traditional techniques due to possession of higher hardness and reinforcement strength. Hence, electrical discharge machining (EDM) process becomes viable method that does not required any mechanical energy for removal of the material. In EDM process, MRR does not influenced by the mechanical properties like strength, hardness, toughness, etc. Materials like composites and cemented tungsten carbide that has very poor machinability can be processed by the EDM process without any noticeable difficulties [1,2].

The explorations on the machining aspects of Al-MMCs with particle reinforcement have been performed and reported. George et al. studied the carbon-carbon composites considering three process parameters at two levels and disclosed that pulse on time and pulse current are significant parameter for MRR and EWR [3]. The influence of rotation of electrode on die sinking EDM of $\mathrm{Al}-\mathrm{SiC}$ and $\mathrm{Al}-\mathrm{Al} 2 \mathrm{O} 3$ composites yielded significant effect on MRR, EWR and SR [4, 5]. The effect of reinforcement percentage of SiC and other machining characteristics were investigated while machining $\mathrm{Al}-\mathrm{SiC}$, and reported that MRR get decreased with increase in $\mathrm{SiC}$, whereas SR and EWR increases [6,7]. Kumar and Paulo Davim have experimentally investigate the effects of machining parameters in powder mixed ED- machining of $\mathrm{Al}-10 \% \mathrm{SiC}$ MMC. They incorporated silicon powder into the dielectric fluid and found that the MRR increases and SR decreases with addition of silicon powder into the dielectric fluid of EDM [8]. However, literatures on the machining of cenosphere reinforced $\mathrm{Al} \mathrm{MNCs}$ are scarce in general and investigations on the EDM characteristics in particular. In recent decades, the application of both Taguchi and response surface methodology have implemented for appraisal of machining performance [9]. Agarwal et al. carried out a comparative study of CNC turned parts employing both Taguchi and response surface approach. They considered four machining parameters at three levels of each and performed 27 trials for Taguchi method and 30 trials for face centered CCD of response surface approach. The results conclude that (i) the significance of interactions and square terms of process parameters is more clearly anticipated in RSM than Taguchi approach. (ii) RSM technique can model the performance characteristics in terms of significant process variables, their interactions and square terms, which are not provided by Taguchi technique. (iii) 3D response surfaces developed by RSM can help in visualizing the influence of process parameters on response in the entire domain specified whereas Taguchi technique gives the average values of response at specified level of parameters.

Thus, RSM approach can better predict the influence of process variables on performance characteristics and is a better tool for optimization [10]. Hence, in this study the face centred central composite design (CCD) of RSM is employing for the design of experiments. The present work is confronted to investigate the microstructure of prepared MMC and EDM studies by developing mathematical model and examine the effects of 
$10^{\text {TH }}$ INTERNATIONAL CONFERENCE ON SUSTAINABLE ENERGY AND ENVIRONMENTAL Protection (June $27^{\mathrm{TH}}-30^{\mathrm{TH}}, 2017$, Bled, Slovenia), MeChanical ENGineERING

A. Dey, Krishna M. Pandey \& B. Das: Optimisation of Wire Electro Discharge Machining Parameter Using Desirability Based Multi Objective RSM While Machining of Al6061-Cenosphere AMCs

process parameters on the performance characteristics of prepared MMC using response surface methodology. Consequently, the quantitative mathematical models have been developing to study the effects of pulse current (Ip), pulse on time (Ton), percentage of reinforcement $(\mathrm{Vol} . \%)$ and flushing pressure $\left(\mathrm{P}_{\mathrm{flu}}\right)$ on the material removal rate(MRR), tool wear rate (TWR) and surface roughness (SR) by using RSM approach [11].

\section{$2 \quad$ Experimental Details}

Response surface methodology (RSM) is a collection of mathematical and statistical techniques utilization for modelling and optimizing the response characteristics, which incorporates quantitative independent variables . The quality characteristic of the system is explained by a second order polynomial quadratic model also called regression model as shown in Eq.1. The coefficients of regression model can be approximated from the experimental data by 'Design Expert 9.0' software.

$Y=C_{0}+\sum_{i=1}^{n} C_{i} X_{n}+\sum_{i=1}^{n} d_{i} X_{i}^{2} \pm \varepsilon$

The experiments were designed in the present work based on face cantered central composite second order design (CCD) technique. The CCD full factorial design with all factors combination at two levels (high, +1 , and low, - 1) are considered which composed of eight star points, and six central point's (coded level 0), corresponds to an $\alpha$ value of 1 . The "face-centred CCD" includes 30 experimental trial at four distinct process variables. Table 1 shows both actual and coded values of all the machining parameters and their feasible ranges.

Table 1 EDM Machining parameters with their levels.

\begin{tabular}{|l|l|l|l|l|l|l|}
\hline Parameters & Units & Labels & \multicolumn{3}{|l|}{ Levels } & \multicolumn{2}{l|}{} \\
\hline & & & & -1 & 0 & +1 \\
\hline Pulse on Time & $\mu \mathrm{s}$ & $\mathrm{A}$ & 12 & 16 & 20 \\
\hline Pulse off Time & $\mu \mathrm{s}$ & $\mathrm{B}$ & 46 & 49 & 52 \\
\hline Wire feed & $\mathrm{m} / \mathrm{min}$ & $\mathrm{C}$ & 4 & 6 & 8 \\
\hline $\begin{array}{l}\text { 'Wt. } \\
\text { percentage of } \\
\text { reinforcements }\end{array}$ & $\%$ & $\mathrm{D}$ & 0 & 4 & 8 \\
\hline
\end{tabular}

\subsection{Performing experiments}

The machining experiments on the prepared composites has been performed in a CNC Wire Electro Discharge Machine (Sprintcut Electronica Machine Tools Ltd.). A schematic of the wire EDM process have been shown in Fig. 1(a). Deionized water was used as the dielectric fluid of the machine. $0.25 \pm 0.001 \mathrm{~mm}$ diameter cupper coated brass (Cu60Zn40) wire material was selected for machining of the prepared AMCs. The spark gap maintained 
$10^{\mathrm{TH}}$ InTERnATIONAL CONFERENCE ON Sustainable ENERgy AND ENVIRONMENTAL Protection (June $27^{\mathrm{TH}}-30^{\mathrm{TH}}, 2017$, Bled, Slovenia), Mechanical EngineERING

A. Dey, Krishna M. Pandey \& B. Das: Optimisation of Wire Electro Discharge Machining Parameter Using Desirability Based Multi Objective RSM While Machining of Al6061-Cenosphere AMCs

between wire and specimen was approximately $0.002-0.005 \mathrm{~mm}$. The prepared composite samples $(0 \%, 2 \%$ and $4 \%, 6 \% \& 8 \%)$ with dimension $20 \mathrm{~mm} \times 20 \mathrm{~mm} \times 6 \mathrm{~mm}$ were polished by a set of emery papers to ready for machining. The pre-set length of the slot was set $15 \mathrm{~mm}$ for each machining cut at different process parameters of the WEDM. Three different levels has been considered for each of the processing parameters (Pulse-on-time, Pulse-off-time and Wire speed). The schematic of EDM process have been shown in Fig.1.

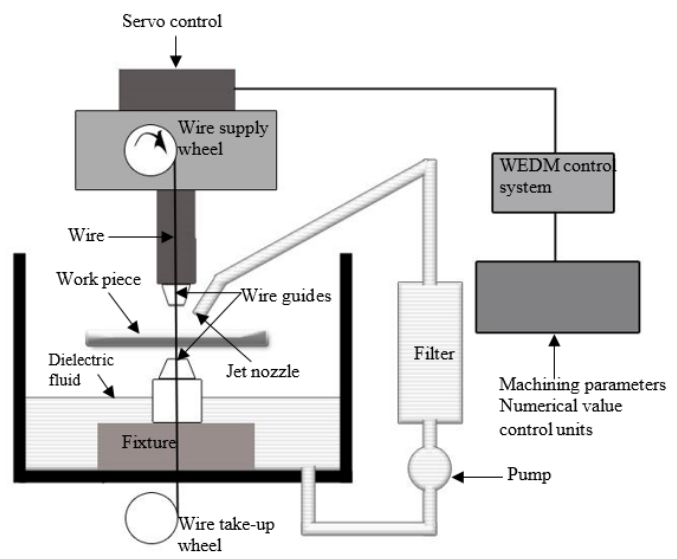

Figure 1. Schematic diagram of Wire EDM setup

\subsection{Analysis of variance (ANOVA) for CS, KW and SR}

The model fit summary prescribed that the second order quadratic model is significant statistically for the analysis of CS, KW and SR. The model F value implies that the model is significant. The value of 'Probability, $p$ greater than $F$ ' for the models term are less than 0.05 (i.e., $\alpha=0.05$, or $95 \%$ confidence) implies that the developed models are appraised to be statistically significant and it is desirable as it indicates that the model terms have a significant influence on the performance characteristics [12]. The probability of a greater F-value caused by the unmanageable noise factors was noticed to be less $(0.01 \%)$. The obtains response model have better fits with actual data, when the multiple regression co efficient R2 approaches to unity. It exists the less the deviation between the actual and predicted values. The plot of actual vs. predicted values of all the responses prove the degree of proximity. Most of the values are fall close to a straight line implying that errors are distributed normally. Moreover, the value of adequate precision (AP) in present models, which compares the span of the predicted value at the design point to the mean prediction error, is fairly above 3 . This represents the adequate model discrimination. These developed models propose grater values of the determination coefficients (R2) and adequate precision (AP) at the same time. The obtained values were as follows: $\mathrm{R} 2=0.9239$ and $\mathrm{AP}=13.56$ for $\mathrm{CR} ; \mathrm{R} 2=0.9627$ and $\mathrm{AP}=20.808$ for $\mathrm{KW}$; $\mathrm{R} 2=0.9783$ and $\mathrm{AP}=25.586$ for $\mathrm{SR}$. Consequently, these developed quadratic mathematical models of CR, KW and SR can be 
$10^{\mathrm{TH}}$ INTERNATIONAL CONFERENCE ON SUSTAINABLE ENERGY AND ENVIRONMENTAL Protection (June $27^{\mathrm{TH}}-30^{\mathrm{TH}}, 2017$, Bled, Slovenia), Mechanical ENGineERING

A. Dey, Krishna M. Pandey \& B. Das: Optimisation of Wire Electro Discharge Machining Parameter Using Desirability Based Multi Objective RSM While Machining of Al6061-Cenosphere AMCs

influence significantly on fitting and predicting the observation results and concurrently the lack-of-fit test also found to be insignificant. The process of backward elimination eradicates the insignificant factors to alter the fitted quadratic response surface models. These insignificant quadratic model terms can be eliminated and the test of lack of fit reveals to be insignificant, as it is desired. The absolute quadratic models of response surface equations obtained by using backward elimination technique are shown in Eqs. (2)(4) as given below. This obtained model can be employing for navigate the design space as the ratio of adequate precision illustrates an adequate signal.

Cutting rate $(\mathrm{CS})=+213.7840+0.7989 *$ Ton $-9.0951 *$ Toff $+2.2407 *$ Wfeed $+0.1725 *$ Wt. $\%-6.8593 \mathrm{E}-003 *$ Ton $*$ Toff $-2.1015 \mathrm{E}-003 *$ Ton $*$ Wfeed $+6.6796 \mathrm{E}-004 *$ Ton $*$ Wt. $\%$-9.4687E-003 $*$ Toff $*$ Wfeed $+8.0729 \mathrm{E}-004 *$ Toff $*$ Wt. $\%+0.0175 *$ Wfeed $*$ Wt.\% -9.0558E-003* Ton^2 $+0.0944 *$ Toff $^{\wedge} 2-0.1274 *$ Wfeed $^{\wedge} 2-0.0522 *$ Wt.\%^2.

Kerf width $(\mathrm{KW})=+357.8761-1.1207 *$ Ton-9.5998*Toff- $5.4333 *$ Wfeed $+0.0607 *$ Wt. $\%$ $-3.0052 \mathrm{E}-003 *$ Ton $*$ Toff $+0.0341 *$ Ton $*$ Wfeed $+0.0561 *$ Ton $*$ Wt. $\%+0.0430 *$ Toff $*$ Wfeed $-0.0289 *$ Toff $*$ Wt. $\%+0.0363 *$ Wfeed $*$ Wt. $\%+0.0477 *$ Ton^ $2+0.0952 *$ Toff^ 2 $+0.2789 * \mathrm{Wfeed}^{\wedge} 2-0.0381 * \mathrm{Wt} . \% \wedge 2$

Surface roughness $(\mathrm{SR})=+5.7935+0.0695 *$ Ton $-0.1392 *$ Toff $-0.1649 *$ Wfeed -0.0108 $*$ Wt. $\%-2.1718 \mathrm{E}-003 *$ Ton $*$ Toff $+4.4296 \mathrm{E}-003 *$ Ton $*$ Wfeed $+5.8984 \mathrm{E}-004 *$ Ton $*$ Wt. $\%$-7.1874E-004 $*$ Toff $*$ Wfeed +1.5625E-005 $*$ Toff $*$ Wt. $\%-1.2578 \mathrm{E}-003 *$ Wfeed $*$ Wt. $\%+9.8863 \mathrm{E}-004 *{ }^{*}{ }^{\wedge} 2+1.8131 \mathrm{E}-003 * \mathrm{Toff}^{\wedge} 2+0.0164 * \mathrm{Wfeed}^{\wedge} 2+8.8323 \mathrm{E}-003 *$ Wt. $\% \wedge 2$. 
$10^{\mathrm{TH}}$ International Conference on Sustainable EnERgy and Environmental Protection (June $27^{\mathrm{TH}}-30^{\mathrm{TH}}, 2017$, Bled, Slovenia), Mechanical EngineERING

A. Dey, Krishna M. Pandey \& B. Das: Optimisation of Wire Electro Discharge Machining Parameter Using Desirability Based Multi Objective RSM While Machining of Al6061-Cenosphere AMCs

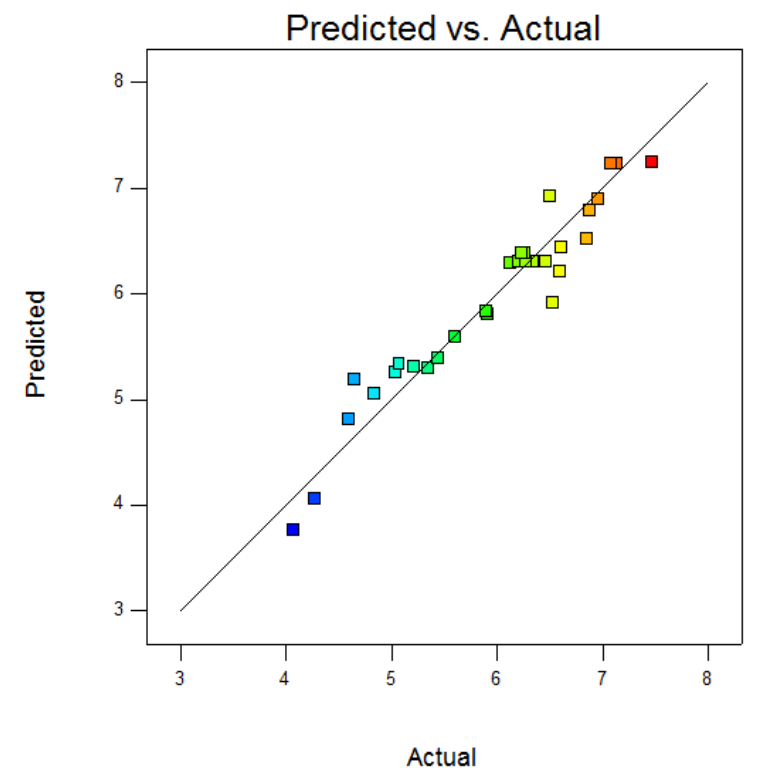

Figure 2. Predicted vs. actual plot for cutting speed (CS)

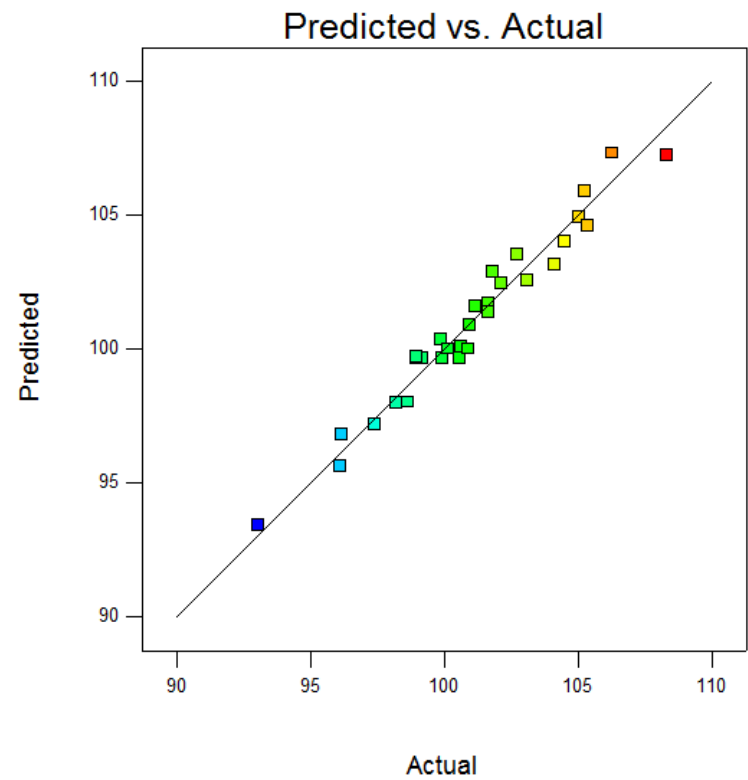

Figure 3. Predicted vs. actual plot for Kerf width (KW) 
$10^{\mathrm{TH}}$ INTERNATIONAL CONFERENCE ON SUSTAINABLE ENERGY AND ENVIRONMENTAL Protection (June $27^{\mathrm{TH}}-30^{\mathrm{TH}}, 2017$, Bled, Slovenia), MeChanical ENGineERING

A. Dey, Krishna M. Pandey \& B. Das: Optimisation of Wire Electro Discharge Machining Parameter Using Desirability Based Multi Objective RSM While Machining of Al6061-Cenosphere AMCs

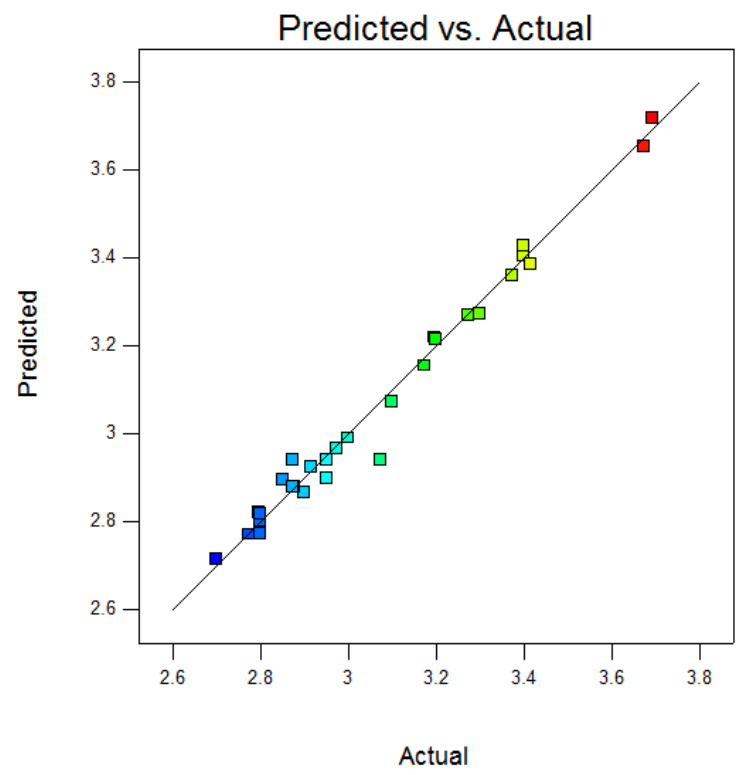

Figure 4. Predicted vs. actual plot for Surface roughness (SR)

\subsection{Desirability based multi response optimization}

The goals and ranges of process variables viz. pulse on time, pulse off time, wire feed and percentage of reinforcement and the response characteristics viz. cutting speed, kerf width and surface roughness are given in table 2 . The goal of desirability approach is to find a set of optimal processing conditions that will encounter all the goals. 1.0 desirability value is not obligatory, as the value is entirely reliant on how intently the upper and lower limits are set relative to the real optimum. A set 50 optimal solution is acquired for the specific design space constraints for CR, KW and SR using statistical Design Expert software 10.0. The set of parametric conditions possessing highest value of desirability is preferred as optimal processing condition for the desired performance characteristics [13, 14]. The optimal parametric condition with greater desirability function is given in Table 3 . Once the optimal set of the input parameters is chosen, the final measure is to predict and verify the enhancement of the response characteristics using the optimal level of the processing parameters. 
$10^{\text {TH }}$ International Conference on Sustainable Energy and Environmental Protection (June $27^{\mathrm{TH}}-30^{\mathrm{TH}}, 2017$, Bled, Slovenia), Mechanical ENGineERING

A. Dey, Krishna M. Pandey \& B. Das: Optimisation of Wire Electro Discharge Machining Parameter Using Desirability Based Multi Objective RSM While Machining of Al6061-Cenosphere AMCs

Table 2. Range of input parameters and responses for desirability.

\begin{tabular}{|c|c|c|c|c|c|c|}
\hline $\begin{array}{l}\text { Proces } \\
\text { s } \\
\text { Param } \\
\text { eter }\end{array}$ & Goal & $\begin{array}{l}\text { Low } \\
\text { er } \\
\text { Lim } \\
\text { it }\end{array}$ & $\begin{array}{l}\text { Upp } \\
\text { er } \\
\text { Lim } \\
\text { it }\end{array}$ & $\begin{array}{l}\text { Lowe } \\
\mathrm{r} \\
\text { Weig } \\
\text { ht }\end{array}$ & $\begin{array}{l}\text { Uppe } \\
\mathrm{r} \\
\text { Weig } \\
\text { ht }\end{array}$ & $\begin{array}{l}\text { Importa } \\
\text { nce }\end{array}$ \\
\hline A:Ton & $\begin{array}{l}\text { in } \\
\text { range }\end{array}$ & $\begin{array}{l}12 \\
\end{array}$ & 20 & 1 & 1 & 3 \\
\hline B:Toff & $\begin{array}{l}\text { in } \\
\text { range }\end{array}$ & 46 & 52 & 1 & 1 & 3 \\
\hline $\begin{array}{l}\text { C:Wfe } \\
\text { ed }\end{array}$ & $\begin{array}{l}\text { in } \\
\text { range }\end{array}$ & 4 & 8 & 1 & 1 & 3 \\
\hline $\begin{array}{l}\text { D:Wt. } \\
\%\end{array}$ & $\begin{array}{l}\text { in } \\
\text { range }\end{array}$ & 0 & 8 & 1 & 1 & 3 \\
\hline CS & $\begin{array}{l}\operatorname{maxim} \\
\text { ize }\end{array}$ & $\begin{array}{l}4.06 \\
6\end{array}$ & $\begin{array}{l}7.4 \\
7\end{array}$ & 1 & 1 & 5 \\
\hline KW & $\begin{array}{l}\operatorname{minim} \\
\text { ize }\end{array}$ & $\begin{array}{l}93.0 \\
41\end{array}$ & $\begin{array}{l}108 \\
.31 \\
4\end{array}$ & 1 & 1 & 2 \\
\hline SR & $\begin{array}{l}\operatorname{minim} \\
\text { ize }\end{array}$ & $\begin{array}{l}2.69 \\
9\end{array}$ & $\begin{array}{l}3.6 \\
93\end{array}$ & 1 & 1 & 3 \\
\hline
\end{tabular}

Table 3. Predicted and observed values of responses of $\mathrm{Al}$-Cenosphere MMC

\begin{tabular}{|r|r|r|r|r|r|l|}
\hline $\begin{array}{c}\text { Resp } \\
\text { onse }\end{array}$ & $\begin{array}{c}\text { Pred } \\
\text { ictio } \\
\mathrm{n}\end{array}$ & $\begin{array}{c}\text { 95\% } \\
\text { CI } \\
\text { low }\end{array}$ & $\begin{array}{c}\text { 95\% } \\
\text { CI } \\
\text { high }\end{array}$ & $\begin{array}{c}\text { 95\% } \\
\text { PI } \\
\text { low }\end{array}$ & $\begin{array}{c}\text { 95\% } \\
\text { PI } \\
\text { high }\end{array}$ & $\begin{array}{l}\text { Actual } \\
\text { value }\end{array}$ \\
\hline CS & $\mathbf{7 . 2 0}$ & 6.690 & 7.72 & 5.46 & 8.95 & $\mathbf{7 . 3 1}$ \\
& $\mathbf{9 6 3}$ & 3 & 897 & 653 & 273 & \\
\hline KW & $\mathbf{1 0 0}$ & 99.37 & 102. & 96.1 & 105. & $\mathbf{9 9 . 8 7}$ \\
& $\mathbf{7 3 2}$ & 6 & 088 & 81 & 283 & \\
\hline SR & $\mathbf{2 . 8 6}$ & 2.789 & 2.94 & 2.60 & 3.13 & $\mathbf{2 . 9 2}$ \\
& $\mathbf{9 3 3}$ & 78 & 888 & 232 & 633 & \\
\hline
\end{tabular}

The desirability function for performance characteristics using ramp function graph and bar graph illustrates in Figs. 11 and Fig. 12 respectively. Each dot on the ramp indicates the parameter settings or response prediction for that performance characteristic. The elevation of the dot reveals the amount of desirability of that response. A linear ramp function is generated between the high value and the goal or the low value and the target as the weight for each factor was set equal to one. Bar graph depicts the overall desirability function of the quality characteristics. Depending upon the proximity of the response towards goal the value of desirability varies from 0 to 1 . The bar graph illustrates how well 
$10^{\mathrm{TH}}$ INTERNATIONAL CONFERENCE ON SUSTAINABLE ENERGY AND ENVIRONMENTAL 49

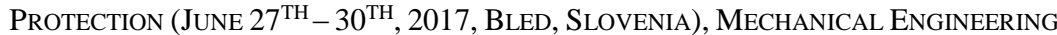
A. Dey, Krishna M. Pandey \& B. Das: Optimisation of Wire Electro Discharge Machining Parameter Using Desirability Based Multi Objective RSM While Machining of Al6061-Cenosphere AMCs

each process variable satisfies the design criterion, desirability value close to one are appraised good.

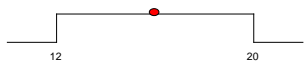

ATon $=16.0398$

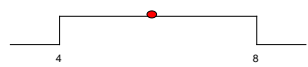

C.Wleed $=5.91014$

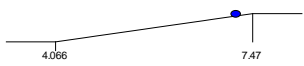

$\mathrm{CS}=7.20963$

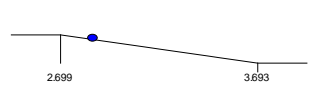

$\mathrm{SR}=2.86933$

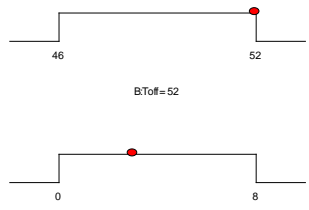

$\mathrm{D}: \mathrm{W}: \%=3.0399$

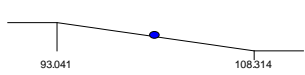

$\mathrm{KW}=100.732$

Desirability $=0.790$

Figure 5. Ramp function plot of Desirability for AA6061-cenosphere AMC.

\section{Desirability}

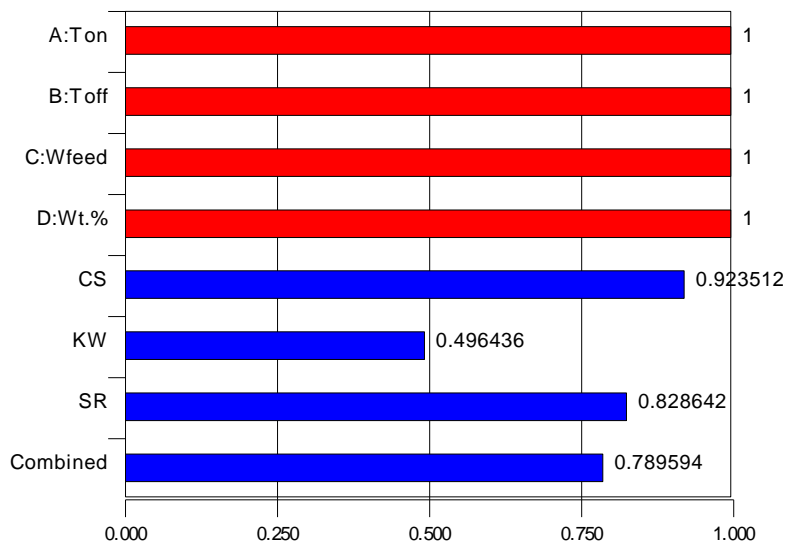

Figure 6. Bar graph of Desirability of AA6061-cenosphere AMC. 
$10^{\mathrm{TH}}$ InTERNATIONAL CONFERENCE ON Sustainable ENERGy AND ENVIRONMENTAL Protection (June $27^{\mathrm{TH}}-30^{\mathrm{TH}}, 2017$, Bled, Slovenia), Mechanical EngineERING

A. Dey, Krishna M. Pandey \& B. Das: Optimisation of Wire Electro Discharge Machining Parameter Using Desirability Based Multi Objective RSM While Machining of Al6061-Cenosphere AMCs

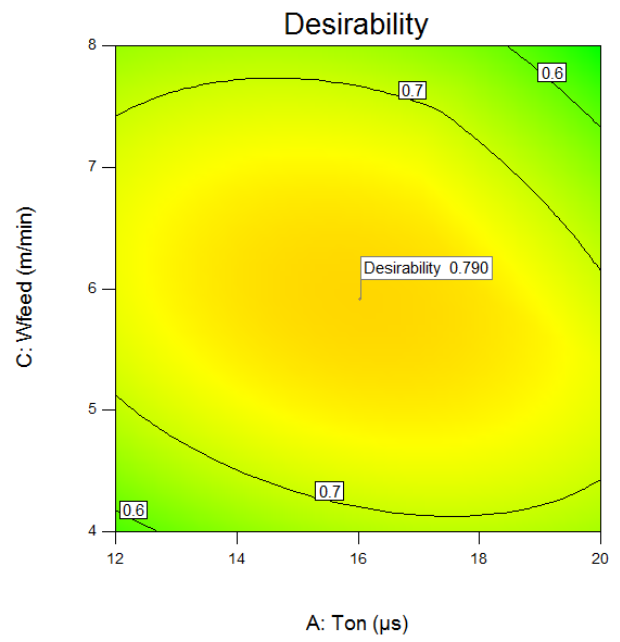

Figure 7. 3D Surface plot of desirability of AA6061-cenosphere AMC.

\subsection{Conclusions}

In the present study, machinability were studied on the newly prepared compo-casted AMCs through wire electrical discharge machining using face centered central composite design(CCD) of response surface methodology(RSM) by attending 30 experimental trials with repetition of three in each for four processing parameters at three levels. The obtained predicted values of $\mathrm{R}^{2}$ for $\mathrm{CR}, \mathrm{KW}$ and $\mathrm{SR}$ reflects the model adequacy. The Pulse on time and $\mathrm{Wt} . \%$ are two main significant factors that affect the CR. The CR increases with an increase in pulse on time. The Wire feed and pulse on time have statistical significance on both KW and SR. The combination of optimum parameter setting forAA6061- cenosphere AMCs obtained by using desirability approach. The agreeable error percentage of predicted and observed values of the CR, KW and SR confirm precision of the methodology.

\section{References}

[1] K.H. Ho, S.T. Newman, State of the art electrical discharge machining (EDM), Int. J. Mach. Tool Manuf. 43 (2003) 1287-1300.

[2] S. Gopalakannan, T. Senthilvelan, K. Kalaichelvan, Modeling and optimization of Al $7075 / 10 \mathrm{wt} \% \mathrm{Al}_{2} \mathrm{O}_{3}$ metal matrix composites by response surface method, Adv. Mater. Res. 488-489 (2012) 856-860.

[3] P.M. George, B.K. Ragunath, L.M. Manocha, M.W. Ashish, EDM machining of carboncarbon composite - a Taguchi approach, J. Mater. Process. Technol. 147 (2004) 66-71.

[4] B. Mohan, A. Rajadurai, K.G. Satyanarayana, Effect of SiC and rotation on electric discharge machining of Al-SiC composite, J. Mater. Process. Technol. 124 (2002) 297-304.

[5] Che.Chung. Wang, Biing.Hwa. Yan, Blind-hole drilling of $\mathrm{Al}_{2} \mathrm{O}_{3} \mathrm{Al}$ composite using rotary electro-discharge machining, J. Mater. Process. Technol. 102 (2000) 90-102. 
$10^{\mathrm{TH}}$ INTERNATIONAL CONFERENCE ON SUSTAINABLE ENERGY AND ENVIRONMENTAL Protection (June $27^{\mathrm{TH}}-30^{\mathrm{TH}}, 2017$, Bled, Slovenia), MeChanical ENGineERING

A. Dey, Krishna M. Pandey \& B. Das: Optimisation of Wire Electro Discharge Machining Parameter Using Desirability Based Multi Objective RSM While Machining of Al6061-Cenosphere AMCs

[6] P. Narendar Singh, K. Raghukandan, M. Rathinasabapathi, B.C. Pai, Electric discharge machining of $\mathrm{Al}-10 \% \mathrm{SiCp}$ as-cast metal matrix composites, J. Mater. Process. Technol. 156157 (2004) 1653-1657.

[7] Sushant Dhar, Rajesh Purohit, Nishant Saini, Akhil Sharma, G. Hemath Kumar, Mathematical modeling of electric discharge machining of cast $\mathrm{Al}-4 \mathrm{Cu}-6 \mathrm{Si}$ alloy-10wt\% SiCp composites, J. Mater. Process. Technol. 194 (2007) 24-29.

[8] Harmesh Kumar, J. Paulo Davim, Role of powder in the machining of Al-10\% SiCp metal matrix composites by powder mixed electric discharge machining, J. Compos. Mater. 45 (2) (2011) 133-151.

[9] E. Kilickap, Modeling and optimization of burr height in drilling of Al-7075 using Taguchi method and response surface methodology, Int. J. Manuf. Technol. 49 (2010) 911-923.

[10] Aman Agarwal, Hari Singh, Pradeep Kumar, Manmohan Singh, Optimisation of power consumption for CNC turned parts using response surface methodology and Taguchi's technique - a comparative study, J. Mater. Process. Technol. 200 (2008) 373-384.

[11] T.L. Taweel, S.A. Gouda, Performance analysis of wire electrochemical turning process RSM approach, Int. J. Adv. Manuf. Technol. 53 (2010). 181-180.

[12] Kumar PRS, Kumaran S, Srinivasa Rao T, Natarajan S. High temperature sliding wear behaviour of press-extruded AA6061/fly ash composite. Mater Sci Eng A 2010; 527:15019.

[13] I. Puertas, C.J. Luis, A study on the machining parameters optimization of electrical discharge machining, J. Mater. Process. Technol. 143-144 (2003) 521-526.

[14] F. Muller, J. Monaghan, Non-conventional machining of particle reinforced metal matrix composites, Int. J. Mach. Tool Manuf. 40 (2000) 1351-1366.

[15] H.K. Kansal, Sehijpal. Singh, P. Kumar, Technology and research developments in powder mixed electric discharge machining (PMEDM), J. Mater. Process. Technol. 184 (2007) 3241.

[16] C.J. Luis, I. Puertas, L. Alvarez, Analysis of the influence of EDM parameters on surface quality, MRR and EW of WC-Co, J. Mater. Process. Technol. 153-154 (2004) 1026-1032.

[17] B. Lauwers, J.P. Kruth, W. Liu, W. Eeraerts, B. Schact, P. Bleys, Investigation of material removal mechanisms in EDM of composite ceramic materials, J. Mater. Process. Technol. 149 (2004) 347-352.

[18] T.A. Taweel, Multi-response optimization of EDM with $\mathrm{Al}-\mathrm{Cu}-\mathrm{Si}-\mathrm{TiC} \mathrm{P} / \mathrm{M}$ composite electrode, Int. J. Adv. Manuf. Technol. 44 (2009) 100- 113.

[19] K.T. Chiang, Modeling and analysis of the effects of machining parameters on the performance characteristics in EDM process of $\mathrm{Al}_{2} \mathrm{O}_{3}+\mathrm{TiC}$ mixed ceramic, Int. J. Adv. Manuf. Technol. 37 (2008) 523-533. 
$52 \quad 10^{\mathrm{TH}}$ International Conference on Sustainable EnERgy and ENVIRONMENTAL Protection (June $27^{\mathrm{TH}}-30^{\mathrm{TH}}, 2017$, Bled, Slovenia), Mechanical EngineERING 
$10^{\mathrm{TH}}$ InTERnational CONFERENCE ON Sustainable ENERgy AND EnVironmental Protection (June $27^{\mathrm{TH}}-30^{\mathrm{TH}}$, 2017, Bled, Slovenia), MEChaniCAL ENGINEERING

J. Krope, A.Ghani Olabi, D. Goričanec \& S. Božičnik

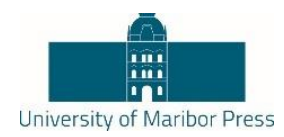

\title{
A Parametric Thermal Analysis of Triangular Fins for Improved Heat Transfer in Forced Convection
}

\author{
SAROJ YADAV \& KRISHNA M PANDEY
}

\begin{abstract}
Thermal management systems in electronic devices require a reduction in size due to improve the overall performance of the system. The aim is to improve the heat transfer with reduction in weight of the system. Fins are the extended surfaces that ease the heat transfer process by increasing the wetted surface area. The thermal diffusion in a fin is always affected by parameters like the size, the shape, the material, the relative arrangement, orientation and position of the fins, the working fluid and its velocity, etc. Moreover, an extended surface may affect the pressure gradient in the flow domain. In this article, a 3-D system of aluminium fin system has been numerically modelled. Simulations are done for conjugate heat transfer problem with fins of triangular shape. The thermal analysis is performed for various input parameters viz., arrangements, orientation and the number of fins.
\end{abstract}

Keywords: • conjugate heat transfer $\bullet$ extended surfaces $\bullet$ finite element method $\bullet$ heat transfer co-efficient $\bullet$ Nusselt number $\bullet$

CORRESPONDENCE AdDRESS: Saroj Yadav, Research Scholar, National Institute of Technology, Department of Mechanical Engineering, Silchar Assam India, 788010, Krishna M Pandey, Ph.D., Professor, National Institute of Technology, Department of Mechanical Engineering, Silchar Assam India, 788010, e-mail: kmpandey2001@yahoo.com. 
$10^{\mathrm{TH}}$ INTERNATIONAL CONFERENCE ON Sustainable ENERGy AND ENVIRONMENTAL Protection (June $27^{\mathrm{TH}}-30^{\mathrm{TH}}, 2017$, Bled, Slovenia), Mechanical ENGineERING S.Yadav \& Krishna M. Pandey: A Parametric Thermal Analysis of Triangular Fins for Improved Heat Transfer in Forced Convection

Any system is under working condition generates heat. Sometimes, the amount of heat that it generates reaches the threshold limit of the system. Therefore, in order to avoid the damaging of the components of the system due to burning or overheating, it is very important to remove the heat in an effective way. Thus, heat transfer in enhanced rate is one of the important topics of thermal engineering. Enhancing the heat transfer rate with the controlled system dimension in the equipment like electronics, heat exchangers, aeronautical, internal combustion engine, etc. have always been a challenging task. To conquer this, researchers are continuously giving their effort in designing or reconstructing a new device with high thermal performance. These devices are intended for cost-effective and energy efficient transfer of heat in the compact areas without any thermodynamic loss. In this concern, an array of fins (or extended surfaces), is one of the possible ways to increase the heat transfer rate from the base surfaces by two techniques. One of the techniques is to produce turbulence in the flowing fluid through its perceptive geometry. It can reduce the thermal resistance of the fluid by impinging stagnant film over the solid surface. Secondly, by building up the fin arrays. This method can increase the heat transfer area that comes in contact with the fluid. Fin geometries and fin arrays can create turbulence in the fluid flowing, this further increase the heat transfer coefficient between systems and surrounding and thus improve the performance. However, it gives rise to the pressure drop, which is a critical condition in most high performance applications. Consequently, it can be said that an optimized fin geometry and fin array combination is a conciliation of performance, pressure drop, weight, and size.

The fin materials usually have a high thermal conductivity, thus it conducts the heat from the wall in high rate. Mostly, fins are used to enhance convective heat transfer by creating the temperature difference between the object and the environment. This in turn increases the convection heat transfer coefficient. Pin fin heat sinks are one of the competent heat exchanging devices used in many electric cooling appliances including CPU, transformer and thyristor. Thus most of the high thermal performance application based fins are made of copper or aluminum. Aluminum is always a preferred material for fins used in electronic system for cooling applications, due to its higher thermal conductivity and light weight.

Researcher proposed many techniques through experimental, analytical and numerical analysis for the performance augmentation of extended surfaces, specifically pin fin heat exchanger. Pin-fin arrays induced turbulence in the flow field which further helpful in enhancement of heat transfer. Axtmann et al. [1] focused their studies on thermally inactive pin-fins and presented the heat transfer results in terms of Nusselt number and also discussed about other individualities like pressure drop and thermal performance parameter of investigated configurations. Şara [2], experimentally investigated the heat transfer, pressure and performing individualities for the array of staggered square pin fins attached on a flat surface in a rectangular duct and compared it with those for the inline arrangement. Jeng and Tzeng [3] also explore the heat transfer and the pressure drop in square pin-fins with variable inter-fin pitches for understandings of pin-fin arrays and systematic experiments has been performed, consequently the optimal inter-fin pitches are provided. 
$10^{\text {TH }}$ INTERNATIONAL CONFERENCE ON SUSTAINABLE ENERGY AND ENVIRONMENTAL Protection (June 27 $7^{\mathrm{TH}}-30^{\mathrm{TH}}$, 2017, Bled, Slovenia), Mechanical EngineERing S.Yadav \& Krishna M. Pandey: A Parametric Thermal Analysis of Triangular Fins for Improved Heat Transfer in Forced Convection

Metzger et al. [4] presented variation in stream wise heat transfer, overall array heat transfer, and overall flow friction behavior for large aspect ratio ducts, that contained uniformly spaced staggered arrays of circular pin fins. Agarwal et al. [5] explored the effectiveness of pin fins for heat transfer in a channel cooled by air and agitated by a translational oscillating plate. Park et al. [6] designed a staggered pin-fin radial heat sink. The system was optimized for cooling of light-emitting diode (LED) device. They developed a numerical model to simulate various pin-fin array heat sinks. The results were verified experimentally. Huang et al. [7] estimated the optimal diameters for perforated pin fin array based on the desired temperature difference between base plate averaged temperature and ambient temperature and system pressure drop. The heat transfer and friction factor characteristics of the perforated rectangular fins were determined by Sahin and Demir [8]. The performances of 3-D conjugate thermo-fluid analysis of micro pin-fins were presented by Abdoli et al. [9]. They considered a conventional circular shape, a hydrofoil shape, a modified hydrofoil shape and a symmetric convex lens shape of a fin. Joo and Kim [10] presented an analytical comparison of the thermal performances of optimized plate-fin and optimized pin-fin heat sinks under fixed volume condition. McNeil et al. [11] measured the heat-transfer coefficient and pressure drop measurements for a heat sink comprising micro pin-fins. In order to improve the performance of thermoelectric power generators in automotive applications Pandit et al. [12] evaluated the heat transfer enhancement methods. Pin fin geometries were examined in this work in a fixed configuration array. Sahiti et al. [13], [14] aimed at the comprehensive and systematic investigation of the influence of pin cross-section on the pressure drop of pin fin arrays and on their overall performance. Also in their work, authors found that elliptical pin fins with a staggered arrangement gave the best performance. Sara et al. [15] obtain the correlation equations of heat transfer and friction factor and studied the effect of various geometrical and flow conditions on the effectiveness of the square pin-fin arrays attached over a flat plate in a rectangular channel. Three-dimensional laminar fluid flow and convective heat transfer around an array of solid and perforated rectangular fins are analyzed numerically by Shaeri et al. [16].

In the following case, a study has been performed on triangular fins with different geometrical parameters. The solver and the developed model is validated first with the available literature. Further, the variation of Nusselt number and heat transfer co-efficient is studied by varying the arrangement, orientation and the number of fins.

\section{Formulations and Geometry}

Thermal analyses of extended surfaces of different shapes are performed in this article. Consideration is given to a 3-D numerical model of aluminum pipe bundle placed in an air duct of dimension $L \times H \times L$ "Fig. 1a". The fins of diameter $D$ and height $l$, arranged in a staggered formation are placed over a base plate of dimension $L_{b} \times L_{b} \times H_{b}$ "Fig. 1". The arrangement is located inside the air duct at a distance $\left(H-L_{b}\right) / 2$ from the inlet. With a 
longitudinal and transverse pitch of $S_{L}$ and $S_{T}$, the system is analyzed for a forced convection scenario. The considered numerical model is validated prior to the analysis of different cases. Air is driven inside the duct at an isothermal room temperature $T_{f}$ and velocity $\vec{V}$ in the positive $y$ - direction. Numerically, the outlet is considered to be at atmospheric pressure $\left(P_{o}\right)$ and at outflow condition $(\hat{n} \cdot k \nabla T=0)$. The walls of the air duct are at no slip conditions $(|\vec{V}|=0)$ and at an isothermal room temperature $T_{f}$ "Fig.1a". The base plate of the fin system is supplied with a total uniform heat of $Q_{s}$.

Thermal behavior of any system is determined by the participated modes of heat transfer, and the thermo physical properties of the system. With a consideration of the conductive and the convective modes of heat transfer, the energy equation given by

$$
\rho c_{p}\left(\frac{\partial T}{\partial t}+\vec{V} \cdot \nabla T\right)=\nabla \cdot(k \nabla T)
$$

Where, $\rho, c_{p}$ and $k$ are the thermal properties of the system. With the known values of thermal properties, evaluation of temperature field of the system from (1) requires the knowledge of the velocity field. Hence, apart from the energy equation, the governing equations of the considered system "Fig. 1a" also include steady form of continuity and momentum equations, given by

$$
\begin{aligned}
& \nabla \cdot(\rho \vec{V})=0 \\
& \vec{V} \cdot \nabla \vec{V}=-\frac{1}{\rho} \nabla p+v \nabla^{2} \vec{V}
\end{aligned}
$$

The governing equation (1)-(3) has been discretized using finite element method (FEM). The discretization is performed using COMSOL Multiphysics, a commercially available FEM solver. Solving (1)-(3) simultaneously using the above mentioned boundary conditions gives the velocity and temperature profiles in the computational domain. The average Nusselt number and the heat transfer co-efficient in such cases are calculated using,

$$
N u=\frac{Q_{s} D}{k_{f} A\left(T_{w}-T_{f}\right)}=\frac{h_{f} D}{k_{f}}
$$


where $A$ and $T_{w}$ are the area of the base plate $\left(=L_{b} \times L_{b}\right)$ and the average surface temperature of the fin walls, respectively.

Fluid flow across a cylinder is a common in various engineering applications. There are many works that has proposed empirical co-relationship for convection heat transfer coefficient. One of such special case is the flow over a cylindrical pin fin heat sink with application in electronic thermal management system. Khan et al. [30] worked on such cases and proposed co-relationship for convective heat transfer co-efficient of fin, $h_{f}$. With an approaching fluid velocity of $U(=|\vec{V}|)$, the Reynolds number for this flow is defined as

$$
\operatorname{Re}_{D}=\frac{\nu U_{\max }}{D}
$$

where $v$ is the kinematic viscosity of the flowing fluid and $U_{\max }$ is the maximum fluid velocity between the fins given by

$$
U_{\max }=\max \left(\frac{S_{T}}{S_{T}-D} U, \frac{S_{T}}{2\left(S_{D}-D\right)} U\right)
$$

where $S_{D}=\sqrt{S_{L}^{2}+\left(S_{T} / 2\right)^{2}}$ is the diagonal pitch in the present case. The average Nusselt number for the fin is

$$
N u=\frac{h_{f} D}{k_{f}}=C_{1} \operatorname{Re}_{D}^{1 / 2} \operatorname{Pr}^{1 / 3}
$$

$C_{1}=\frac{0.61 S_{T}^{0.091} S_{L}^{0.053}}{1-2 e^{-1.09 S_{L}}}$

The calculated values of $\mathrm{Nu}$ and $h_{f}$ obtained from the numerical solution, and the empirical relationship proves the correctness of the numerical modeling and the considered boundary conditions. Further, consideration is given to analysis of triangular fins with different parametric conditions. Schematic diagram of triangular fin systems are shown in "Fig. 2", with inline and staggered arrangements. The relative angular orientation of the fins with the direction of flow is assumed as $\theta$. The $N u$ and the $h_{f}$ are calculated and compared for 
$10^{\mathrm{TH}}$ InTERnAtional CONFERENCE ON Sustainable ENERgy AND ENVIRONMENTAL Protection (June 27 $7^{\mathrm{TH}}-30^{\mathrm{TH}}, 2017$, Bled, Slovenia), Mechanical EngineERING S.Yadav \& Krishna M. Pandey: A Parametric Thermal Analysis of Triangular Fins for Improved Heat Transfer in Forced Convection

different cases with varying arrangements (staggered vs. inline), angular orientations $(\theta)$ and number of fins $(N)$.

\section{$3 \quad$ Results and Discussion}

All headings should commence at the left-hand margin of the In the following, we validate the formulations, the numerical model and the boundary conditions using the results obtained from the empirical relations given by Khan et al. [30]. The 17 numbers of cylindrical Aluminum $\left(k=237 \mathrm{~W} / \mathrm{m} \cdot \mathrm{K}, \rho=2700 \mathrm{~kg} / \mathrm{m}^{3}\right.$ and $\left.\mathrm{c}_{\mathrm{p}}=900 \mathrm{~J} / \mathrm{kg} \cdot \mathrm{K}\right)$ pin fins of are arranged in staggered fashion as shown in Figure 1(b). With $S_{L}=19.6 \mathrm{~mm}$ and $S_{T}=30 \mathrm{~mm}$, the fins $(D=100 \mathrm{~mm}, l=100 \mathrm{~mm})$ are fixed over a base plate of size 118 $\mathrm{mm} \times 118 \mathrm{~mm} \times 5 \mathrm{~mm}$, maintaining a gap of $1 \mathrm{~mm}$ from both the side walls of the air duct. The dimensions of the air duct are $120 \mathrm{~mm} \times 120 \mathrm{~mm} \times 320 \mathrm{~mm}$. A total uniform heat $\left(Q_{s}\right)$ of $115 \mathrm{~W}$ is supplied at the bottom of the base plate in all the considered cases. The heated base plate conducts heat to the fins and finally the heat is dissipated into the air inside the duct. The forced air inside the duct carries the heat in upward direction using a fan.

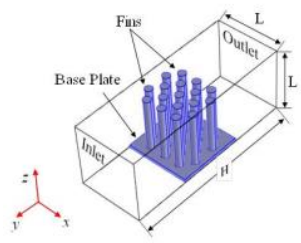

(a)

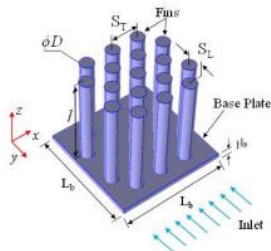

(b)

Figure1 Schematic diagram of the (a) computational domain and the (b) fin geometry

Nusselt number is a parameter that depicts the strength of the convection heat transfer rate compared to the conductive heat transfer rate. The performance parameters $\left(N u\right.$ and $\left.h_{f}\right)$ in the considered system are calculated using the empirical relations "(5)-(7)" and computationally "(4)". With tetrahedral grid to discretize the computational domain, the grid dependency tests were performed for different sizes of the grid. Using a grid having 1584685 numbers of elements, the governing equations were solved for a steady-state condition. Table 1 shows comparative values of average $N u$ and $h_{f}$ for different cases of inlet velocity. A comparative plot of the same is also presented in "Fig. 2a" and "Fig. 2b". From the results it has been observed that with increase in the inlet velocity of the air, the convective heat transfer coefficient increases. The increased value of $h_{f}$ is due to elevation in the convective heat transfer rate. That also increases the value of average $\mathrm{Nu}$. The compared results of average $\mathrm{Nu}$ and $h_{f}$ are found within the acceptable accuracy. The 
deviation in the numerical result from the empirical one is due to the ignored thermal radiation phenomenon in the mathematical modeling.

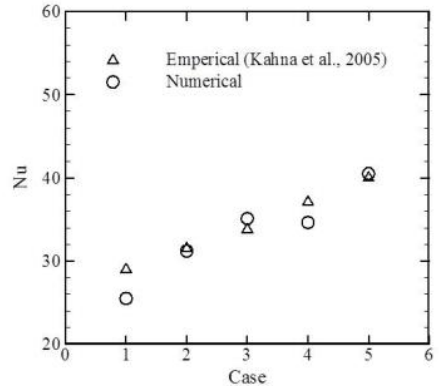

(a)

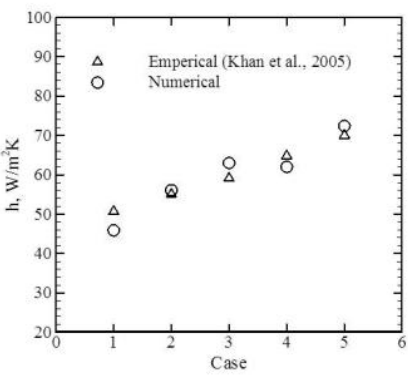

(b)

Fig. 2 Comparison of numerical and empirical values of (a) Nusselt number and (b) heat transfer coefficient

Table1. Comparison of empirical and numerically obtained $\mathrm{Nu}$ and $h_{f}$ for various conditions of Inlet velocity and temperature

\begin{tabular}{|c|c|c|c|c|c|}
\hline & \multirow{2}{*}{$T_{f} \circ \mathrm{C}$} & $\begin{array}{c}\text { Inlet } \\
\text { Veloc } \\
\text { ity } \\
|\vec{V}| \mathrm{m} / \mathrm{s}\end{array}$ & \multicolumn{2}{|c|}{ Empirical } & \multicolumn{2}{|c|}{ Computational } \\
\cline { 3 - 6 } & & $h_{f}$ & $\mathrm{Nu}$ & $h_{f}$ \\
\hline 21.1 & 1.1 & 29.0 & 50.7 & $\begin{array}{c}25 . \\
5\end{array}$ & 45.9 \\
\hline 21.8 & 1.34 & 31.5 & 55.1 & $\begin{array}{c}31 . \\
2\end{array}$ & 56.1 \\
\hline 21.9 & 1.5 & 33.8 & 59.1 & $\begin{array}{c}35 . \\
1\end{array}$ & 63.0 \\
\hline 21.8 & 1.81 & 37.1 & 64.8 & $\begin{array}{c}34 . \\
64\end{array}$ & 62.03 \\
\hline 21.9 & 2.1 & 40.0 & 70.0 & $\begin{array}{c}40 . \\
53\end{array}$ & 72.43 \\
\hline
\end{tabular}

Having validated the numerical solver, the fins of triangular shape are considered for study. The fins are modeled in such a way that the volume of the system is always maintained constant $\left(229 \mathrm{~mm}^{3}\right)$. For the study of effect of number of fins, in order to maintain uniformity in the modeling, the heights to base ratio of the fins are always kept same for all the cases, i.e., 2.5 . 
$10^{\mathrm{TH}}$ InTERnAtional CONFERENCE ON Sustainable ENERgy AND ENVIRONMENTAL Protection (June 27 $7^{\mathrm{TH}}-30^{\mathrm{TH}}, 2017$, Bled, Slovenia), Mechanical EngineERING S.Yadav \& Krishna M. Pandey: A Parametric Thermal Analysis of Triangular Fins for Improved Heat Transfer in Forced Convection

\section{Inline vs. Staggered Arrangement}

The relative position of the fins plays an important role in the heat transfer process. In this study, the thermal analysis is performed on a 2-2 inline and 2-1-2 staggered arrangement of fins as described in "Fig. 3". The base $(b)$ and the altitude $(a)$ of the fin are selected in a way to accommodate the fin-base plate assembly in a space of $13 \times 13 \mathrm{~mm}^{2}$. For the inline arrangement of the fins, the base $(b)$ and the altitude $(a)$ is taken as $4.9857 \mathrm{~mm}$ and $10 \mathrm{~mm}$, respectively.

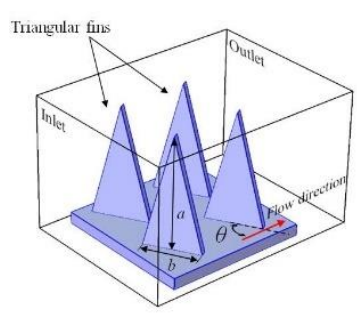

(a)

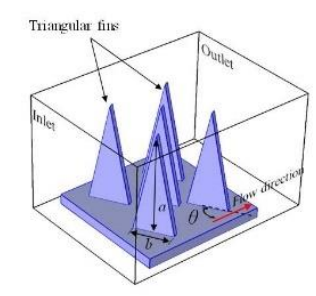

(b)

Fig. 3 Schematic diagram of (a) inline and (b) staggered arrangement of triangular fins

As the number of fins in the considered staggered arrangement is more than that of the inline arrangement, the base and altitude of the fins in this case will reduce to $3.989 \mathrm{~mm}$ and $10 \mathrm{~mm}$ to maintain a total volume of $229 \mathrm{~mm}^{3}$. The thicknesses of the fins are also maintained at a constant value of $0.6 \mathrm{~mm}$, throughout the study. The set of fins are placed over a baseplate of $1 \mathrm{~mm}$ thickness with the trailing edge located at $y=0$. The system is supplied with a total uniform heat $\left(Q_{s}\right)$ of $2 \mathrm{~W}$ from the base of the base plate. A unidirectional flow of air is imposed as the inlet condition with velocity of $5 \mathrm{~cm} / \mathrm{s}$. "Fig. $4 \mathrm{a}$ " and "Fig. 4b" shows the results obtained from the numerical simulations. The stream line of velocity plot in a horizontal section $(\mathrm{z}=6 \mathrm{~mm})$ shows the flow over the considered extended surfaces. In the staggered arrangement, the interaction between the solid and air is observed to be more compared to the inline arrangement. It is due to the placement of the fifth fin between two rows in the staggered arrangement. The contours in the "Fig. 4" shows variation of temperature at the horizontal middle plane $(\mathrm{z}=6 \mathrm{~mm})$ of the rectangular domain. Following the formulations in the previous section, the values of heat transfer coefficient $h$ and the Nusselt number Nu is calculated for the considered inline and staggered arrangement. For the staggered arrangement of triangular fins, $h$ is observed to be 14.7 $\mathrm{W} / \mathrm{m} \cdot \mathrm{K}$, which is $6.6 \%$ higher than the value in case of inline arrangement, i.e., 13.8 $\mathrm{W} / \mathrm{m} \cdot \mathrm{K}$. The observed increment in heat transfer co-efficient is due to a better interaction at the fluid-solid interface. The increased number of fins in this case also helped in increasing the total wetted surface area of the fin by $2.56 \%$, which in turn enhances the heat transfer rate. The presence of the fins inside the rectangular duct induces a circulation in the flow. The same is realized from the variation of $y$-component of velocity "Fig. 5", immediately after the flow passes over the fins (at $y=0$ ). The clockwise and the counterclockwise vortices formed due to the fin structure shows more prominent presence 
near the left and the right wall of the duct, respectively, for both arrangements. Therefore, the air near these boundaries have almost equal thermal interaction and heat dissipation near the walls as that of the core "Fig. 5". With an improved rate of heat transfer in staggered arrangement in triangular fins, next the study has been done on variation of relative orientation of the fins with the flow direction.

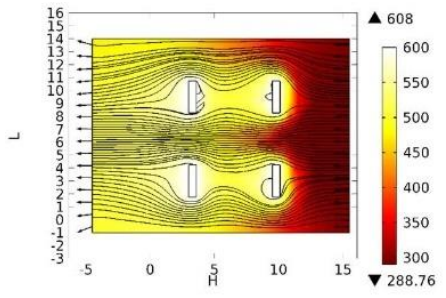

(a)

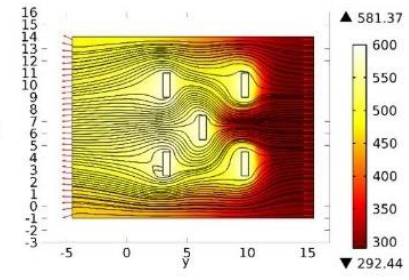

(b)

Fig. 4 Velocity streamline, direction and surface temperature (in $\mathrm{K}$ ) variation in (a) inline and (b) staggered arrangement of fins in a plane at $\mathrm{z}=6 \mathrm{~mm}$

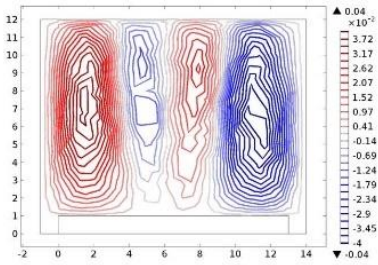

(a)

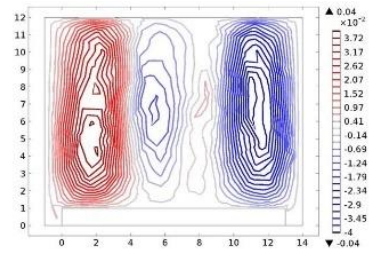

(b)

Fig. 5 Contour profile of $y$-component of velocity $(v, \mathrm{~m} / \mathrm{s})$ in (a) inline and (b) staggered Relative orientation of the fins arrangement of fins in a plane at $y=0$

A fin or extended surface that eases the heat transfer process by enhancing the wetted surface area. However, presence of an extended surface also contributes in the pressure drop along the flow direction. In this regard, the orientation of the surfaces plays a major role. In the previous study, the triangular fins are made to fix over a base plate with triangular face of the fin placed normal $\left(\theta=90^{\circ}\right)$ to the fluid flow direction. The current study focuses on the study of relative orientation of the fins with flow direction on heat transfer and fluid flow. Considering five variation of angles viz., $0^{\circ}, 30^{\circ}, 45^{\circ}, 60^{\circ}$ and $90^{\circ}$, thermal analysis is made on triangular fins under same thermal load and boundary conditions. 

Protection (June $27^{\mathrm{TH}}-30^{\mathrm{TH}}, 2017$, Bled, Slovenia), Mechanical ENGineERING S.Yadav \& Krishna M. Pandey: A Parametric Thermal Analysis of Triangular Fins for Improved Heat Transfer in Forced Convection
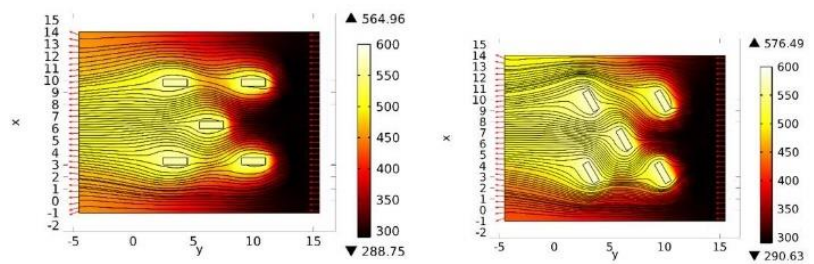

(a)

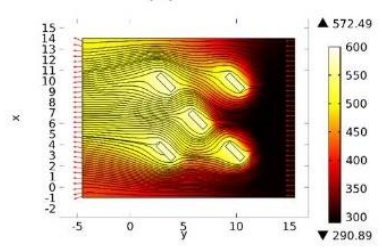

(c)

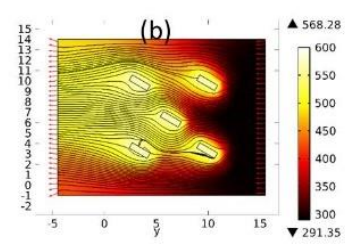

(d)

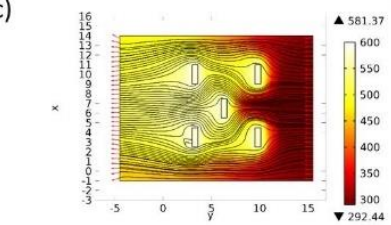

(e)

Fig. 6 Velocity streamline, direction and surface temperature (in K) variation in staggered arrangement of fins at $\mathrm{z}=6 \mathrm{~mm}$, with $\theta=(\mathrm{a}) 0^{\circ}$ (b) $30^{\circ}$ (c) $45^{\circ}$ (d) $60^{\circ}$ and (e) $90^{\circ}$

"Fig. 6" shows the surface temperature contour and the velocity streamlines at $z=6 \mathrm{~mm}$ for all the considered cases. In case of triangular fins with $\theta=0^{\circ}$, the temperature contour shows a better distribution of temperature of air throughout the computational domain. However, due to angular orientation of the fins the flow is diverted towards one of the boundary which is parallel to the horizontal axis. Therefore, in case $30^{\circ}, 45^{\circ}$ and $60^{\circ}$, the temperature contour and the streamlines are observed to deviate towards the flow direction. In case with $\theta=90^{\circ}$, for the fluid moving normal to the triangular face of the fins, the fluid particles reaches a stagnation condition and imposes pressure on the fin wall "Fig. 7". The situation is less prominent as one moves from $90^{\circ}$ through $0^{\circ}$. Therefore, due to symmetric flow of air, in case of $\theta=0^{\circ}$, with better thermal interaction, a better heat transfer phenomenon is observed. The same may be realized from the calculation of $\mathrm{Nu}$ and $h$. "Fig. 8 " shows a comparative bar diagram of all the above cases. For the fins with triangular faces parallel to the flow direction, the $\mathrm{Nu}$ and $h$ is observed to be 0.85 and 15.63 , respectively. For all other values of $\theta$, the values $\mathrm{Nu}$ and $h$ is found to be lesser than the above values. 


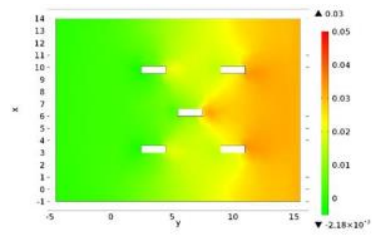

(a)

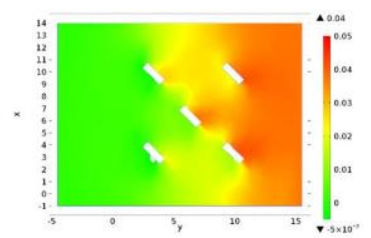

(c)

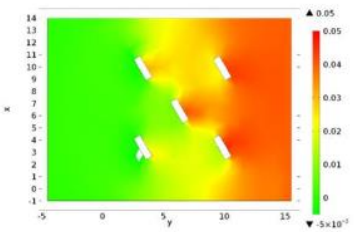

(b)

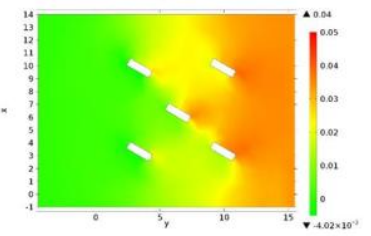

(d)

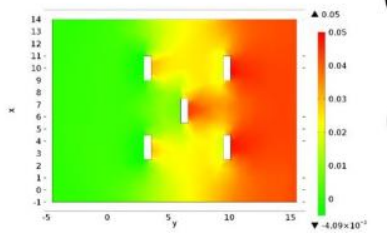

(e)

Fig. 7 Contour profile of pressure $(\mathrm{Pa})$ in staggered arrangement of fins with $\theta=(\mathrm{a}) 0^{\circ}$ (b) $30^{\circ}$ (c) $45^{\circ}$ (d) $60^{\circ}$ and (e) $90^{\circ}$

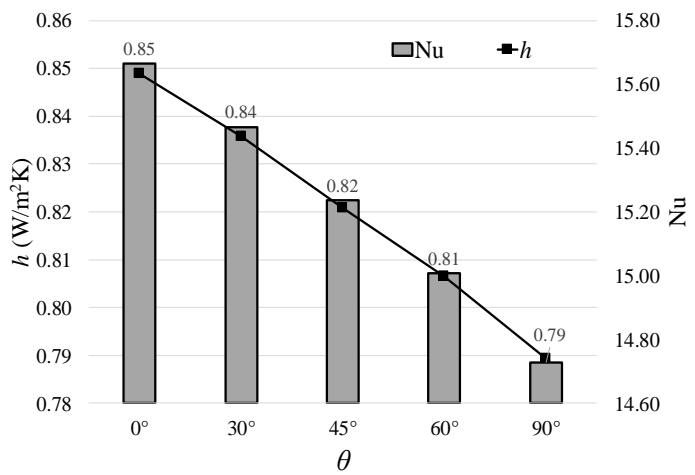

Fig. 8 Variation of $\mathrm{Nu}$ and $h$ for values of angle $\theta$ of triangular fins arranged in 2-1-2 staggered arrangement.

\section{Number of fins}

With the understanding of heat transfer process in different arrangements of the fins, next the study has been extended to observe the effect of number of fins in the system. Four different cases with staggered arrangement of fins are considered with 2-1-2 (5 fins), 3-23 (8 fins), 4-3-4 (11 fins) and 5-4-5 (14 fins) staggered arrangement. The fins are place at 
$10^{\text {TH }}$ International Conference on Sustainable Energy and Environmental Protection (June 27 $7^{\mathrm{TH}}-30^{\mathrm{TH}}, 2017$, Bled, Slovenia), Mechanical EngineERING

S.Yadav \& Krishna M. Pandey: A Parametric Thermal Analysis of Triangular Fins for Improved Heat Transfer in Forced Convection

angle $\theta=0^{\circ}$ with the flow direction. A schematic diagram of the same is shown in "Fig. 9". To maintain uniformity, the volume of all the fins and the aspect ratio (altitude: base) of individual fin is maintained the same as the earlier cases i.e. 2.5. "Table 2" shows the results obtained from the numerical analysis for same boundary and thermal load conditions. It has been observed that as the numbers of fins are increased, the wetted surface area of the fins also increases, although the volume is remaining constant. However, the characteristic length of the fins decreases with increase in the number of fins. This affects the value of $\mathrm{Nu}$ and $h$. As the number of fins increases the Nusselt number and the convective heat transfer co-efficient decreases.

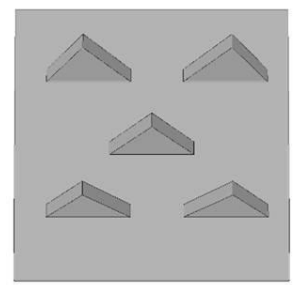

(a)

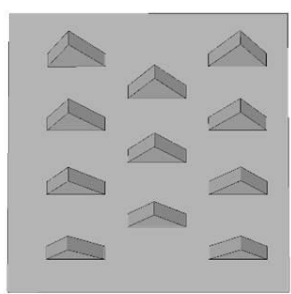

(c)

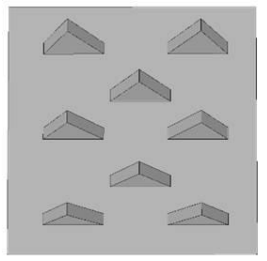

(b)

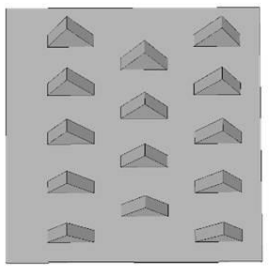

(d)

Fig.9 Schematic diagram of staggered arrangement of fins placed parallel to the flow direction with (a) 2-1-2 (b) 3-2-3 (c) 4-3-4 and (d) 5-4-5 configuration 
$10^{\mathrm{TH}}$ InTERNATIONAL CONFERENCE ON SUSTAINABLE ENERGY AND ENVIRONMENTAL Protection (June $27^{\mathrm{TH}}-30^{\mathrm{TH}}, 2017$, Bled, Slovenia), MeChaniCAl ENGineERING S.Yadav \& Krishna M. Pandey: A Parametric Thermal Analysis of Triangular Fins for Improved Heat Transfer in Forced Convection

Table 2. Comparison of values of nu and $h$ for various numbers of fins placed parallel to the flow direction with staggered arrangements

\begin{tabular}{|c|c|c|c|c|c|}
\hline Case & $\begin{array}{c}\text { Num } \\
\text { ber } \\
\text { of } \\
\text { fins }\end{array}$ & $\mathbf{N u}$ & $\begin{array}{c}\boldsymbol{h} \\
(\mathbf{W} / \mathbf{m} 2 \\
\mathbf{K})\end{array}$ & $\begin{array}{c}\text { Wetted } \\
\text { surface } \\
\text { area } \\
(\mathbf{m m 2})\end{array}$ & $\begin{array}{c}\text { Characteri } \\
\text { stic length } \\
(\mathbf{m m})\end{array}$ \\
\hline $2-1-2$ & 5 & 0.85 & 15.63 & 469.66 & 1.95 \\
\hline $3-2-3$ & 8 & 0.67 & 13.08 & 482.69 & 1.90 \\
\hline $4-3-4$ & 11 & 0.51 & 10.77 & 493.45 & 1.85 \\
\hline $5-4-5$ & 14 & 0.42 & 9.30 & 502.73 & 1.82 \\
\hline
\end{tabular}

\section{$4 \quad$ Conclusions}

The present work reported thermal analysis of triangular shaped fins for different parametric conditions. The problem is analyzed numerically using an FEM solver. The numerical model, boundary conditions and the solver is validated for cylindrical fins of staggered arrangement using the empirical relationship proposed by Khan et al [30]. The comparison shows an acceptable agreement. Further, the analysis is done on triangular shaped fins for a fixed value of inlet Reynolds number. A comparison of the inline and staggered arrangement is shown and is observed that the staggered arrangement gives a better heat transfer rate from a solid surface to the fluid. Fins with staggered arrangement and placed parallel to the incoming flow is found to yield an enhanced value of $\mathrm{Nu}$ and $h$. It has also been observed, as the number of fins increases the heat transfer rate deteriorate due to reduced value of characteristic length of the fins geometries.

\section{References}

[1] M. Axtmann, R. Poser, J. V. Wolferdorf, and B. Bouchez, "End wall heat transfer and pressure loss measurements in staggered arrays of adiabatic pin fins", Applied Thermal Engineering, Vol.103, pp. 1048-1056, June 2016.

[2] O. N. Şara, "Performance analysis of rectangular ducts with staggered square pin fins", Energy Conversion and Management, Vol. 44, Aug., pp. 1787-1803, July 2003.

[3] T. M. Jeng, and S. C. Tzeng, "Pressure drop and heat transfer of square pin-fin arrays in inline and staggered arrangements", International Journal of Heat and Mass Transfer, Vol. 50, pp. 2364-2375, June 2007.

[4] D. E. Metzger, R. A. Berry, and J. P. Bronson, "Developing heat transfer in rectangular ducts with staggered arrays of short pin fins", Journal of Heat Transfer, Vol. 104(4), pp. 700-706, Oct. 2009.

[5] S. Agrawal, W. Terrence, M. North, D. Bissell, and T. Cui, "Heat transfer augmentation of a channel flow by active agitation and surface mounted cylindrical pin fins", International Journal of Heat and Mass Transfer, Vol. 87, pp. 557-567, April 2015. 
$10^{\mathrm{TH}}$ INTERNATIONAL CONFERENCE ON Sustainable ENERGy AND ENVIRONMENTAL Protection (June 27 $7^{\mathrm{TH}}-30^{\mathrm{TH}}, 2017$, Bled, Slovenia), Mechanical EngineERING S.Yadav \& Krishna M. Pandey: A Parametric Thermal Analysis of Triangular Fins for Improved Heat Transfer in Forced Convection

[6] S. J. Park, D. Jang, S. J. Yook, and K. S. Lee, "Optimization of a staggered pin-fin for a radial heat sink under free convection”, International Journal of Heat and Mass Transfer, Vol. 87, pp. 184-188, April 2015.

[7] C. H. Huang, Y. C. Liu, and H. Ay, "The design of optimum perforation diameters for pin fin array for heat transfer enhancement", International Journal of Heat and Mass Transfer, Vol. 84, pp. 752-765, Feb. 2015.

[8] B. Sahin, and A. Demir, "Performance analysis of a heat exchanger having perforated square fins", Applied Thermal Engineering, Vol. 28, pp. 621-632, April 2007.

[9] A. Abdoli, G. Jimenez, and G. S. Dulikravich, "Thermo-fluid analysis of micro pin-fin array cooling configurations for high heat fluxes with a hot spot", International Journal of Thermal Sciences, Vol. 90, pp. 290-297, Jan. 2015.

[10] Y. Joo, and S. J. Kim, “Comparison of thermal performance between plate-fin and pin-fin heat sinks in natural convection", International Journal of Heat and Mass Transfer, Vol. 83, pp. 345-356, Dec. 2015.

[11] D. A. McNeil, A. H. Raeisi, P. A. Kew, and R. S. Hamed, "An investigation into flow boiling heat transfer and pressure drop in a pin-finned heat sink", International Journal of Multiphase Flow, Vol. 67, pp. 65-84, July 2014.

[12] J. Pandit, M. Thompson, S. V. Ekkad, and S. T. Huxtable, "Effect of pin fin to channel height ratio and pin fin geometry on heat transfer performance for flow in rectangular channels", International Journal of Heat and Mass Transfer, Vol. 77, pp. 359-368, June 2014.

[13] N. Sahiti, A. Lemouedda, D. Stojkovic, F. Durst, and E. Franz, "Performance comparison of pin fin in-duct flow arrays with various pin cross-sections", Applied Thermal Engineering, Vol. 26, pp. 1176-1192, Dec. 2005.

[14] N. Sahiti, F. Durst, and P. Geremia, "Selection and optimization of pin cross-sections for electronics cooling", Applied Thermal Engineering, Vol. 27, pp. 111-119, July 2006.

[15] O. N. Sara, S. Yapici, and M. Yilmaz, "Second law analysis of rectangular channels with square pin-fins", International Communication of Heat and Mass Transfer, Vol. 28(5), pp. 617-630, July 2001.

[16] M. R. Shaeri, M. Yaghoubi, and K. Jafarpur, "Thermal enhancement from heat sinks by using perforated fins”, Energy Conversion and Management, Vol. 50, pp. 1264-1270, Feb. 2009.

[17] P. Dutta, "Heat and Mass Transfer", http: // nptel. iitk. ac. in/ courses / Webcourse - contents / IISc- BANG /Heat\%20and \%20 Mass\%20 Transfer /pdf /Module3. pdf.

[18] S. P. Sukhatme, U. N. Gaitonde, "Heat transfer from extended surfaces", http://www.cdeep.iitb.ac.in/nptel/Mechanical/Heat\%20and\%20Mass\%20Transfer/Conducti on/Module\%203/main/3.6.html.

[19] R. S. Gorla, and A. Y. Bakier, "Thermal Analysis of Natural Convection and Radiation in Porous Fins", International Communications in Heat and Mass Transfer, Vol. 38, pp. 638 645, May 2011.

[20] S. F. Tsai, T. W. H. Sheu, and S. M. Lee, "Heat Transfer in a Conjugate Heat Exchanger with a Wavy Fin Surface", International Journal of Heat and Mass Transfer, Vol. 42, pp. 17351745, May 1999.

[21] A. K. Saha, and S. Acharya, S., "Parametric Study of Unsteady Flow and Heat Transfer in a Pin-Fin Heat Exchanger", International Journal of Heat and Mass Transfer, Vol. 46, pp. 3815-3830, Sept. 2003.

[22] R. R. Jassem, "Effect the Form of Perforation on the Heat Transfer in the Perforated Fins", SAVAP. International Journal, Vol. 4 (3), pp. 198-207, May 2013.

[23] S. Yadav, K. Das, and K. M. Pandey, "A Comparative Analysis of Heat Transfer in Extended Surfaces With And Without Holes", 5th International and 41st National Conference on Fluid Mechanics and Fluid Power (FMFP), Dec. 2014. 
$10^{\mathrm{TH}}$ INTERNATIONAL CONFERENCE ON SUSTAINABLE ENERGY AND ENVIRONMENTAL Protection (June $27^{\mathrm{TH}}-30^{\mathrm{TH}}, 2017$, Bled, Slovenia), MeChaniCAl ENGineERING S.Yadav \& Krishna M. Pandey: A Parametric Thermal Analysis of Triangular Fins for Improved Heat Transfer in Forced Convection

[24] S. Gururatana, and X. Li, "Heat Transfer Enhancement of Small Scale Heat Sinks Using Vibrating Pin Fin", American Journal of Applied Science, Vol. 10 (8), pp. 801-809, 2013.

[25] A. Sarma, and A. Ramakrishna, "CFD Analysis of Splayed Pin Fin Heat Sink for Electronic Cooling”, International Journal of Engineering Research and Technology, Vol. 1 (10), Dec. 2012.

[26] S. Agrawal, T. W. Simon, M. North, D. Bissell, and T. Cui, "Heat Transfer Augmentation of a Channel Flow by Active Agitation and Surface Mounted Cylindrical Pin Fins", International Journal of Heat Mass Transfer, Vol. 87, pp. 557-567, Aug. 2015.

[27] R. S. Sukumar, G. Sriharsha, S. B. Arun, D. P. Kumar, and C. S. Naidu, "Modelling and Analysis of Heat Sink with Rectangular Fins Having Through Holes" International Journal of Engineering Research and Applications (IJERA), Vol. 3(2), pp. 1557-1561, 2013.

[28] S. Yadav, K. Das, and K. M. Pandey, "A Comparative Analysis of Heat Transfer in Extended Surfaces", 23rd National and 1st International ISHMT-ASTFE Heat and Mass Transfer Conference, IHMTC2015-480, Dec. 2015.

[29] L. Micheli, K. S. Reddy, and T. K. Mallick, "Experimental Comparison of Micro-Scaled Plate-Fins And Pin-Fins Under Natural Convection", International Communications in Heat and Mass Transfer, Vol. 75, pp. 59-66, July 2016.

[30] W. A. Khan, J. R. Culham, M. M. Yovanovich, "Modelling of cylindrical pin fin heat sinks for electronic packaging", Proceedings of 21st IEEE Semiconductor Thermal Measurement and Management (SEMI-THERM) Symposium, San Jose, California, March 2005. 
$68 \mid 10^{\mathrm{TH}}$ International CONFERENCE on Sustainable ENERgy AND ENVIRONMENTAL Protection (June $27^{\mathrm{TH}}-30^{\mathrm{TH}}, 2017$, Bled, Slovenia), Mechanical EngineERING 
$10^{\mathrm{TH}}$ InTERnational CONFERENCE ON Sustainable ENERgy AND EnVironmental Protection (June $27^{\mathrm{TH}}-30^{\mathrm{TH}}$, 2017, Bled, SLOVENIA), MECHANICAL ENGINEERING

J. Krope, A.Ghani Olabi, D. Goričanec \& S. Božičnik

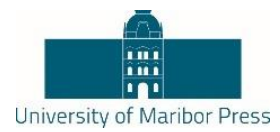

\title{
Modeling and Simulating a Water Distribution Network Using the Epanet Software. Case Study
}

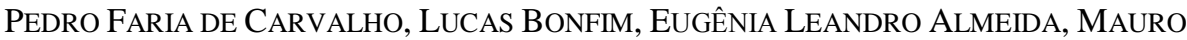

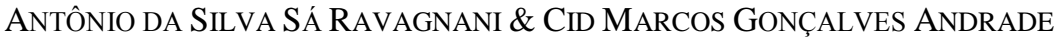

\begin{abstract}
Normally, water distribution projects are made based on the Technical Standards, in the case of Brazil, ABNT NBR 5626, which is based on International Technical Standard BS 6700: 1997. However, these Standards are often conservative. In this way many cold water distribution networks are oversized, causing unnecessary energy and material expenditure. Thus, the objective of this work was by means of a case study (an actual network in operation) and using the free software Epanet to simulate the losses of pressure drops, speed and power expenditure in the actual network (to validate the simulation) and another network (an simulated network) with another pipe diameter. The results showed that the actual network was indeed overestimated, and that even with the simulated changes, the new network continues to obey the Technical Norms, with less expense in the purchase of pipes and plumbing fitting, pumping power savings and an others things.
\end{abstract}

Keywords: • Modeling $\bullet$ Epanet $\bullet$ water distribution networks $\bullet$ simulating - water distribution •

Correspondence AdDress: Pedro Faria de Carvalho, M.Sc, Universidade Estadual de Maringá, Chemical Engineering Department, Av. Colombo, 5790 - Vila Esperança, Maringá - Paraná, Brasil, email: pedrofariacarvalho@gmail.com. Lucas Bonfim, Ph.D, Universidade Estadual de Maringá, Chemical Engineering Department, Av. Colombo, 5790 - Vila Esperança, Maringá Paraná, Brasil, email: pg52814@uem.br. Eugênia Leandro Almeida, M.Sc, Universidade Estadual de Maringá, Chemical Engineering Department, Av. Colombo, 5790 - Vila Esperança, Maringá Paraná, Brasil, email: eugenia-almeida@hotmail.com. Mauro Antônio da Silva Sá Ravagnani, Ph.D, Universidade Estadual de Maringá, Chemical Engineering Department, Av. Colombo, 5790 - Vila Esperança, Maringá - Paraná, Brasil,email: massravagnani@uem.br. Cid Marcos Gonçalves Andrade, Ph.D, Universidade Estadual de Maringá, Chemical Engineering Department, Av. Colombo, 5790 - Vila Esperança, Maringá - Paraná, Brasil, email: cid@deq.uem.br.

https://doi.org/10.18690/978-961-286-057-8.7

ISBN 978-961-286-057-8

(C) 2017 University of Maribor Press

Available at: http://press.um.si. 
$10^{\mathrm{TH}}$ InTERnAtional CONFERENCE ON Sustainable ENERgy AND ENVIRONMENTAL Protection (June $27^{\mathrm{TH}}-30^{\mathrm{TH}}, 2017$, Bled, Slovenia), Mechanical ENGineERING P. Faria de Carvalho, L. Bonfim, E. Leandro Almeida, M. Antônio da Silva Sá Ravagnani \& C. Marcos Gonçalves Andrade: Modeling and Simulating a Water Distribution Network Using the Epanet Software. Case Study

Distribution and water projects usually take Technical Standards into account. In Brazil the Technical Standard is ABNT 5626 [1], which is based on the International Technical Standard BS 6700: 1997 [2]. These Standards are usually conservative and lead to oversized projects with high costs on equipment and energy costs.

Energy recovery in pressurized water distribution networks (both urban and irrigation) has great significance. With regard to urban supply systems, energy consumption in water supply networks accounts for 7\% of world energy consumption [3]. In addition to energy consumption, the energy analysis of these networks shows that the increase in pressure is correlated with the increase in leakage [4]. This problem justifies the installation of pressure relief valves in many water distribution networks. These valves reduce the pressure and thus the leakage volume. This directly proportional correlation between the pressures led to the pioneering study of alternatives to leverage the energy dissipated by in water supply systems [5].

Water collection and supply systems can be classified into: upstream and upstream reservoir systems, other upstream and upstream reservoirs, systems serving both upper and lower zones [6].

EPANET [7] is free software, developed by the US Environmental Protection Agency (EPA), which performs hydraulic and water quality simulations and their behavior within pressurized pipe networks [8]. This simulator is characterized by a robust model with a large amount of users worldwide [9], offering a user interface and without limitation in the number of elements of the network. It uses either metric units or US units and enables the calculation of load losses according to: Darcy-Weisbach, Hazen-Williams and ChezyManning.

In this way, this work aims, through a case study of a real system designed according to Brazilian Technical Norms, to show through simulations, using EPANET software, that another network could replace the current one, with economy in the costs for the purchase of mains pipes, valves, etc. And, that the new network could be safe from the point of view of generating leaks, due to working with lower pressures. We also suggest at the end of the paper that a more rigorous approach to a more realistic future analysis.

\section{$2 \quad$ Methodology}

For the simulation of a water distribution system of the real EPANET we use the water distribution system of the UEM/Goioerê-PR-Brazil Regional Campus. The Campus has a water tank structure with a capacity of approximately 45,000 liters, responsible for supplying all the Campus units, thus using the water collection system of the distribution network with a high upstream reservoir, according to [6]. Figure 1 shows the aerial view of the location of the water distribution system that we want to evaluate. It is observed that 
$10^{\mathrm{TH}}$ INTERNATIONAL CONFERENCE ON SUSTAINABLE ENERGY AND ENVIRONMENTAL Protection (June $27^{\mathrm{TH}}-30^{\mathrm{TH}}, 2017$, Bled, SLOVENIA), MECHANiCAl ENGINEERING

P. Faria de Carvalho, L. Bonfim, E. Leandro Almeida, M. Antônio da Silva Sá Ravagnani \& C. Marcos Gonçalves Andrade: Modeling and Simulating a Water Distribution Network Using the Epanet Software. Case Study

we have a high water reservoir and three places of water consumption. The three blocks are almost at the same level.

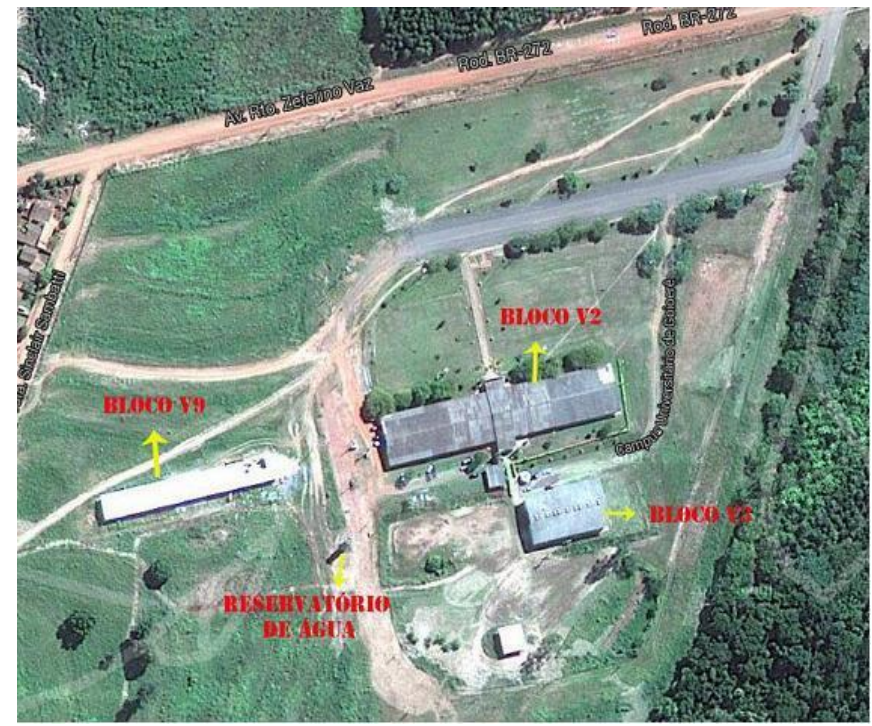

Figure 1: Aerial image of the location of the water distribution system

Next there is the Figure 2, where have the scheme of the pipes and the nodes. We use numbers for the nodes and letters for the pipes.

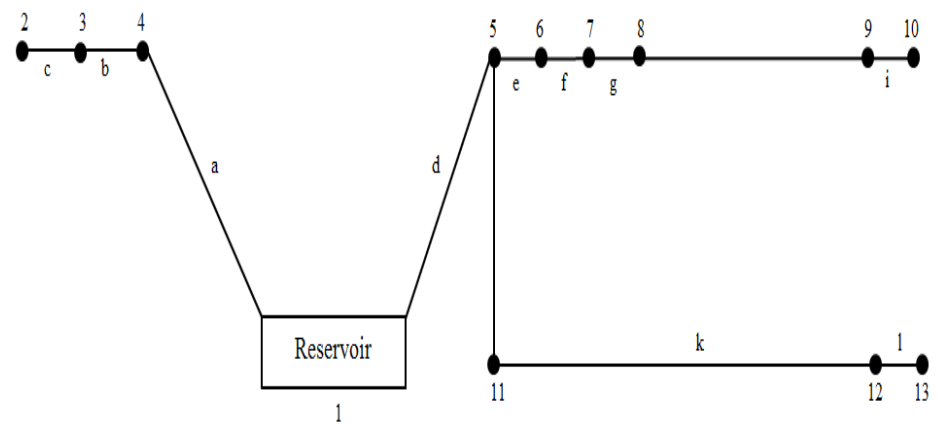

Figure 2: Hydraulic mesh of the cold water system CRG UEM

The current distribution network was dimensioned according to Standards [1], and the same pipe, DN $80 \mathrm{~mm}$, was used in all pipes. 
$10^{\mathrm{TH}}$ INTERNATIONAL CONFERENCE ON Sustainable ENERGY AND ENVIRONMENTAL Protection (June $27^{\mathrm{TH}}-30^{\mathrm{TH}}, 2017$, Bled, Slovenia), Mechanical ENGineERING P. Faria de Carvalho, L. Bonfim, E. Leandro Almeida, M. Antônio da Silva Sá Ravagnani \& C. Marcos Gonçalves Andrade: Modeling and Simulating a Water Distribution Network Using the Epanet Software. Case Study

We will not enter here in the details of what the nodes are and we do not justify the demands of flows, we only use those that we were told by the users of the system. With this, and using the EPANET software, we arrive at Table 1: Pressure values with DN $80 \mathrm{~mm}$.

Table 1: Pressure values with DN $80 \mathrm{~mm}$.

\begin{tabular}{|c|c|c|c|}
\hline Node & $\begin{array}{c}\text { Demand } \\
\text { LPS }\end{array}$ & $\begin{array}{c}\text { Hydraulic } \\
\text { Loading } \\
\text { m }\end{array}$ & $\begin{array}{c}\text { Pressure } \\
\text { mWC }\end{array}$ \\
\hline 2 & 0.25 & 513.49 & 8.69 \\
\hline 3 & 4.00 & 513.49 & 8.69 \\
\hline 4 & 1.75 & 513.55 & 8.75 \\
\hline 5 & 0.00 & 511.21 & 8.51 \\
\hline 6 & 0.90 & 511.06 & 8.26 \\
\hline 7 & 1.00 & 510.93 & 8.13 \\
\hline 8 & 0.00 & 510.65 & 7.85 \\
\hline 9 & 1.24 & 510.37 & 7.57 \\
\hline 10 & 3.01 & 510.36 & 7.56 \\
\hline 11 & 0.00 & 509.98 & 8.98 \\
\hline 12 & 1.24 & 509.77 & 8.77 \\
\hline 13 & 3.01 & 509.73 & 8.73 \\
\hline 1 & -16.40 & 515.80 & 0.00 \\
\hline
\end{tabular}

The EPANET software also lists the data in table 2, as follows:

Table 2: speed values in the sections DN $80 \mathrm{~mm}$

\begin{tabular}{|c|c|c|c|}
\hline Pipe & $\begin{array}{c}\text { Flow rate } \\
\text { LPS }\end{array}$ & $\begin{array}{c}\text { Speed } \\
\mathbf{m} / \mathbf{s}\end{array}$ & $\begin{array}{l}\text { Cargo loss } \\
\mathbf{m} / \mathbf{k m}\end{array}$ \\
\hline $\mathrm{a}$ & 6.0 & 1.35 & 22.17 \\
\hline $\mathrm{b}$ & 4.25 & 0.95 & 11.71 \\
\hline $\mathrm{c}$ & 0.25 & 0.06 & 0.07 \\
\hline $\mathrm{d}$ & 10.40 & 2.32 & 61.40 \\
\hline $\mathrm{e}$ & 10.40 & 2.32 & 61.41 \\
\hline $\mathrm{f}$ & 9.50 & 2.12 & 51.93 \\
\hline $\mathrm{g}$ & 8.50 & 1.89 & 42.26 \\
\hline $\mathrm{h}$ & 4.25 & 0.09 & 11.71 \\
\hline $\mathrm{i}$ & 3.01 & 0.67 & 6.18 \\
\hline $\mathrm{j}$ & 4.25 & 0.95 & 11.70 \\
\hline $\mathrm{k}$ & 3.01 & 0.67 & 13.10 \\
\hline $\mathrm{l}$ & 4.25 & 0.95 & 11.71 \\
\hline
\end{tabular}


$10^{\mathrm{TH}}$ InTERNATIONAL CONFERENCE ON SUSTAINABLE ENERGY AND ENVIRONMENTAL 73 Protection (June $27^{\mathrm{TH}}-30^{\mathrm{TH}}, 2017$, Bled, Slovenia), MeCHANiCAl ENGINEERING P. Faria de Carvalho, L. Bonfim, E. Leandro Almeida, M. Antônio da Silva Sá Ravagnani \& C. Marcos Gonçalves Andrade: Modeling and Simulating a Water Distribution Network Using the Epanet Software. Case Study

The results presented in tables 1 and 2 are for the current network, it is noticed that the speeds and pressures in the nodes meet the specifications of the Brazilian Standards [1].

Next, we simulate a new distribution network, with the same demands, but changing the pipe by a DN $65 \mathrm{~mm}$. In Table 3, we have the same variables as Table 1.

For the actual condition of the network, it is observed that it obeyed the requirements of NBR 5626 and the values obtained with maximum speed corresponded to $2.32 \mathrm{~m} / \mathrm{s}$, lower than the $3.0 \mathrm{~m} / \mathrm{s}$ recommended by NBR 5626.

The pressures recorded for the actual diameter (DN $80 \mathrm{~mm}$, DI $75.6 \mathrm{~mm}$ ) used in the network varied between $7.56 \mathrm{~m}$ and $8.77 \mathrm{~m}$. Note that the values also were well below the limit of $40 \mathrm{mWA}$ imposed by the standard.

Table 3: Pressure values with DN $65 \mathrm{~mm}$

\begin{tabular}{|c|c|c|c|}
\hline Node & $\begin{array}{c}\text { Demand } \\
\text { LPS }\end{array}$ & $\begin{array}{c}\text { Hydraulic } \\
\text { Loading m }\end{array}$ & $\begin{array}{c}\text { Pressure } \\
\text { mWC }\end{array}$ \\
\hline 2 & 0.25 & 511.52 & 6.72 \\
\hline 3 & 4.00 & 511.52 & 6.72 \\
\hline 4 & 1.75 & 511.63 & 6.83 \\
\hline 5 & 0.00 & 507.29 & 4.29 \\
\hline 6 & 0.90 & 507.01 & 4.21 \\
\hline 7 & 1.00 & 506.76 & 3.96 \\
\hline 8 & 0.00 & 506.26 & 3.46 \\
\hline 9 & 1.24 & 505.73 & 2.93 \\
\hline 10 & 3.01 & 505.70 & 2.90 \\
\hline 11 & 0.00 & 505.01 & 4.01 \\
\hline 12 & 1.24 & 504.61 & 3.61 \\
\hline 13 & 3.01 & 504.55 & 3.55 \\
\hline 1 & -16.40 & 515.80 & 0.00 \\
\hline
\end{tabular}

Table 4 presents the same variables as Table 2, as we said, now for another pipe. 
$10^{\mathrm{TH}}$ INTERNATIONAL CONFERENCE ON Sustainable ENERGY AND ENVIRONMENTAL Protection (June $27^{\mathrm{TH}}-30^{\mathrm{TH}}, 2017$, Bled, Slovenia), Mechanical ENGineERING P. Faria de Carvalho, L. Bonfim, E. Leandro Almeida, M. Antônio da Silva Sá Ravagnani \& C. Marcos Gonçalves Andrade: Modeling and Simulating a Water Distribution Network Using the Epanet Software. Case Study

Table 4: Speed values in the sections DN 65mm

\begin{tabular}{|c|c|c|c|}
\hline Pipe & $\begin{array}{c}\text { Flow } \\
\text { rate } \\
\text { LPS }\end{array}$ & $\begin{array}{c}\text { Speed } \\
\mathbf{m} / \mathbf{s}\end{array}$ & $\begin{array}{c}\text { Cargo } \\
\text { loss } \\
\mathbf{m} / \mathbf{k m}\end{array}$ \\
\hline $\mathrm{a}$ & 6.0 & 1.72 & 41.11 \\
\hline $\mathrm{b}$ & 4.25 & 1.22 & 21.70 \\
\hline $\mathrm{c}$ & 0.25 & 0.07 & 0.12 \\
\hline $\mathrm{d}$ & 10.40 & 2.99 & 113.84 \\
\hline $\mathrm{e}$ & 10.40 & 2.99 & 113.85 \\
\hline $\mathrm{f}$ & 9.50 & 2.73 & 96.26 \\
\hline $\mathrm{g}$ & 8.50 & 2.44 & 78.35 \\
\hline $\mathrm{h}$ & 4.25 & 1.22 & 21.70 \\
\hline $\mathrm{i}$ & 3.01 & 0.86 & 11.46 \\
\hline $\mathrm{j}$ & 4.25 & 1.22 & 21.70 \\
\hline $\mathrm{k}$ & 3.01 & 0.86 & 24.27 \\
\hline $\mathrm{l}$ & 4.25 & 1.22 & 21.70 \\
\hline
\end{tabular}

For the condition where it replaces the actual diameter with one immediately below the current network, it is noted that the requirements of NBR 5626 were met and the values obtained with maximum speed corresponded to $2.99 \mathrm{~m} / \mathrm{s}$, inferior to $3.0 \mathrm{~m} / \mathrm{s}$ recommended by NBR 5626. The pressures recorded for the diameter (DN $6580 \mathrm{~mm}$, DI $66.6 \mathrm{~mm}$ ) used in the network varied between 2.9 and $6.83 \mathrm{~m}$. Note that the values also were well below the limit of $40 \mathrm{mWC}$ imposed by the standard.

\section{$3 \quad$ Methodology Results and Discussions}

Table 5, below shows the speeds found in each of the systems, for DN $80 \mathrm{~mm}$ and DN 65 $\mathrm{mm}$. 
$10^{\mathrm{TH}}$ InTERNATIONAL CONFERENCE ON SUSTAINABLE ENERGY AND ENVIRONMENTAL Protection (June $27^{\mathrm{TH}}-30^{\mathrm{TH}}, 2017$, Bled, Slovenia), Mechanical ENGineERING

P. Faria de Carvalho, L. Bonfim, E. Leandro Almeida, M. Antônio da Silva Sá Ravagnani \& C. Marcos Gonçalves Andrade: Modeling and Simulating a Water

Distribution Network Using the Epanet Software. Case Study

Table 5: Speed in the pipes

\begin{tabular}{|c|c|c|}
\hline \multirow{2}{*}{ Pipe } & \multicolumn{2}{|c|}{ Speed (m/s) } \\
\cline { 2 - 3 } & DN 80 mm & DN 65 $\mathbf{~ m m}$ \\
\hline $\mathrm{a}$ & 1.35 & 1.72 \\
\hline $\mathrm{b}$ & 0.95 & 1.22 \\
\hline $\mathrm{c}$ & 0.06 & 0.07 \\
\hline $\mathrm{d}$ & 2.32 & 2.99 \\
\hline $\mathrm{e}$ & 2.32 & 2.99 \\
\hline $\mathrm{f}$ & 2.12 & 2.73 \\
\hline $\mathrm{g}$ & 1.89 & 2.44 \\
\hline $\mathrm{h}$ & 0.09 & 1.22 \\
\hline $\mathrm{i}$ & 0.67 & 0.86 \\
\hline $\mathrm{j}$ & 0.95 & 1.22 \\
\hline $\mathrm{k}$ & 0.67 & 0.86 \\
\hline 1 & 0.95 & 1.22 \\
\hline
\end{tabular}

In Table 6, we have the node pressures for the two systems considered.

Table 6: Pressure in the nodes

\begin{tabular}{|c|c|c|}
\hline \multirow{2}{*}{ Node } & \multicolumn{2}{|c|}{ Pressure (mWC) } \\
\cline { 2 - 3 } & DN 80mm & DN 65mm \\
\hline a & 8.69 & 6.72 \\
\hline b & 8.69 & 6.72 \\
\hline c & 8.75 & 6.83 \\
\hline d & 8.51 & 4.29 \\
\hline e & 8.26 & 4.21 \\
\hline f & 8.13 & 3.96 \\
\hline g & 7.85 & 3.46 \\
\hline h & 7.57 & 2.93 \\
\hline i & 7.56 & 2.90 \\
\hline j & 8.98 & 4.01 \\
\hline k & 8.77 & 3.61 \\
\hline l & 8.73 & 3.55 \\
\hline
\end{tabular}

Table 5 and 6 showed that the current campus network presented a maximum flow velocity of $2.32 \mathrm{~m} / \mathrm{s}$ and pressures ranging from $7.56 \mathrm{~m}$ to $8.77 \mathrm{~m}$, when Diameter currently installed in the mesh by the immediately lower commercial diameter obtained a maximum 
$10^{\mathrm{TH}}$ International Conference on Sustainable Energy and Environmental Protection (June $27^{\mathrm{TH}}-30^{\mathrm{TH}}, 2017$, Bled, Slovenia), Mechanical ENGineERING P. Faria de Carvalho, L. Bonfim, E. Leandro Almeida, M. Antônio da Silva Sá Ravagnani \& C. Marcos Gonçalves Andrade: Modeling and Simulating a Water Distribution Network Using the Epanet Software. Case Study

flow velocity of $2.99 \mathrm{~m} / \mathrm{s}$ and pressures ranging from $2.9 \mathrm{~m}$ to $6.83 \mathrm{~m}$, the alternative would make the network more economical in its construction and would meet the current demand, but leaves the flow velocity of $2.99 \mathrm{~m} / \mathrm{s}$ in the maximum limit imposed by NBR 5464, that value of $3.0 \mathrm{~m} / \mathrm{s}$.

\section{$4 \quad$ Conclusions}

Both the current network and the simulated network are within the Brazilian standards NBR 5464. The construction of the current network was more expensive than it would be if we used the simulated pipe. The current network pressure is higher than the simulated network, which can lead to leaks. Since in the water distribution system we have a high reservoir, which if filled can have a high pressure.

More rigorous work could be done by simulating the pipe change for each stretch, which would probably lead to even better results.

\section{Acknowledgements}

The authors would like to thank Coordenação de Aperfeiçoamento de Pessoal de Nivel Superior (CAPES) for the financial support.

\section{References}

[1] ABNT-Associação Brasileira de Normas Técnicas- NBR 5626, 1998.

[2] International Technical Standard. Specification for Design, installation, testing and maintenance of services: supplying water for domestic use within buildings and their curtilages. BS 6700: 1997.

[3] B. Coelho et al., "A. Efficiency achievement in water supply systems-A review", Renew. Sustain. Energy Rev, Vol. 30, pp. 59-84, 2014.

[4] J. Almandoz, E. Cabrera, F. Arregui, R. Cobacho, "Leakage Assessment through Water Distribution Network Simulation", Journal Water Resour. Plan. Manag., Vol. 131, pp. 458466, 2005.

[5] H. Ramos, A. Borga, "Pumps as turbines: An unconventional solution to energy production", Urban Water, Vol.1, pp. 261-263, 1999.

[6] M.T. Tsutiya, Abastecimento de água. São Paulo: EDUSP, 2006.

[7] L.A.Rossman "EPANET2-user's manual. Cincinnati: Nationa 1Risk Managment Research Laboratory, Office of Research and Development, U. S. Environmental Protection Agency, 2000.

[8] EPANET. Drinking Water Research. Available from: 〈http://www.epa.gov/nrmrl/wswrd/dw/epanet.html〉 Accessed: 15/05/2017

[9] F. Vieira and H.N., "Optimization of operational planning for wind/hydro hybrid water supply systems",RenewableEnergy, Vol. 34, pp. 928-36, 2009. 
$10^{\mathrm{TH}}$ INTERNATIONAL CONFERENCE ON Sustainable ENERgy AND EnVironmental Protection (June $27^{\mathrm{TH}}-30^{\mathrm{TH}}, 2017$, BLed, SLOVENIA), MeChaniCAL ENGINEERING

J. Krope, A.Ghani Olabi, D. Goričanec \& S. Božičnik

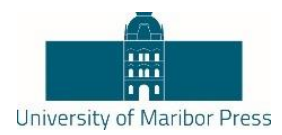

\title{
Hydrodynamic Vibratory Filtration as a Method Removing of Mechanical Impurities in Regeneration Systems of Highly Viscous Working Fluids
}

\author{
VLADIMIR DEVISILOV, ElENA SHARAI \& ANATOLY ALEKSANDROV
}

\begin{abstract}
The perspective of hydrodynamic filters application based on modern overview of state in the field of hydrodynamic filtration was shown. The classification of well-known hydrodynamic filters constructive schemas by three types: the presence of slime fluid, the type of the body and the filtering baffle, the method of additional force field formation, was given. Advantages and disadvantages of every type of hydrodynamic filter were marked. Main approaches to hydrodynamic filters descriptions based on deterministic approach was considered. Special attention to hydrodynamic filters with additional flow twisting cylinder-in-cylinder and cylinder-in-cone was paid. Research direction perspective of further investigation of hydrodynamic filtration was suggested.
\end{abstract}

Keywords: • hydrodynamic filtration • rotary filters • permeable cylinder • separation • Taylor-Couette flow •

CoRRESPONDENCE AdDRess: Vladimir Devisilov, Ph.D., Associate professor, Bauman Moscow State Technical University, Faculty of Power Engineering, ul. Baumanskaya 2-ya, 5/1, Moscow, 105005, Russia, e-mail: devisil@mail.ru. Elena Sharai, Senior Lecturer, Bauman Moscow State Technical University, Faculty of Power Engineering, ul. Baumanskaya 2-ya, 5/1, Moscow, 105005, Russia, e-mail: e9.sharay@yandex.ru. Anatoly Aleksandrov, Rector of Bauman Moscow State Technical University, Faculty of Power Engineering, ul. Baumanskaya 2-ya, 5/1, Moscow, 105005, Russia, e-mail: rector@bmstu.ru. 
$10^{\mathrm{TH}}$ International Conference on Sustainable EnERgy and Environmental Protection (June $27^{\mathrm{TH}}-30^{\mathrm{TH}}, 2017$, Bled, Slovenia), Mechanical ENGineERING

V. Devisilov, E. Sharai \& A. Aleksandrov: Hydrodynamic Vibratory Filtration as a Method Removing of Mechanical Impurities in Regeneration Systems of Highly Viscous Working Fluids

\section{$1 \quad$ Introduction}

There is very vexed problem of cleaning high-viscous fluids from mechanical contaminations in chemical, petrochemical, textile and food industries. High viscosity of fluid and clogging of pores leads to the need of creating high pressure drop on the filtering baffle. It is expediently to use combined action devices such as hydrodynamic filters providing highly efficient separation processes to solve the problem. Hydrodynamics filtration differs from traditional filtration by velocity component of speed $v_{t}$ tangential to filtration surface (Fig. 1a, 1b). The hydrodynamic effect consists in the continuous removal of the accumulated sediment layer and in the increasing of purification fineness due to the fact that particles with a size smaller than the dimensions of the cells themselves do not pass through the cells of the filter material. The realization of the latter effect requires a high tangential velocity $v_{t}$ of the flow with respect to the filtration rate $v_{0}$. Within reasonable limits of the ratio of these velocities, the hydrodynamic effect appears for large particles of contamination larger than $300 \mu \mathrm{m}$. To reduce the size of particles that can be removed from the filtering baffle, a combination of hydrodynamic filtering with additional force is used (Fig. 1c, 1d). In this case, additional forces appear, usually centrifugal and vibratory, which exert an additional influence on the particle of contamination near the filtering baffle and do not allow it to adhere to it on the surface.

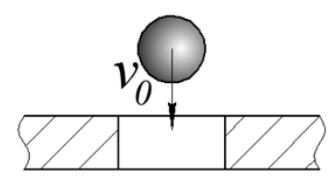

a

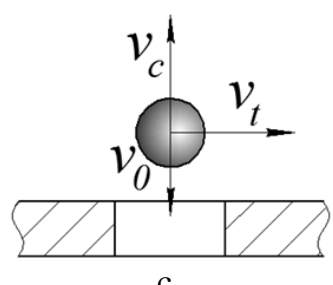

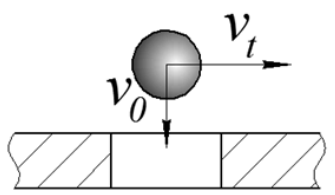

$\mathrm{b}$

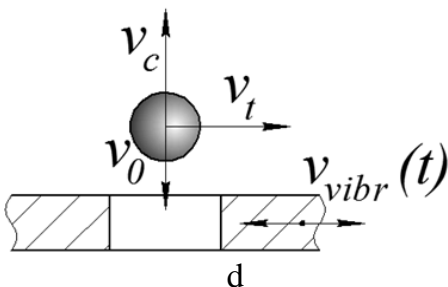

d

Figure 1. Filtration schemas:

$\mathrm{a}$ - traditional; $\mathrm{b}$ - hydrodynamic;

$\mathrm{c}, \mathrm{d}$ - hydrodynamic with force action

The field of application of hydrodynamic filters is wide enough. They can be used in the chemical, petrochemical, mining, metallurgical industries, in the municipal services. The advantage of these devices is that, with guaranteed compliance with the purity required in the process, which is determined by the size of the cell of the filter material, they have a self-cleaning ability, which increases the time to regeneration and the filter life. 
V. Devisilov, E. Sharai \& A. Aleksandrov: Hydrodynamic Vibratory Filtration as a Method Removing of Mechanical Impurities in Regeneration Systems of Highly Viscous Working Fluids

In this paper, we consider the current schemes of hydrodynamic filters and the main approaches to describing the processes occurring in them.

At the present time, several types of hydrodynamic filters are known, differing in the organization of the output streams, the shape of the working area channel, and the method of swirling the flow, which provides the creation of an additional force field. Conditionally they can be divided into the following groups [1].

\subsection{Presence of slime fluid}

The first class of hydrodynamic filters is characterized by the presence or absence of slime fluid and includes two groups of filters - full-flow and bypass-flow. In the full-flow filters (Fig. 2a), all fluid supplied for purification passes through the filtering wall. The advantage of this mode of operation is obvious - this is the absence of slime fluid. However, the selfcleaning ability of such filters is lower than that of incomplete flow filters (Fig. 2b). They are used wherever a complete collection of impurities is required, with a low viscosity of the medium to be cleaned with low obliteration properties or with a slight difference between the densities of the solid and fluid phases.

In the case of bypass-flow hydrodynamic filters, part of the filtered fluid (usually 10-15\%) is bypassed along the filtering wall to flush the accumulated sediment from its surface, and then is dumped together with contaminants into the filter fluid container or disposed as a waste.

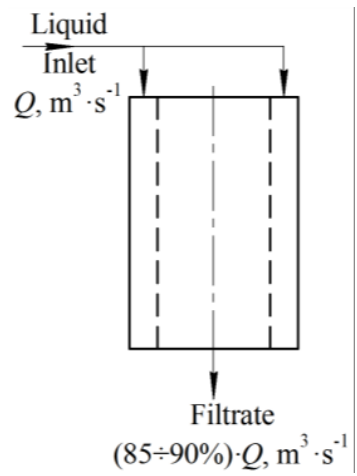

a

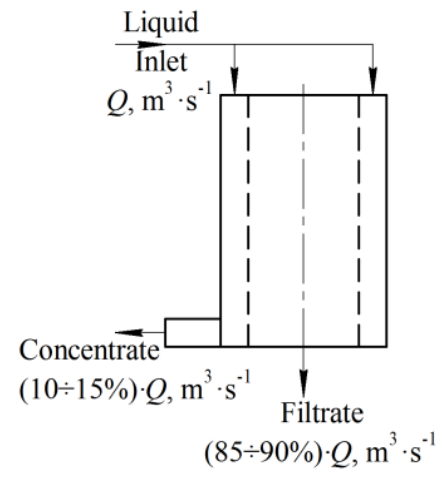

b

Figure 2. Hydrodynamic filters schemas:

$a$ - full-flow, $b$ - incomplete flow 
$10^{\mathrm{TH}}$ InTERNATIONAL CONFERENCE ON SuSTAINABLE ENERGy AND ENVIRONMENTAL Protection (June $27^{\mathrm{TH}}-30^{\mathrm{TH}}, 2017$, Bled, Slovenia), Mechanical ENGineERING

V. Devisilov, E. Sharai \& A. Aleksandrov: Hydrodynamic Vibratory Filtration as a Method Removing of Mechanical Impurities in Regeneration Systems of Highly Viscous Working Fluids

\subsection{Type of body form and filtering wall}

There is a wide variety of hydrodynamic filters in the form of the body and the filtering wall, which determines the configuration of the working channel, in which the separation of particles by force fields occurs. The most common configuration is the cylinder-incylinder (Fig. 2) [2], which is explained by the ease of manufacturing. In such filters, there is an irregular load on the filter material due to the fact that as the flow of the fluid to be cleaned flows along the working channel, the fluid consumption decreases, and also the longitudinal velocity and, as a consequence, the hydrodynamic flushing effect decrease. The mentioned disadvantages lack the hydrodynamic filters of the cylinder-in-cone type (Fig. 3a) [3], [4], [5] and the cone-in-cylinder [6] due to the changing cross-sectional area of the channel, but they require high manufacturing costs.

The least spread has devices such as disk and ball-in-ball due to their specific forms. In the disk [7] hydrodynamic filter, the working channel is flat, formed by a filter partition and the wall of the body, made in the form of horizontal disks. Passing through the channel, the main part of the stream is filtered through a disk filtering baffle, and the remaining part with the contamination concentrate is removed through the hole in the centre of the baffle. Devices of such design are characterized by a low proportion of the bypass fluid (5-7\%) with the simplicity of the design, but they have a significant drawback, which consists in the irregularity of the velocity along the length of the channel due to the reduction in the flow rate of the fluid to be cleaned from the periphery to the centre. The problem is solved by performing one of the channel surfaces in the form of a cone, however then the design ceases to be simple.

The most complex in the design are ball-in-ball devices, which consist of a spherical shell with a spherical filtering baffle inside. At the same time, they have the largest filtering area with minimal overall dimensions, which is their advantage over all other types of hydrodynamic filters of this classification group.

\subsection{The method of force field creation}

The third classification group includes hydrodynamic filters containing in their design elements creating an additional flow twist that allows reducing the load on the filter material by separating part of the impurities by a centrifugal mechanism. There are five principal types of hydrodynamic filters: with rotating filtering baffle; with rotating and vibrating filtering baffle; with rotating filtering baffle and protective shell; with large curvature of the surface filter element; with special twist devices.

The greatest effect on the flow swirling can be obtained by devices with a rotating filtering baffle [8] (Fig. 3, 4), because they have the ability to adjust the speed of rotation depending on the properties of the medium to be cleaned and, as a result, to obtain the greatest force effect on the cleaned flow with the minimum size of the filter. The combination of the rotation of the filter baffle with vibration along the axis of rotation [3], [9], [10] (Fig. 3) 
V. Devisilov, E. Sharai \& A. Aleksandrov: Hydrodynamic Vibratory Filtration as a Method Removing of Mechanical Impurities in Regeneration Systems of Highly Viscous

increases the self-cleaning ability of the filter by destroying the accumulated sediment layer and simultaneously removing it from the surface of the filter baffle by centrifugal and hydrodynamic forces. However, the flow in the channel formed by the body and the filtering baffle is close in structure to Couette-Taylor flow, which, as is known, can be unstable [11].

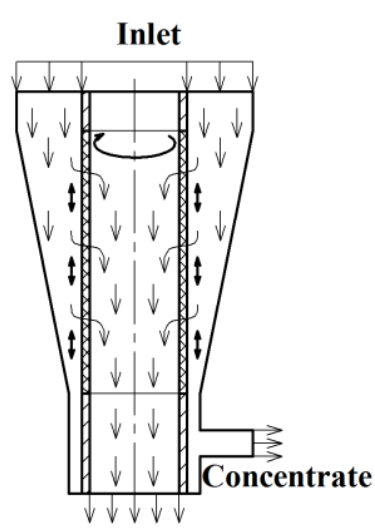

Filtrate

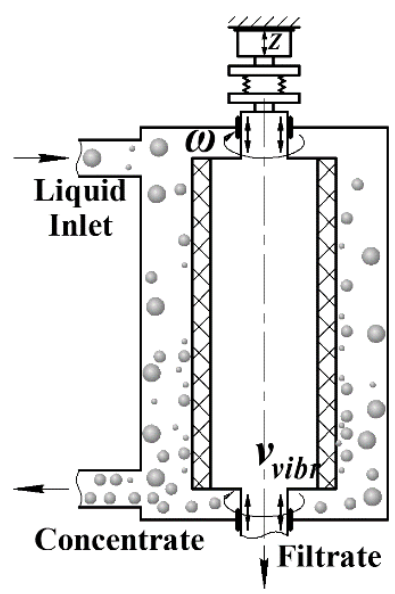

b

Figure 3. Hydrodynamic vibration filters schemas: a - cylinder-in-cone, $\mathrm{b}$ - cylinder-in-cylinder

With the appearance of macro-vortex structures, the separation of particles worsens due to the irregular distribution of radial and longitudinal velocities along the length of the channel, part of the filtering wall can be excluded from work due to the circulation of secondary currents. In addition, the presence of vortex structures increases the hydraulic resistance in the filter. Therefore, for hydrodynamic filters with a rotating filter baffle, the question is to choose the optimal operating modes, in which the flow in the working channel is vortex-free and stable. It should be noted that in some literature hydrodynamic filters with a rotating filter baffle, in which the separation of solid particles is carried out by a centrifugal mechanism, have been called rotational filters [2]. 
$10^{\mathrm{TH}}$ InTERnATIONAL CONFERENCE ON Sustainable EnERgy and ENVIRONMENTAL Protection (June 27 $7^{\mathrm{TH}}-30^{\mathrm{TH}}, 2017$, Bled, Slovenia), Mechanical EngineERING

V. Devisilov, E. Sharai \& A. Aleksandrov: Hydrodynamic Vibratory Filtration as a Method Removing of Mechanical Impurities in Regeneration Systems of Highly Viscous Working Fluids

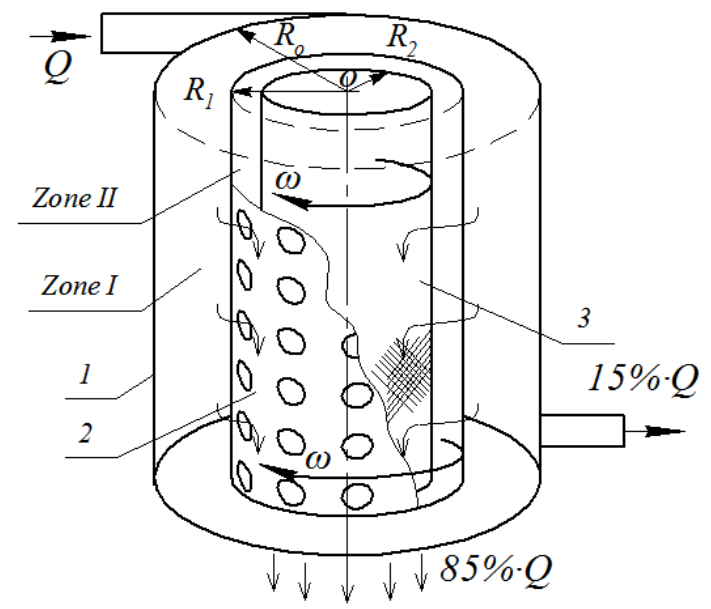

Figure 4. Flow schema in hydrodynamic filter: 1 - filter body; 2 - perforated shell, 3 - filtering baffle, I - tangential fluid input zone, II - protective zone [12]

In [12], structures with a perforated protective shell located between the body and the filtering baffle or with two protective perforated shells are provided, between which there is a rotating filtering wall. In this case, the perforated protective shell can be fixed or rotating at the same speed as the filtering baffle [12]. In the first case, the effect of using a protective perforated shell is to reduce energy consumption for cleaning by reducing filter pressure losses. The presence of a rotating perforated shell allows separation of not only coarse but fine particles of contaminants too due to the fact that in the annular gap between the filter plate and the perforated protective shell the fluid rotates as a solid with a constant angular velocity, which creates an obstacle for penetration to the filtration surface of fine contamination particles [12]. Thus, the rotating perforated shell allows to increase the service life of the hydrodynamic filter by a self-cleaning of filtering baffle and to reduce the size of the particles separated by centrifugal forces than at similar rotational speeds of the filter plate, but in the absence of a protective perforated shell. However, this design, complicated by the presence of additional moving elements, does not solve the problem of vortex formation in the working ring channel and requires selection of the operating parameters ensuring a steady flow.

The principle of creating an additional force field in the next group of hydrodynamic filters is based on the use of stationary devices that allow the stream to be cleaned to receive an initial twist at the entrance of the device. Such devices are swirlers in the form of ribbon spiral guides installed in the inlet zone of the filter or an inlet branch installed tangentially with respect to the filter body (Fig. 5) [3], [4], [12]. Such design allows the tangential velocity component to be communicated to the stream being cleaned, which makes it possible to discard solid particles of a certain size to the periphery of the shell, preventing them from settling on the filtering baffle. The size of such particles depends on the intensity of the swirling flow, which is determined by the flow rate or the average velocity at the 
$10^{\mathrm{TH}}$ INTERNATIONAL CONFERENCE ON SUSTAINABLE ENERGY AND ENVIRONMENTAL Protection (June $27^{\mathrm{TH}}-30^{\mathrm{TH}}, 2017$, Bled, SLOvenia), MeCHANiCAl ENGINEERING

V. Devisilov, E. Sharai \& A. Aleksandrov: Hydrodynamic Vibratory Filtration as a Method Removing of Mechanical Impurities in Regeneration Systems of Highly Viscous

Working Fluids

entrance of device. In order to ensure that a particle of contamination does not reach the filtering wall, it is necessary to create a high tangential velocity in the inlet zone of the filter commensurate with the input velocities in the hydrocyclones, which deprives the hydrodynamic filtering of the energy saving advantage.

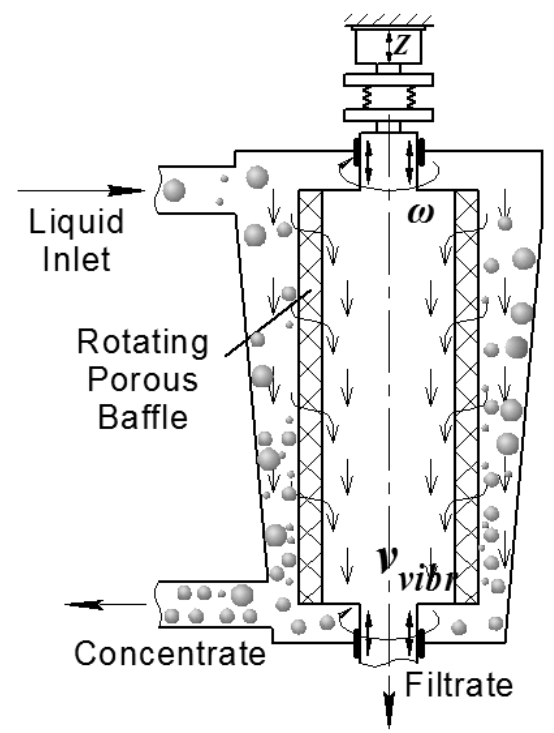

Figure 5. Hydrodynamic vibratory filter

In the case of using a special stationary twist device in the design of a hydrodynamic filter with a rotating filtering baffle [3], [4], the particle separation zone by the centrifugal mechanism is located along the entire length of the annular channel and there is no need to create high speeds at the entrance to the apparatus.

In [13] the hydrodynamic filter designs are described, in which the flow being cleaned moves not along the generatrix of the cylindrical filtering surface, as in [12], but across. In this case, in addition to the hydrodynamic effect, inertial forces also appear that discard particles from the filtering surface. However, to achieve this effect, a large curvature of the surface is required, which leads to large overall dimensions of the device in one direction, and a high velocity of fluid flow through the channel relative to the filtration rate, which causes fluid loss with sludge drainage to $30 \%$. To reduce the overall dimensions, designs of a spherical shape have been proposed, but in this case the cost of the filter is associated with the manufacture of a casing and a filtering surface of a complex shape.

Thus, from the view point of cleaning efficiency, production and operation costs, the most promising are the hydrodynamic filters with a cylindrical filter baffle, cleaned flow in which moves along the generatrix of the cylinder, and the design uses an additional twist of the flow. By the authors wad developed the design of a hydrodynamic vibration filter 
$10^{\mathrm{TH}}$ International Conference on Sustainable EnERgy and Environmental Protection (June $27^{\mathrm{TH}}-30^{\mathrm{TH}}, 2017$, Bled, Slovenia), Mechanical ENGineERING

V. Devisilov, E. Sharai \& A. Aleksandrov: Hydrodynamic Vibratory Filtration as a Method Removing of Mechanical Impurities in Regeneration Systems of Highly Viscous Working Fluids

[4] (Fig. 5). The device consists of a conical body in which a cylindrical filtering baffle rotating around its axis is disposed. The fluid is supplied through a tangentially disposed inlet. Due to this, the stream receives an additional twist. Under the influence of pressure drop, the fluid is filtered through the baffle. A part of the fluid (15\% of the input flow) passes along the baffle and exits through the lower tangential pipe. To intensify selfcleaning, the filter baffle can vibrate along the axis of rotation, which destroys the accumulated layer of sediment. Rotation and additional swirling of the flow in the annular channel create centrifugal forces that promote the movement of contaminant particles from the baffle to the body. Then the particles enter the concentrate together with the bypass flow (15\% of the input flow). This flow arrangement reduces the load on the filter material. Let's consider further analytical, numerical and experimental researches, concerning exactly this performance of hydrodynamic filters.

\section{Approaches to the Hydrodynamic Filtering Description}

The currently available approaches to the description of hydrodynamic filtering through a cylindrical filtering baffle affect two types of devices: cylinder-in-cylinder and cylinderin-cone, with a greater number of studies devoted to the first kind due to the less complex geometric shape of the channel under study. The main task of most of the known works is the description of hydraulic and separation processes in the annular channel formed by a cylindrical filtering baffle and the filter body in order to determine the optimum operating parameters of the filter operation, which guarantee the stable flow.

The most common is the deterministic approach to the description of the hydrodynamic filtering process, and only a small part of the work [12] takes into account the presence of random processes by a probabilistic-statistical approach to description. In this article, we limit the discussion of known works using a deterministic approach for swirling flow in an annular tapered channel with rotating internal filtering baffle.

The determination of the optimum operating parameters in a hydrodynamic filter with a rotating filtering baffle and additional twisting of a cylinder-in-cone flow is reduced to finding the ratio between the speed of filtering baffle rotation and the average flow velocity at the filter inlet providing additional twist of the flow. A limited number of works are devoted to the research in this field [14], [15], [16],[17]. In a certain approximation, one can find an analogue between the processes taking place in the gap between the rotating filter baffle and the conical body, with the currents being organized in the conical hydrocyclone, and with a separate examination of the narrowing annular channel with an inner permeable surface [18]. Known in this issue studies have not yet been applied to the description of hydrodynamic filters such as a cylinder-in-cone. It should be noted that it is impossible to directly use the existing descriptions, since they do not take into account all the processes of hydrodynamic filtering. Thus, there are no papers describing the flow in a tapered annular channel with a rotating permeable inner wall. When calculating cylinderin-cone type filters, numerical simulation methods and full-scale experiment are used [19], [20]. By solving the Navier-Stokes equations, the distributions of the circumferential, radial 
$10^{\mathrm{TH}}$ INTERNATIONAL CONFERENCE ON SUSTAINABLE ENERGY AND ENVIRONMENTAL Protection (June $27^{\mathrm{TH}}-30^{\mathrm{TH}}, 2017$, Bled, SLOvenia), MeCHANiCAl ENGINEERING

V. Devisilov, E. Sharai \& A. Aleksandrov: Hydrodynamic Vibratory Filtration as a Method Removing of Mechanical Impurities in Regeneration Systems of Highly Viscous

Working Fluids

and axial velocities in the working part of the filter are obtained, and streamlines determining the flow structure for Newtonian and pseudoplastic media are found [19], [20].

\section{$4 \quad$ Conclusion}

Hydrodynamic filtration as a method of cleaning fluids from solids deserves attention, as it has several advantages over traditional filtration, especially when cleaning highly viscous media. The effectiveness of using hydrodynamic filters in technological systems is shown. To date, there is no complete methodology for calculating them due to the multifactority of the processes occurring in the working area of the filter. When finding the optimal operating parameters for hydrodynamic filters operation, the most commonly used is numerical simulation based on solving the Navier-Stokes equations system, which requires appropriate skills. For the wide distribution of hydrodynamic filters in certain industries, it is necessary to create an engineering calculation technique that will reduce the time and effort required for design. The authors developed the design of a hydrodynamic vibration filter. This filter has a high self-cleaning ability and low energy costs in comparison with analogues. The determining parameters of the separation and the optimal operational parameters are determined.

This work was performed under the state order of the Ministry of Education and Science of the Russian Federation No. 10.7766.2017.

\section{References}

[1] V. Devisilov, E. Sharay, "Hydrodynamic Filtration”, Safety in technosphere, vol. 4, no 3, pp. 68-80, 2015.

[2] E. Mochalin, I. Mochalin, "Scale effect in the physical modelling of mechanical purification of liquids rotary filters", The collection of proceedings of DonSTU, vol. 33, pp. 30-38, 2011.

[3] V. Devisilov, E. Sharay and I. Myagkov, "The self-cleaning filter", Patent RU, no. 150505, 2014.

[4] V. Devisilov, E. Sharay and I. Myagkov, "The hydrodynamic filter vibrating", Patent RU, no. 150506, 2014.

[5] V. Cheban, "Specific features of the hydrodynamic filter of the liquid of type «The Cylinder in the Cone»", Eastern-European Journal of Enterprise Technologies, no. 2/12 (56), pp. 4649, 2012.

[6] S. Belov, V. Devisilov and V. Zhdanov, "Method of filtering and vibrating filter for its implementation", A.S., no. 1567246, 1990.

[7] V. Cheban, "Methods of separating liquid into filtrate and concentrate", The Patent Ukraine, no. 54061, 2010.

[8] E. Mochalin, I. Mochalin, "The separation efficiency of suspended impurities rotating filter element", Bulletin Of The NAT. tech. University "KHPI": collection of scientific papers, no. 10, pp. 3-9, 2011.

[9] V. Devisilov, E. Sharay, "Modelling of Work of the Hydrodynamical Filter with Use of the Program Complex", Safety in technosphere, no. 5, pp. 21-30, 2009. 
$10^{\mathrm{TH}}$ InTERnATIONAL CONFERENCE ON Sustainable EnERgy AND ENVIRONMENTAL Protection (June $27^{\mathrm{TH}}-30^{\mathrm{TH}}, 2017$, Bled, Slovenia), Mechanical ENGineERING

V. Devisilov, E. Sharai \& A. Aleksandrov: Hydrodynamic Vibratory Filtration as a Method Removing of Mechanical Impurities in Regeneration Systems of Highly Viscous Working Fluids

[10] V. Devisilov, E. Sharay, "Current stability limits in hydrodynamic filter", Safety in technosphere, no. 4, pp. 26-32, 2013.

[11] D. Joseph, Stability of fluid motions. Moscow: Mir Publ., 1981.

[12] V. Devisilov, V. Lvov, I. Myagkov, E. Sharay, "Analytical Model of Suspensions Separation in Hydrodynamic Filter with Pivoting Perforated Partition”, Safety in technosphere, no. 5, pp. 32-41, 2014.

[13] V. Bondarenko "The cleaner a fluid flow", The Patent Ukraine, no. 46507, 2001.

[14] D. L.Cotrell, A. J. Pearlstein, "Linear stability of spiral and annular Poiseuille flow for small radius ratio", J. Fluid Mech., vol. 547, pp. 1-20, 2006.

[15] D. I. Takeuchi, D. F. Jankowski "A numerical and experimental investigation of the stability of spiral Poiseuille flow”, J. Fluid Mech., vol. 102, pp. 101-126, 1981.

[16] R. Ostilla, R. J. Stevens, S. Grossmann, "Optimal Taylor-Couette flow: direct numerical simulations", J. Fluid Mech., vol. 719, pp. 14-46, 2013.

[17] P. Bunyawanichakul, M. P. Kirkpatrick, J. E. Sargison, G. J. Walker, "Numerical and experimental studies of the flow field in a cyclone dryer", ASME Journal of Fluid Engineer, no. 128 (6), pp. 1240-1250, 2006.

[18] A. Khalatov, "Heat transfer and fluid dynamics in fields of mass forces: review of work performed by the ITTF NAS. Part 1. Twist flow in the channels", Industrial Heat Engineering, vol. 33, no. 6, pp. 11-25, 2011.

[19] V. Devisilov, E. Sharai, "Hydrodynamics of a Rheologically Complicated Liquid in a SelfCleaning Filter", Theoretical Foundations of Chemical Engineering, vol. 46, no. 6, pp. 594580, 2012.

[20] V. Devisilov, E. Sharai, "Hydrodynamics of a Numerical study of the flow structure in a hydrodynamic filter", Theoretical Foundations of Chemical Engineering, vol. 50, no. 2, pp. 209-216, 2016. 
$10^{\mathrm{TH}}$ InTERnational CONFERENCE ON Sustainable ENERgy AND EnVironmental Protection (June $27^{\mathrm{TH}}-30^{\mathrm{TH}}$, 2017, Bled, SLOVENIA), MECHANICAL ENGINEERING

J. Krope, A.Ghani Olabi, D. Goričanec \& S. Božičnik

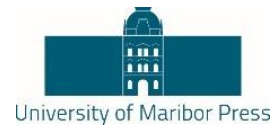

\title{
Numerical Investigation of the Separation of Two-Phase Media With Complex Power Effects in Order to Reduce Energy Consumption for Cleaning
}

\author{
VLADIMIR DEVISILOV \& ELENA SHARAI
}

\begin{abstract}
Today lots of industries require filtration of two-phase flows with high viscosity non-Newtonian dispersion medium and solid dispersion phase in order to reduce energy consumption for cleaning applications. Specific feature of the separation process for such flows is the limited service life of the filtering equipment. These problems can be solved by modernized tangential filtration with complex flow organization. In the working convergent annular channel are implemented two mechanisms of purification: centrifugal separation and filtration. This work investigates the behaviour of solids in non-Newtonian fluids in a context of complex force impacts on flow, as implemented in hydrodynamic filters. The numerical investigation of the flow structure in the convergent annular channel with rotating inner permeable wall was performed. The optimal ratios of the operating parameters are obtained, which ensure steady flow and minimum separation load on the permeable baffle. The obtained results can be used in the design of systems for cleaning high-viscosity fluids from solid particles.
\end{abstract}

Keywords: $\bullet$ tangential filtration $\bullet$ non-Newtonian fluid $\bullet$ convergent channel $\bullet$ rotating porous baffle $\bullet$ cleaning $\bullet$

CoRrespondence AdDress: Vladimir Devisilov, Ph.D., Associate professor, Bauman Moscow State Technical University, Faculty of Power Engineering, ul. Baumanskaya 2-ya, 5/1, Moscow, 105005, Russia, e-mail: devisil@mail.ru. Elena Sharai, Senior Lecturer, Bauman Moscow State Technical University, Faculty of Power Engineering, ul. Baumanskaya 2-ya, 5/1, Moscow, 105005, Russia, e-mail: e9.sharay@yandex.ru. 
$10^{\mathrm{TH}}$ INTERNATIONAL CONFERENCE ON Sustainable ENERGy AND ENVIRONMENTAL Protection (June $27^{\mathrm{TH}}-30^{\mathrm{TH}}, 2017$, Bled, Slovenia), Mechanical ENGineERING

V. Devisilov \& E. Sharai: Numerical Investigation of the Separation of Two-Phase Media With Complex Power Effects in Order to Reduce Energy Consumption for Cleaning

\section{$1 \quad$ Introduction}

Today lots of industrial applications require filtration of two-phase flows with high viscosity non-Newtonian dispersion medium and solid dispersion phase. From the fineness of filtration process fluids depends on the reliability of technical systems, the probability of occurrence of accidents in production lines, the degree of environmental pollution. The special importance of the removal of mechanical impurities is in the systems of regeneration of waste liquids.

A large number of liquid media used in the industry, exhibit pseudoplastic properties, which are characterized by an inverse correlation between the effective viscosity and deformation rate. These include solutions of polymers, mineral and synthetic oils, heavily soiled waste water. For these mediums can be applied rheological equation of nonNewtonian fluid state, written in the form of a power-law de Waele-Ostwald within the certain range of shear rates [1]. Specific feature of the process of separation of such flows is the limited service life of the filtering equipment due to the need for frequent regeneration of the filter material because of the clogging of its pores by solid particles and plugging of pore channels because of obliteration processes. The high viscosity of dispersion medium results in the necessity of creating a large pressure drop across the filtering baffle, which requires considerable energy costs.

To address these problems, it is advisable to use a combined action devices, capable of providing high efficiency of separation process coupled with creation of additional strain rates, resulting in decrease in effective viscosity of the fluid being treated [2], [3].

Among the combined action devices can be distinguished the self-cleaning hydrodynamic filter (Figure 1), which allows to considerably reduce energy costs in comparison with traditional filtration. The principle of hydrodynamic filtering is that the liquid is passed through rotating porous baffle, wherein a portion of the fluid flow to be cleansed (10-15\% of total volume) is bypassed lengthwise the filter baffle [4], [5].

The hydrodynamic force acting on the suspended solids from the pumped flow, contributes to their washout from the baffle surface. This ensures constant cleaning of the filter surface. By rotating the filter baffle, it becomes possible to separate under the influence of centrifugal force the solids, having a higher density than the liquid phase. Convergent annular gap between the housing wall and the filter provides uniform degree of selfcleaning of the latter over its entire length because of the constancy of the longitudinal fluid flow rate.

This paper investigates the behavior of solids in power-law non-Newtonian fluids in a context of complex force impacts on flow, as implemented in hydrodynamic filters. Hydrodynamic filter combines a tangential filtration and centrifugal separation in one device. This allows to increase service life (time between regenerations) and the energy costs of cleaning highly viscous media. 


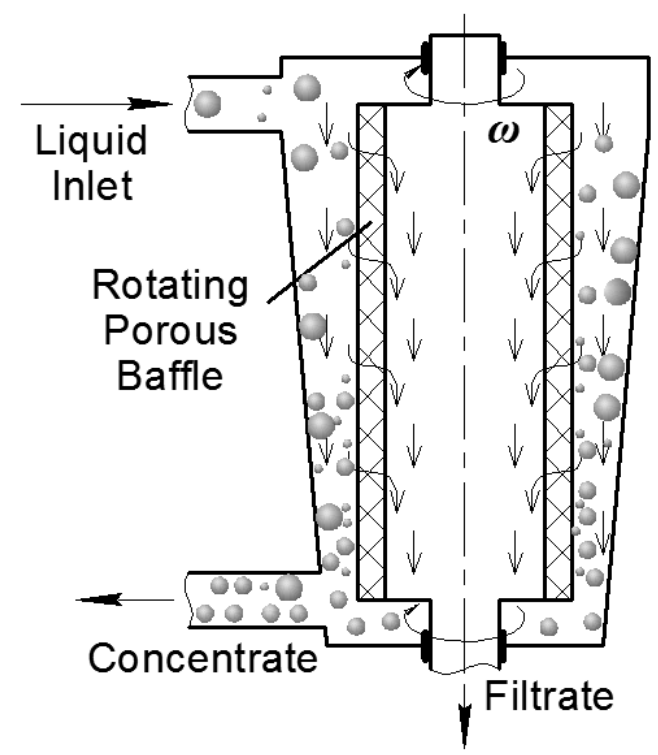

Figure 1. Hydrodynamic filter

The pattern of medium flow in the hydrodynamic filter is rather complex. It is therefore advisable to successively consider the individual components of the separation process, driven by the influence of main force factors occurring in its working area. The working area is an annular channel formed by the stationary outer conical surface and the inner rotating cylinder. For the purpose of this study, let's consider the three component of fluid flow in the working area. The first component of the flow $u_{r}$ is caused by filtration through the permeable inner cylinder, determined by the velocity $u_{R}$ of the fluid suction through its surface (Figure 2). The second component of the flow has to do with the bypassing of the portion of liquid flow at the velocity $w_{r}$ (Figure 2), by means of which hydrodynamic flush of solids from the surface of the permeable cylinder is provided. The third component of the flow is caused by the rotation of the permeable cylinder with radius $R$ and the tangential inlet, which ensures centrifugal separation of solid particles, thereby reducing the load on the filtering material. Tangential velocity $v_{r}$ determines the rate of separation. 
$10^{\mathrm{TH}}$ InTERNATIONAL CONFERENCE ON SuSTAINABLE ENERGy AND ENVIRONMENTAL Protection (June $27^{\mathrm{TH}}-30^{\mathrm{TH}}, 2017$, Bled, Slovenia), Mechanical ENGineERING

V. Devisilov \& E. Sharai: Numerical Investigation of the Separation of Two-Phase Media With Complex Power Effects in Order to Reduce Energy Consumption for Cleaning

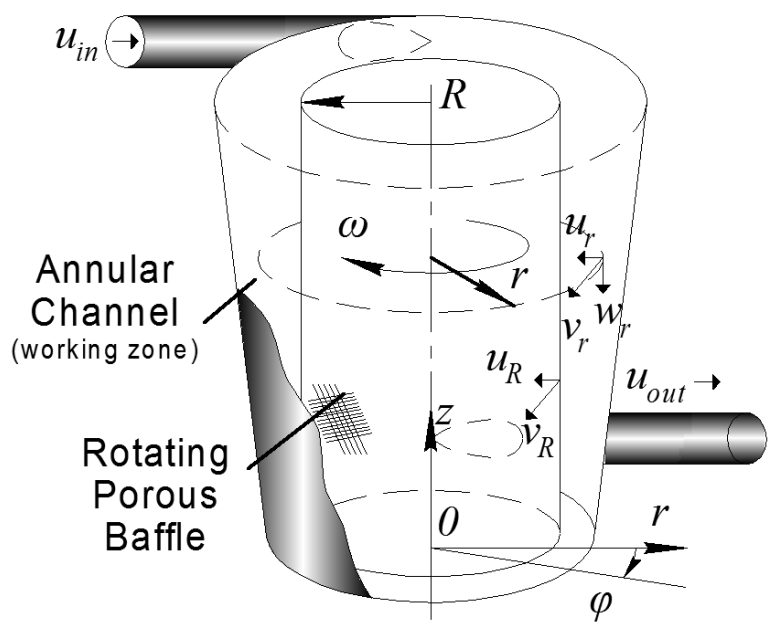

Figure 2. Flow diagram

And the last component of the flow is a special case of a known flow between two coaxial cylinders, where the outer one is fixed and the inner one is rotating [6]. It is known, that in case of such flow, unstable liquid separation may occur due to the fact, which the liquid particles in the vicinity of the rotating cylinder tend to move to the outer cylinder. Thereby, starting from a certain Taylor number, regularly alternating leftward and rightward rotating toroidal vortices, called Taylor vortexes, appear between the cylinders. However, known conditions for the appearances of Taylor vortices are not the flow stability condition in the hydrodynamic filter, since the outer surface is conical and because there are certain factors, that has a stabilizing effect. In the flow being studied, these factors are the viscosity of the fluid and the suction of the fluid through the permeable baffle [7], [8]. When filtering highviscosity media, buckling will occur at a higher rotation speed, as well as by reducing the thickness of the boundary layer due to the suction of the liquid through the rotating cylinder. Therefore, proper selection of operating parameters of the filter to ensure effective separation of particles by the centrifugal mechanism, it is necessary to know the boundaries of appearance vortex structures in view of the aforementioned factors.

Thus, the objective of this study is to determine the effect of the vortexes, which occur between the stationary outer conical wall and the inner permeable rotating cylinder, on the efficiency of separation of solid particles using centrifugal mechanism.

\section{$3 \quad$ Method of Research}

We restrict consideration of heterogeneous mixtures by dispersed mixtures, which consist of two phases, one of which is a pseudoplastic non-Newtonian fluid, and the second one is solid particles. In mathematical modeling of the processes occurring in a hydrodynamic filter, it is advisable to use the methods of continuous medium mechanics in the form of 
conservation equations with the following major assumptions: the size of disperse particles is many times greater than kinetic molecular distances, and the particle size is much smaller than the size of the channels in which the two-phase mixture flows.

The system of equations for hydrodynamics two-phase medium is the system of equations, based on the Euler model and Navier-Stokes equations [9], and can be expressed as follows:

- the law of conservation of momentum for a solid phase

$$
\begin{aligned}
& \frac{\partial}{\partial t}\left(\alpha_{s} \rho_{s} V_{j, s}\right)+\frac{\partial}{\partial x_{j}}\left(\alpha_{s} \rho_{s} V_{j, s} V_{i, s}\right)=-\alpha_{s} \frac{\partial P}{\partial x_{i}}+ \\
& +\frac{\partial \tau_{i j, s}}{\partial x_{j}}+\alpha_{s} \rho_{s} g_{i}+K_{s f}\left(V_{i, f}-V_{i, s}\right)
\end{aligned}
$$

- the law of conservation of momentum for a liquid phase

$$
\begin{aligned}
& \frac{\partial}{\partial t}\left(\alpha_{f} \rho_{f} w_{j, f}\right)+\frac{\partial}{\partial x_{j}}\left(\alpha_{f} \rho_{f} V_{j, f} V_{i, f}\right)=-\alpha_{f} \frac{\partial P}{\partial x_{j}}+ \\
& +\frac{\partial \tau_{i j, f}}{\partial x_{j}}+\alpha_{f} \rho_{f} g_{i}+K_{f s}\left(V_{i, s}-V_{i, f}\right) ;
\end{aligned}
$$

- continuity equation for solid phase

$$
\frac{\partial}{\partial t}\left(\alpha_{s} \rho_{s}\right)+\nabla\left(\alpha_{s} \rho_{s} V_{s}\right)=0
$$

- continuity equation for fluid phase

$$
\frac{\partial}{\partial t}\left(\alpha_{f} \rho_{f}\right)+\nabla\left(\alpha_{f} \rho_{f} V_{f}\right)=0
$$

- the volume fractions of the phases

$$
\alpha_{f}+\alpha_{s}=1
$$


V. Devisilov \& E. Sharai: Numerical Investigation of the Separation of Two-Phase Media With Complex Power Effects in Order to Reduce Energy Consumption for Cleaning

where, $V_{f}$ and $V_{s}$ are the velocities of fluid and solid phases accordingly; $\alpha_{f}$ and $\alpha_{s}$ are relative volumetric concentrations of fluid and solid phases; $\rho_{f}$ and $\rho_{s}$ are their densities; $P$ is pressure within the medium; $g$ - mass forces; $t$ - time; $x$-coordinate; $K_{f s}$ and $K_{s f}$ - phase interaction factors; $i, j$ - summation indexes, $i, j=1,2,3 ; \tau_{i j, f}$ and $\tau_{i j, s}$-stress tensors for fluid and solid phases. Stress tensors:

- for fluid phase

$$
\begin{aligned}
& \tau_{i j, f}=\frac{2}{3} \alpha_{f} \rho_{f} k_{f} \delta_{i j}+ \\
& +\alpha_{f} \mu_{f}^{e f f}\left[\left(\frac{\partial V_{i, f}}{\partial x_{j}}+\frac{\partial V_{j, f}}{\partial x_{i}}\right)-\frac{2}{3} \delta_{i j} \frac{\partial V_{k, f}}{\partial x_{k}}\right]
\end{aligned}
$$

- for solid phase

$$
\begin{gathered}
\tau_{i j, s}=\alpha_{s} \mu_{s}\left(\frac{\partial V_{i, s}}{\partial x_{j}}+\frac{\partial V_{j, s}}{\partial x_{i}}\right)+ \\
+\left(\alpha_{s} v_{s}-\frac{2}{3} \alpha_{s} \mu_{s}\right) \delta_{i j} \frac{\partial V_{k, s}}{\partial x_{k}}
\end{gathered}
$$

where, $\nu_{s}$ and $\mu_{s}$ are volumetric and shearing viscosities of the solid phase; $\mu_{f}^{\text {eff }}$ effective viscosity of the fluid; $k$-summation index, $k=1,2,3$.

The equation of state of a non-Newtonian fluid, which is written as power-law de WaeleOstwald dependence, has the form of [1]:

$$
\tau=m|\gamma|^{n-1} \gamma
$$

where, $m$ is consistency index; $\gamma$ - rate of strain; $n$ - flow index or the intensity of nonNewtonian properties $(n<1)$. The effective viscosity of non-Newtonian liquid is determined as 
V. Devisilov \& E. Sharai: Numerical Investigation of the Separation of Two-Phase

Media With Complex Power Effects in Order to Reduce Energy Consumption for

$\mu_{f}^{e f f}=m|\gamma|^{n-1}$.

As a model of two-phase flow turbulence, we adopted the $k-\varepsilon$ turbulence model, where the transport equations are written for the turbulence kinetic energy $k$ and the turbulent energy $\varepsilon$ dissipation rate for each of the phases separately.

The system of equations (1) - (5) is written in the general form and can be used for stationary and non-stationary calculations. In this paper, the system (1) - (5) is solved numerically by finite volume method in a stationary environment. The solution is implemented as a serial iterative procedure on the grid nodes.

The criterion for the end solution is a condition, when the maximum relative difference between the values of the unknown variables in the previous iteration step and the next iteration step does not exceed specified error $\Delta=1 \cdot 10^{-4}$ in all the nodes of the computational grid,

$\max \left|\frac{q^{l}-q^{l-1}}{q^{l}}\right| \leq \Delta$

where, $q$ is the unknown variable, $l$ - iteration step number.

The system $(1)-(5)$ is supplemented with the following boundary conditions. The «inlet» boundary condition is determined by the flow rate of the dispersed two-phase mixture. The «outlet» conditions are set on the inner cylindrical surface by the three components of speed (Figure 2): $u_{R}(R)=u_{R}$, equal to the filtration rate; circumferential speed $v_{R}(R)=\omega R$ , where $\omega$ is the angular velocity of rotation, $R$ is the radius of the filter baffle; and the velocity along the axis of rotation $w_{R}(R)=0$. Also the «outlet» boundary condition is determined by the flow rate of the continuous fluid (15\% from «inlet» flow rate). The adhesion condition is set on the outer conical surface, i.e. $V_{f}=0$. The intensity of the turbulence formation in the flow is 0.05 . The interaction of solid particles with the conical surface: perfectly elastic reflection; same with the rotating cylindrical: adhesion condition, under which all of the solid particles striking the wall are consider to be settled thereon. 
$10^{\mathrm{TH}}$ INTERNATIONAL CONFERENCE ON SUSTAINABLE ENERGy AND ENVIRONMENTAL Protection (June $27^{\mathrm{TH}}-30^{\mathrm{TH}}, 2017$, Bled, Slovenia), Mechanical ENGineERING

V. Devisilov \& E. Sharai: Numerical Investigation of the Separation of Two-Phase Media With Complex Power Effects in Order to Reduce Energy Consumption for Cleaning

\section{$4 \quad$ Research Result}

Calculations have been made for two-phase flow with the following parameters:

1. The continuous fluid. Density: $\rho_{f}=900 \mathrm{~kg} \cdot \mathrm{m}^{-3} ;$ consistency index: $m=0.15 \mathrm{~Pa} \cdot \mathrm{s}^{n}$, the degree of intensity of non-Newtonian properties $n$ was varying from 0.8 to 1.0 .

2. The solid phase. Density: $\rho_{s}=2250 \mathrm{~kg} \cdot \mathrm{m}^{-3}$. At the first iteration the solid phase monodispercity condition was adopted. Diameter of particles $d_{s}$ was varying from 20 to $100 \mu \mathrm{m}$.

3. The geometrical parameters. The radius of the filter baffle $R=20 \mathrm{~mm}$; the length of the channel $L=100 \mathrm{~mm}$; the slant angle of $12^{\circ}$; little radius cone of $25 \mathrm{~mm}$.

The following are the results of the numerical solution of the system equations (1)-(5) the analytical model. The effective viscosity in the working area was determined. For this type of complex flow, the influence of dispersed phase particle diameters ds, circumferential velocity of rotation of the inner cylindrical surface and the degree of intensity of nonNewtonian properties of particles on efficiency of particle separation using centrifugal separation mechanism were examined.

\subsection{The effective viscosity in working zone of the hydrodynamic filter}

The rotation of the filter baffle and the tangential input of the cleaned flow into the working zone make it possible to reduce the effective viscosity pseudoplastic fluid in the channel by creating additional shear rates. Figures $3 \mathrm{a}-3 \mathrm{~d}$ shows the distribution of the relative effective viscosity $\bar{\mu}_{\text {eff }}$ along the relative channel radius $\bar{r}$ at $z / L$ equal to 0.1 (Figures $3 a$ ), 0.3 (Figures 3b), 0.5 (Figures 3c), 0.7 (Figures 3d), where:

$\bar{\mu}_{e f f}=\frac{\mu_{e f f}}{m}, \bar{r}=\frac{r}{R}$.

Curves $1(n=0.8), 3(\mathrm{n}=0.9)$ of Figure 3 were obtained for $\omega=100 \mathrm{rad} \cdot \mathrm{s}^{-1}$, and curves 2 $(n=0.8), 4(n=0.9)$ correspond to a fixed filter baffle.

As can be seen from the graphs, the introduction of rotation of the filter baffle really allows reducing the effective viscosity in the annular channel. For instance, the rotation of the filter baffle with $\omega=100 \mathrm{rad} \cdot \mathrm{s}^{-1}$ allows to reduce the effective viscosity by an average of $15 \%$ for fluid with the degree $n=0.9$, and with $n=0.8$ by $25 \%$. 
However, there is a limit to reducing the effective viscosity. For considered continuous fluid, it is not advisable to use rotation more than $\omega=400 \mathrm{rad} \cdot \mathrm{s}^{-1}$. In this case, the decrease in the effective viscosity will be less than $1 \%$ (Figure 4).

\subsection{The efficiency of solids separation by the centrifugal mechanism}

The efficiency of particle separation using centrifugal separation mechanism was estimated by the relative volume concentration of solid particles $\alpha_{s \text {,out }}$ at the exit of the branch pipe of the concentrate.

For evaluation of convenience let's convert $\alpha_{s, \text { out }}$ to initial concentration $\alpha_{s, \text { inlet }}$ at the input of the filter to calculate the efficiency of solids separation by the centrifugal mechanism:

$\eta=\frac{\alpha_{s, \text { out }}}{\alpha_{\text {s,inlet }}}$

where, $\eta$ is the efficiency of solids separation using centrifugal mechanism; $\alpha_{s, \text { out }}$ and $\alpha_{s, \text { inlet }}$ are relative volume concentrations of solids on exit of the branch pipe of the concentrate and at the inlet to the computational domain respectively. 
$96 \quad 10^{\mathrm{TH}}$ International Conference on Sustainable EnERgy and ENVIRONMENTAL Protection (June 27 $7^{\mathrm{TH}}-30^{\mathrm{TH}}, 2017$, Bled, Slovenia), Mechanical Engineering

V. Devisilov \& E. Sharai: Numerical Investigation of the Separation of Two-Phase Media With Complex Power Effects in Order to Reduce Energy Consumption for Cleaning
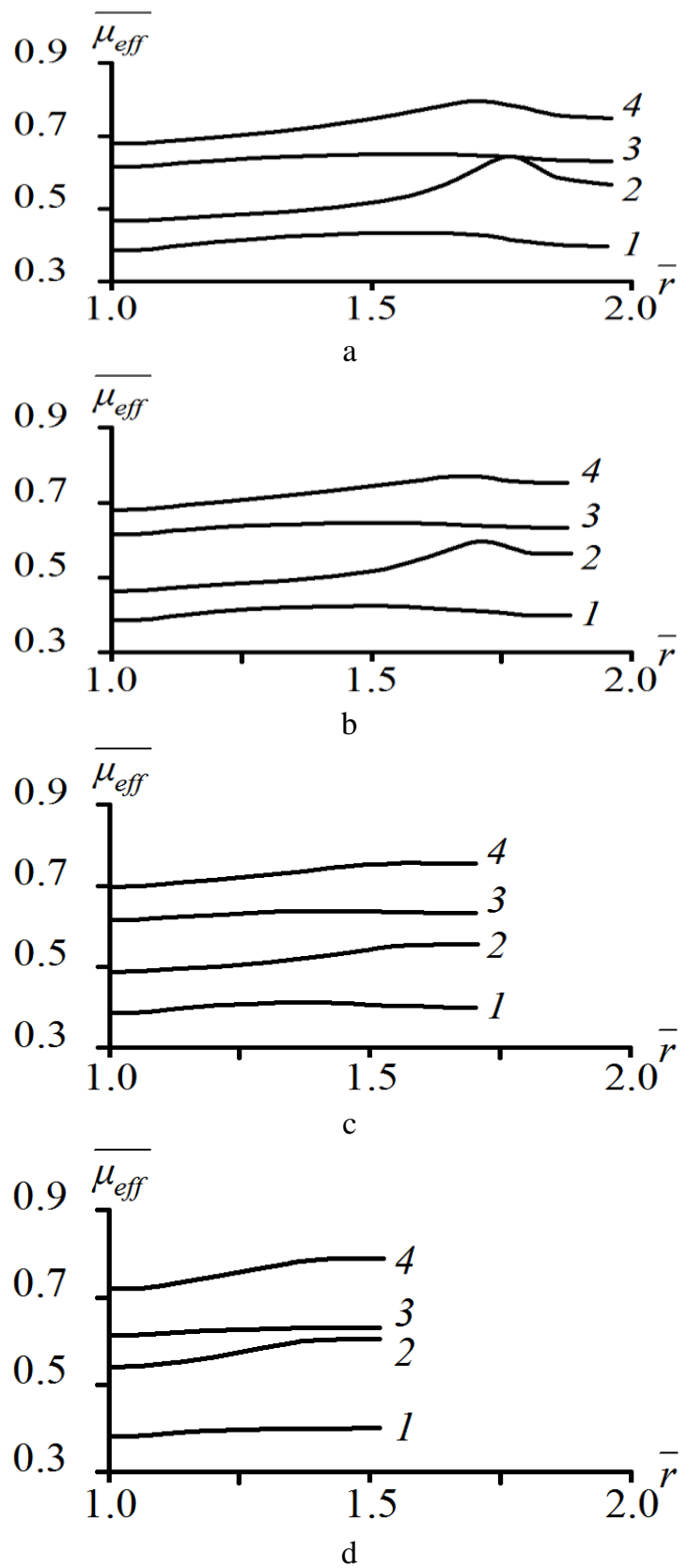

Figure 3. The effective viscosity in working zone of the hydrodynamic filter: $1-$ $\omega=100 \mathrm{rad} \cdot \mathrm{s}^{-1}, n=0.8 ; 2-\omega=0, n=0.8 ; 3-\omega=100 \mathrm{rad} \cdot \mathrm{s}^{-1}, n=0.9 ; 4-\omega=0, n=0.9$ 
$10^{\mathrm{TH}}$ InTERNATIONAL CONFERENCE ON SUSTAINABLE ENERGY AND ENVIRONMENTAL Protection (June $27^{\mathrm{TH}}-30^{\mathrm{TH}}, 2017$, Bled, Slovenia), MeChanical ENGiNEERING

V. Devisilov \& E. Sharai: Numerical Investigation of the Separation of Two-Phase

Media With Complex Power Effects in Order to Reduce Energy Consumption for Cleaning

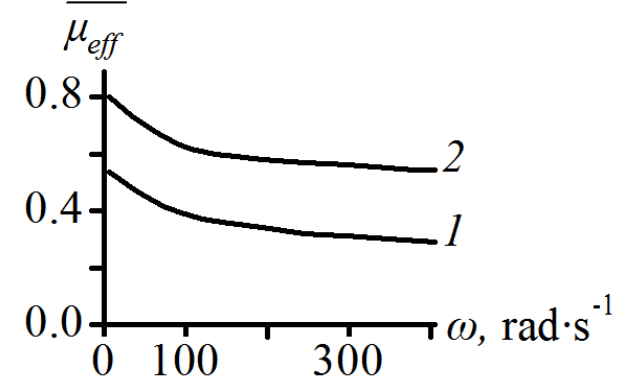

Figure 4. The average effective viscosity in working zone of the hydrodynamic filter at $z / L=0.5$ and: $1-n=0.8 ; 2-n=0.9$

Comparison of Figures 5, 6 shows that the larger particles are separated better. The explanation of this fact is the increase of the centrifugal force for $100 \mu \mathrm{m}$ particles as compared to the particles of $20 \mu \mathrm{m}$.

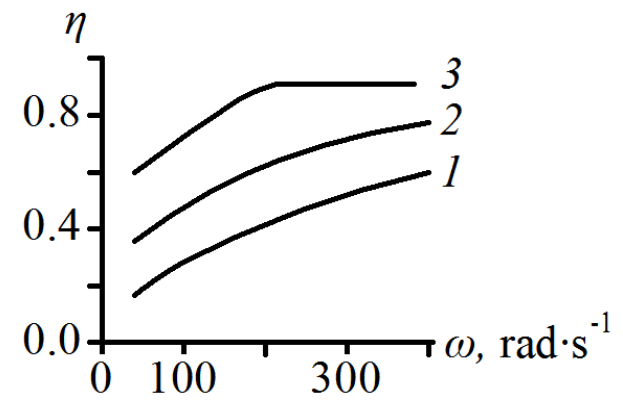

Figure 5. Dependence of solids separation using centrifugal mechanism $\eta$ on angular frequency at $n=0.8$ and: $1-d_{s}=20 \mu \mathrm{m} ; 2-d_{s}=60 \mu \mathrm{m} ; 3-d_{s}=100 \mu \mathrm{m}$

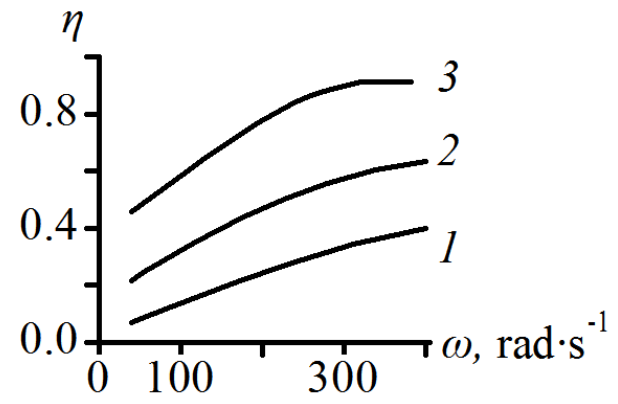

Figure 6. Dependence of solids separation using centrifugal mechanism $\eta$ on angular frequency at $n=0.9$ and: $1-d_{s}=20 \mu \mathrm{m} ; 2-d_{s}=60 \mu \mathrm{m} ; 3-d_{s}=100 \mu \mathrm{m}$

As can be seen from the curves 1-3 on Figures 5, 6, particle separation efficiency using centrifugal mechanism increases as the flow index $n$ decreases. This is due to the effect of 
$10^{\mathrm{TH}}$ International Conference on Sustainable EnERgy and Environmental Protection (June $27^{\mathrm{TH}}-30^{\mathrm{TH}}, 2017$, Bled, Slovenia), Mechanical ENGineERING

V. Devisilov \& E. Sharai: Numerical Investigation of the Separation of Two-Phase Media With Complex Power Effects in Order to Reduce Energy Consumption for Cleaning

"liquefaction" of power-law fluid in case of a complex shift, when the effective viscosity decreases with the decrease of the flow index $n$. Therefore, with the increased $n$, a solid particle is affected by greater drag force, that results in a decrease of separation efficiency using centrifugal mechanism.

Increasing efficiency $\eta$ due to increasing of circumferential speed of the inner permeable cylinder rotation is logical, because centrifugal force, that affects a solid particle, is directly proportional to the square of the circumferential speed. However, this increase is limited and is observed at the steady state for the existence of the circulation vortex in the working zone. Figure 7 shows the two-dimensional streamlines in a meridional section of the channel, which illustrate circulation vortex pattern.

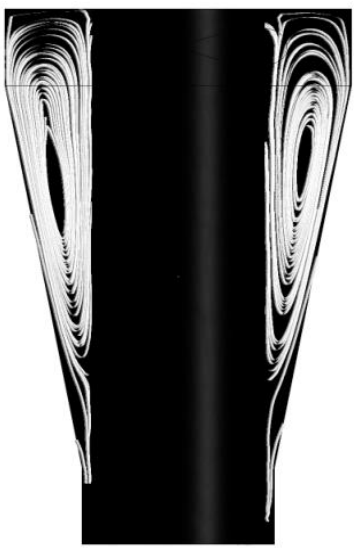

Figure 7. Two-dimensional streamlines in the working zone

\section{$5 \quad$ Inference}

Based on the deterministic approach, we have developed the model of the process of medium flow in the convergent channel formed by the stationary conical outer surface and the inner cylindrical rotating permeable surface. We have examined the process of movement of the two-phase flow containing dispersed phase, consisting of solid particles and liquid disperse medium, the rheological properties of which are described by the power-law de Waele-Ostwald dependence, within an annular channel with rotating permeable inner surface. We have further identified key parameters of the process of separation of solid particles in a complex flow. The results of the study can be used to develop an engineering method for calculating hydrodynamic filters, the principle of operation of which is based on filtering in condition of complex impacts on the flow. The obtained results can be used in the design of systems for cleaning high-viscosity fluids from solid particles. 
$10^{\mathrm{TH}}$ INTERNATIONAL CONFERENCE ON SUSTAINABLE ENERGY AND ENVIRONMENTAL Protection (June $27^{\mathrm{TH}}-30^{\mathrm{TH}}, 2017$, Bled, Slovenia), MeChanical ENGINEERING

V. Devisilov \& E. Sharai: Numerical Investigation of the Separation of Two-Phase Media With Complex Power Effects in Order to Reduce Energy Consumption for Cleaning

This work was performed under the state order of the Ministry of Education and Science of the Russian Federation No. 10.7766.2017.

\section{References}

[1] W. L. Wilkinson, Non-Newtonian fluids. London: Pergamon Press, 1960.

[2] Yao Lun-Shin, Md. Mamun, "Fully-Developed Circular-Pipe Flow of a Non-Newtonian Pseudoplastic Fluid", Universal Journal of Mechanical Engineering, 1(2), pp. 23-31, 2013.

[3] T. K. Bandyopadhyay, S. K. Das, "Non-Newtonian pseudoplastic liquid flow through small diameter piping components", J. of Petroleum Science and Engineering, vol. 55, pp. 156166, 2007.

[4] V. A. Devisilov, E. Yu. Sharai, "Hydrodynamics of a Rheologically Complicated Liquid in a Self-Cleaning Filter", Theoretical Foundations of Chemical Engineering, vol. 46, no. 6, pp. 594-600, 2012.

[5] V. A. Devisilov, E. Yu. Sharai, "Hydrodynamics of a Numerical study of the flow structure in a hydrodynamic filter", Theoretical Foundations of Chemical Engineering, vol. 50, no. 2, pp. 209-216, 2016.

[6] C. D. Andereck, S. S. Liu, H. L. Swinney, "Flow regimes in a circular Couette system with independently rotating cylinders", J. of Fluid Mechanics, 164, pp. 155-183, 1986.

[7] D. L. Cotrell, A. J. Pearlstein, "Linear stability of spiral and annular Poiseuille flow for small radius ratio", J. Fluid Mech., vol. 547, pp. 1-20, 2006.

[8] D. I. Takeuchi, D. F. Jankowski, "A numerical and experimental investigation of the stability of spiral Poiseuille flow", J. Fluid Mech., vol. 102, pp. 101-126, 1981.

[9] D. A. Drew and R. T. Lahey, In Particulate Two-Phase Flow, Boston: ButterworthHeinemann, 1993. 
$100 \quad 10^{\mathrm{TH}}$ International Conference on Sustainable Energy and Environmental Protection (June $27^{\mathrm{TH}}-30^{\mathrm{TH}}, 2017$, BLed, Slovenia), Mechanical EngineERING 
$10^{\mathrm{TH}}$ InTERnational CONFERENCE ON Sustainable ENERgy AND EnVironmental Protection (June $27^{\mathrm{TH}}-30^{\mathrm{TH}}$, 2017, Bled, SLOVENIA), MECHANICAL ENGINEERING

J. Krope, A.Ghani Olabi, D. Goričanec \& S. Božičnik

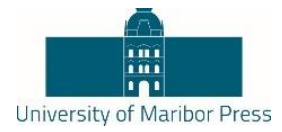

\title{
Assessment of Optimal Drilling Parameter for Bamboo Filler Reinforced Epoxy Composite
}

\author{
CHAIKI MALAKAR \& SUMIT BHOWMIK
}

\begin{abstract}
With the increasing use of structure made of composite materials, eco-friendly reinforced composite materials gained great interest of research. For joining of structures made of composite materials in various applications drilling process plays a pivotal role. An experimental study into the drilling behavior of bamboo filler reinforced epoxy composites has been carried out considering various percentage of bamboo filler. The drilling operation has been conducted on radial drilling machine using HSS twist drill bit. The drill diameter, spindle speed, and bamboo filler content were selected as the input parameters and thrust force as the response parameter. The experimental results show that thrust force increases with the increase in drill diameter and spindle speed on thrust force is found insignificant. It is also seen that the thrust force increases up to $7.5 \%$ filler, after that, decreases. Regression analysis has been performed to develop mathematical model for calculation of thrust force.
\end{abstract}

Keywords: • Bamboo filler $\bullet$ drilling thrust force $\bullet$ high speed steel drills $\bullet$ regression analysis $\bullet$ composites $\bullet$

CORRESPONDENCE AdDRESS: Chaiki Malakar, M.Tech. Department of Mechanical Engineering, National Institute of Technology, Silchar, Silchar, Cachar, Assam 788010, India, email: chaikimalakar@gmail.com. Sumit Bhowmik, PhD., Assistant Professor, Department of Mechanical Engineering, National Institute of Technology, Silchar, Silchar, Cachar, Assam 788010, e-mail: bhowmiksumit04@yahoo.co.in. 
$10^{\mathrm{TH}}$ InTERnational CONFERENCE on Sustainable EnERgy AND ENVIRONMENTAL Protection (June $27^{\mathrm{TH}}-30^{\mathrm{TH}}, 2017$, Bled, Slovenia), Mechanical ENGineERING C. Malakar \& S. Bhowmik: Assessment of Optimal Drilling Parameter for Bamboo Filler Reinforced Epoxy Composite

\section{Introduction}

Modern technologies require materials with superior properties than the conventional ones. There has been an increase in demand for composites in various applications due to the multidimensional properties compared to the constituent materials. A composite is a material having two or more phases that results in combination of properties. The application of composites could be found in diverse engineering disciplines: the automotive industry, the aerospace application and in the leisure industry for fabricating tennis racquets. With increasing demand of composites is also required of assembling some of the parts together. For joining of the part adhesives can be employed, but it has several disadvantages [1]. For creating mechanical joint, surface preparation is not an essential criteria whereas bonding joint with the help of adhesives requires surface preparation. Adhesive bonding requires more skilled people and precision work is required for mechanical joints. Also inspection of the adhesive bonds becomes difficult since the components cannot be broken and put together again [2]. Composite parts which are connected by mechanical fasteners require appropriate holes to be drilled to have a long lasting assembly of the parts. Amongst the numerous machining processes, conventional drilling is easier and quicker process for machining of materials. During drilling operation, different process parameters viz., drill bit diameter, depth of cut speed, torque and feed rate play an important role in the removal of the material. Various researchers carried out different investigation to find the optimal combination of drilling machining parameter for different composite materials. The fiber loading and feed rate has a direct effect on the torque and thrust force of chopped composite material during drilling operation. The push out and peel up delamination also occurred at drill entry and exit. The cutting speed does not have significant effect on the delamination size whereas the delamination size decreases with the decrease in feed [3]. With the increasing cutting speed, both the thrust force and the torque increased. Further carbide drill performed better than the HSS drill [4]. For glasssisal-jute fiber reinforced hybrid composite, lower feed rate and high or moderate spindle speed are appropriate for drilling in order to reduce the induced damages while drilling. For the specific volume fraction glass fiber reinforced epoxy composites with increasing cutting speed the thrust forces and torque were decreased. Also glass fiber reinforced epoxy composites with lower volume fraction at lower feed have greater roughness than that of drilling at higher feed [6]. The delamination size is increased with increasing drill diameter and feed during the drilling operation of woven glass fiber reinforced epoxy composites. On the other side, increasing cutting feed increases the surface roughness. Further, the increased feed fallouts in greater value of thrust force. The thrust force leads to delamination damage which lowers the bearing strength. With the increase of cutting force the tool wear increases. Therefore for drill wear monitoring, cutting forces are very much important. The thrust force in drilling of composite materials are mainly depends on the different input parameters and most of the work carried out on fiber reinforced composites.

As the matter to subject of the topic, the thrust force in drilling is assessed for bamboo filler reinforced composited under different constraint like drill diameter, spindle speed, and different wt. \% of filler. 


\section{$2 \quad$ Materials \& Experimentation}

\subsection{Materials and sample preparation}

In this work bamboo filler belongs to Bambusa Tulda tree species family is used as reinforcement material and epoxy resin (AW106) and corresponding hardener (HV953U) are used for the matrix material to prepare the sample. The samples are prepared using hand layup technique of dimension $110 \mathrm{~mm} \times 110 \mathrm{~mm} \times 5 \mathrm{~mm}$ block. The bamboo fillers are obtained by grinding process and then sieving is done in order to obtain the average dimension of $150 \mu \mathrm{m}$. After proper cleaning and drying, different wt. \% of fillers in $0 \%$, $2.5 \%, 5 \% 7.5 \%, 10 \%$ and $12.5 \%$ ratio are mixed with epoxy. The resin and hardener is mixed in a ratio 10:8 by weight. The mixture of bamboo filler and epoxy is mechanically stirred and steadily discharged in the glass mould placed in vacuum chamber. The mixture is kept in vacuum chamber for $24-48 \mathrm{~h}$ at room temperature to cure.

\subsection{Experimental details}

To determine the thrust force in drilling operation of bamboo filler reinforced epxoy composite under different variable paramete a number of drilling experiments are carried out on a radial drilling machine using HSS twist drill having three diameters of $3 \mathrm{~mm}, 4$ $\mathrm{mm}$ and $5 \mathrm{~mm}$. A load cell with data acquisition system is used to measure the thurst force. The experiment is carried out in three different spindle speed of $250 \mathrm{rpm}, 500 \mathrm{rpm}$ and $1000 \mathrm{rpm}$ with a constant feed rate of $0.59 \mathrm{~mm} / \mathrm{rev}$. under dry cutting condition.

\section{$3 \quad$ Results and Discussions}

\subsection{Thrust force analysis}

In this present work drilling operation is carried out on bamboo filler reinforced epoxy composite to determine the effects of drill diameter, spindle speed and bamboo filler wt. \% on thrust forces. Figure $1-6$ shows the graphs between thrust force and drill diameters with respect to spindle speed of $250 \mathrm{rpm}, 500 \mathrm{rpm}$ and $1000 \mathrm{rpm}$ respectively for various percentage of filler content. From the results it is found that with the increase of drill diameter, the thrust force is also increasing for all the filler wt. \%. This is occurs due to the increase in cross sectional area of the undeformed chip. Therefore, the resistance of chip formation and, consequently, the thrust force were increased. In all the experiment the feed rate is constant at $0.59 \mathrm{~mm} / \mathrm{rev}$. It is also observed from the experimental results that the spindle plays an important role on the thrust force. 
104 10 $10^{\mathrm{TH}}$ InTERnational CONFERENCE ON Sustainable EnERgy and ENVIRONMENTAL Protection (June $27^{\mathrm{TH}}-30^{\mathrm{TH}}, 2017$, Bled, Slovenia), Mechanical ENGineERING

C. Malakar \& S. Bhowmik: Assessment of Optimal Drilling Parameter for Bamboo Filler Reinforced Epoxy Composite

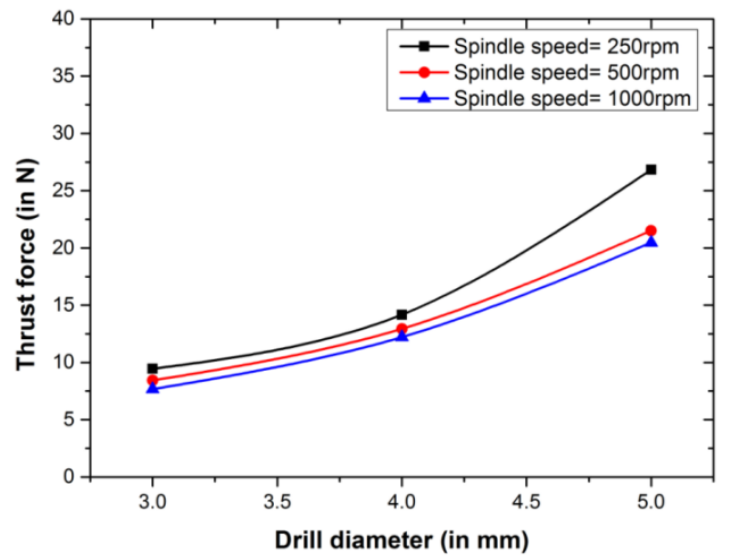

Figure 1. Variation of Thrust force with the drill diameters at different spindle speed for $0 \%$ filler

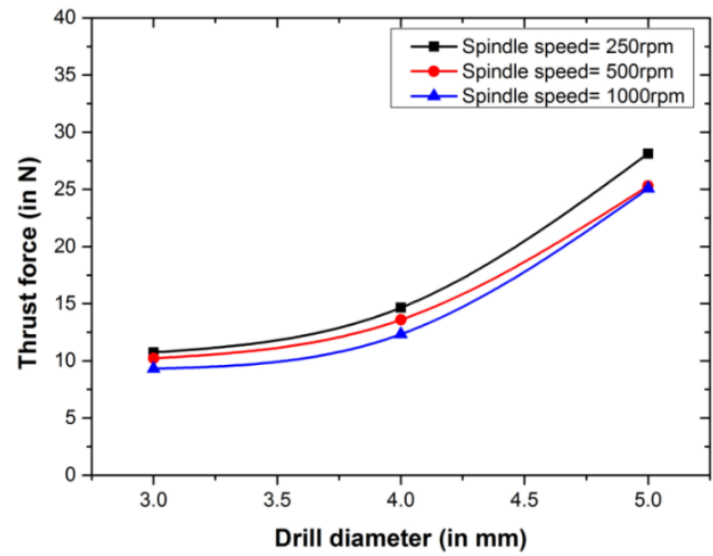

Figure 2. Variation of Thrust force with the drill diameters at different spindle for $2.5 \%$ filler 
Protection (June $27^{\mathrm{TH}}-30^{\mathrm{TH}}, 2017$, Bled, Slovenia), MeChanical ENGineERING

C. Malakar \& S. Bhowmik: Assessment of Optimal Drilling Parameter for Bamboo

Filler Reinforced Epoxy Composite

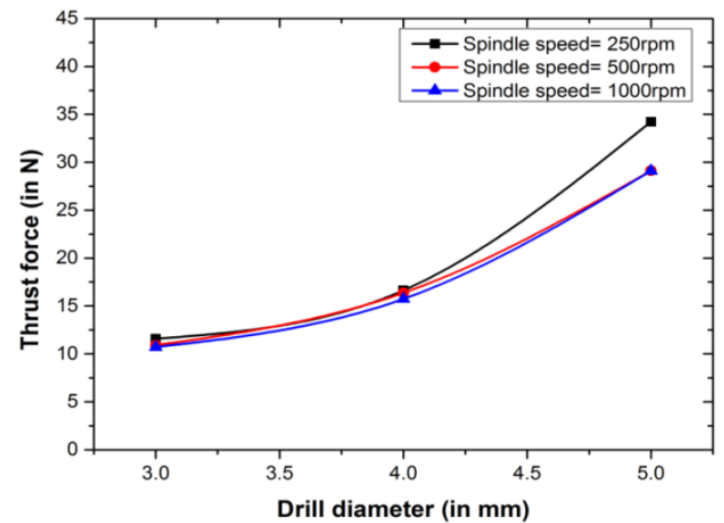

Figure 3. Variation of Thrust force with the drill diameters at different spindle for $5 \%$ filler

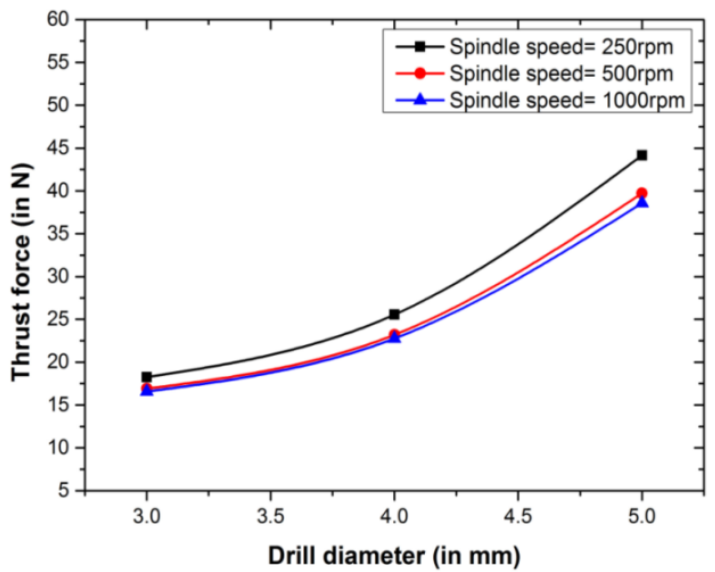

Figure 4. Variation of Thrust force with the drill diameters at different spindle for $7.5 \%$ filler 
106 10 $10^{\mathrm{TH}}$ InTERnational Conference On Sustainable EnERgy and EnVIRONMENTAL Protection (June 27 $7^{\mathrm{TH}}-30^{\mathrm{TH}}, 2017$, Bled, Slovenia), Mechanical EngineERING

C. Malakar \& S. Bhowmik: Assessment of Optimal Drilling Parameter for Bamboo Filler Reinforced Epoxy Composite

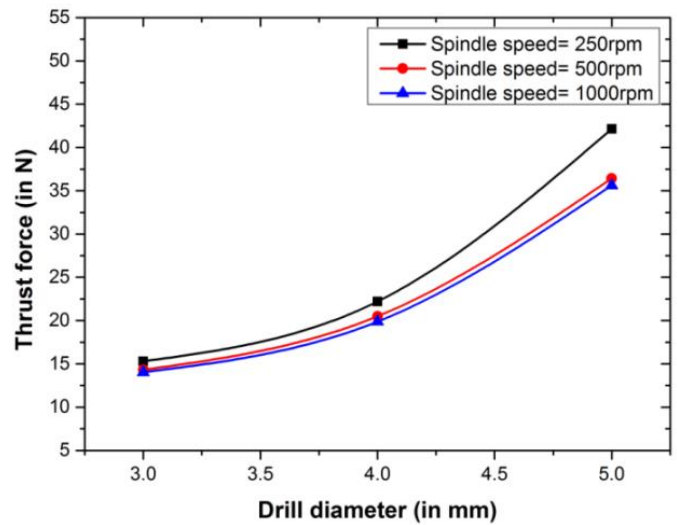

Figure 5. Variation of Thrust force with the drill diameters at different spindle for $10 \%$ filler

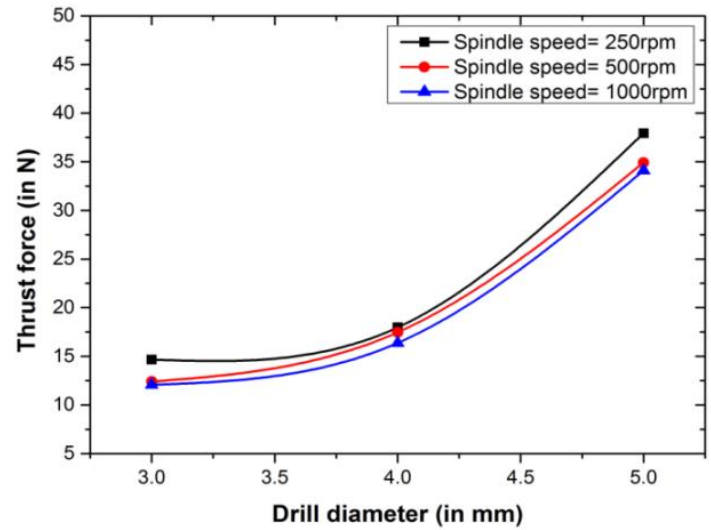

Figure 6. Variation of Thrust force with the drill diameters at different spindle for $12.5 \%$ filler 

Protection (June $27^{\mathrm{TH}}-30^{\mathrm{TH}}, 2017$, Bled, Slovenia), MeChanical ENGineERING C. Malakar \& S. Bhowmik: Assessment of Optimal Drilling Parameter for Bamboo Filler Reinforced Epoxy Composite

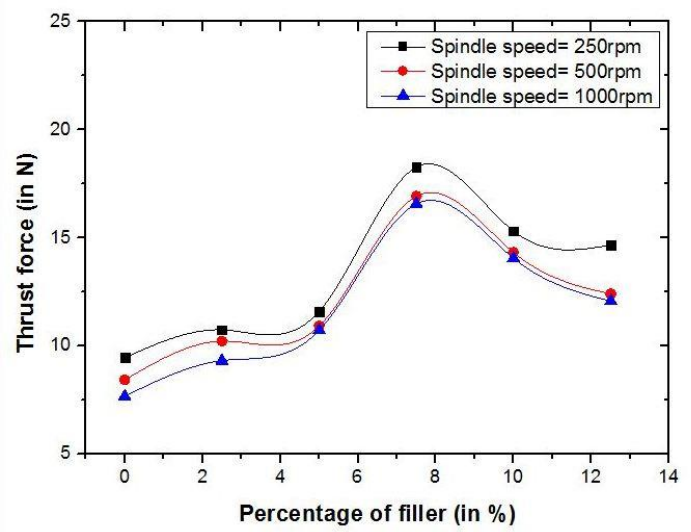

Figure 7. Variation of thrust force with filler $\%$ at different spindle speed for $3 \mathrm{~mm}$ drill dia.

The influence of various filler $\%$ on thrust forces is shown in figure 7, 8 and 9 respectively. It is observed that the thrust force increases with incresae in the $\%$ filler upto $7.5 \%$ filler content for all the drill diameter and with increase in filler content the thrust force decresaes. After certain limit of the filler content, the adhesion between filler and resin decreases. At higher filler content it is also difficult for the epoxy resin to penetrate the small spaces between the bamboo fillers due to which the stress transfer ability across the filler resin interface gets reduce. Thus decrease in the thrust force at higher filler content.

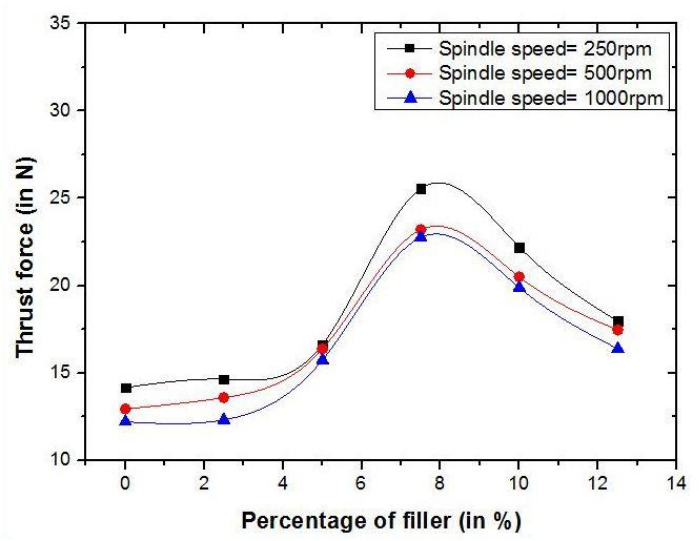

Figure 8 . Variation of thrust force with filler $\%$ at different spindle speed for $4 \mathrm{~mm}$ drill dia. 
$10^{\text {TH }}$ International Conference on Sustainable Energy and Environmental Protection (June 27 $7^{\mathrm{TH}}-30^{\mathrm{TH}}, 2017$, Bled, Slovenia), Mechanical Engineering C. Malakar \& S. Bhowmik: Assessment of Optimal Drilling Parameter for Bamboo Filler Reinforced Epoxy Composite

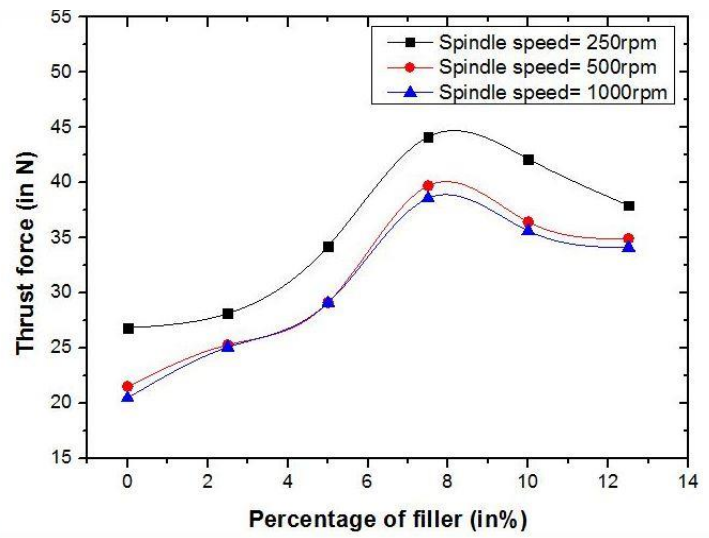

Figure 9. Variation of thrust force with filler \% at different spindle speed for $5 \mathrm{~mm}$ drill dia.

\subsection{Determination of $\mathrm{S} / \mathrm{N}$ ratio}

Signal to Noise $(\mathrm{S} / \mathrm{N})$ ratio is used to study the response variation for the radial drilling of bamboo filler reinforced epoxy composites. This is done in order to reduce the characteristic variations due to some uncontrollable parameters. The output response is thrust force which has been considered with 'smaller the better' concept. For 'smaller the better' concept the relation of S-N ratio is shown in Equation 1.

$$
S / N=-10 \log _{10}\left(\frac{1}{n} \sum y^{2}\right)
$$

where, $n$ is the no. of measurements taken in a row and $y$ is the measured value in that row.

\subsection{Regression model}

A regression model is established for correlating the interactions of parameters such as drill diameter, spindle speed, filler percentages and their effects on the thrust force in drilling bamboo filler reinforced epoxy composites [8]. In order to predict the dependent variable the regression model proposed is given as:

Thrust force

$$
\begin{aligned}
& =-18.368-0.824 \times A-0.88 \times B \\
& +0.004 \times C+0.092 \times A B-0.0001 \\
& \times B C-0.0003 \times A C+0.00007 \times A B C
\end{aligned}
$$


Where, $\mathrm{A}$ is the percentage of bamboo filler, $\mathrm{B}$ is the drill diameter in $\mathrm{mm}$ and $\mathrm{C}$ is the spindle speed in rpm. Input responses and their interactions are the independent variables and the output response i.e., thrust force is the dependent variable. The coefficient of effectiveness ( $\mathrm{R}^{2}$ value) for the thrust force obtained from the regression model is 0.88 . From the $\mathrm{R}^{2}$ value it is found that the input responses are effective in determining the thrust force in drilling of epoxy composites. The regression analysis is carried out at a confidence level of $90 \%$, i.e. p-value $(<0.1)$ in order to predict the thrust force in drilling bamboo filler reinforced epoxy composites.

\subsection{Confirmation analysis}

The conformation analysis is conducted in order to prove the accuracy of the equation obtained from the regression model. The percentage error for each of the prediction is calculated using the equation given below [9].

$$
\% \text { Error }=\left|\begin{array}{l}
\frac{\text { Actual } S N \text { ratio }- \text { Pr edicted } S N \text { ratio }}{\times 100} \\
\text { Actual } S N \text { ratio }
\end{array}\right|
$$

The maximum \% error for thrust force is found to be $8.62 \%$ and the average calculated $\%$ error is $2.32 \%$ which is less than $5 \%$. Therefore, for the prediction of the thrust force in drilling bamboo filler reinforced epoxy composites, the regression model can be used effectively with greater accuracy. The actual S-N ratio values and the predicted $\mathrm{S}-\mathrm{N}$ ratio values are compared by plotting a graph as shown in Figure 10. In the figure, the $\mathrm{x}-$ axis signifies the experiment set number in which 0-9, 10-18, 19-27, 28-36, 37-45 and 46-54 are the experiments performed for $0 \%, 2.5 \%, 5 \%, 7.5 \%, 10 \%$ and $12.5 \%$ filler content respectively, while the $\mathrm{y}$-axis shows the actual and predicted $\mathrm{S}-\mathrm{N}$ ratio values. 
$110 \quad 10^{\mathrm{TH}}$ International Conference on Sustainable Energy and Environmental Protection (June $27^{\mathrm{TH}}-30^{\mathrm{TH}}, 2017$, Bled, Slovenia), Mechanical ENGineERING C. Malakar \& S. Bhowmik: Assessment of Optimal Drilling Parameter for Bamboo Filler Reinforced Epoxy Composite

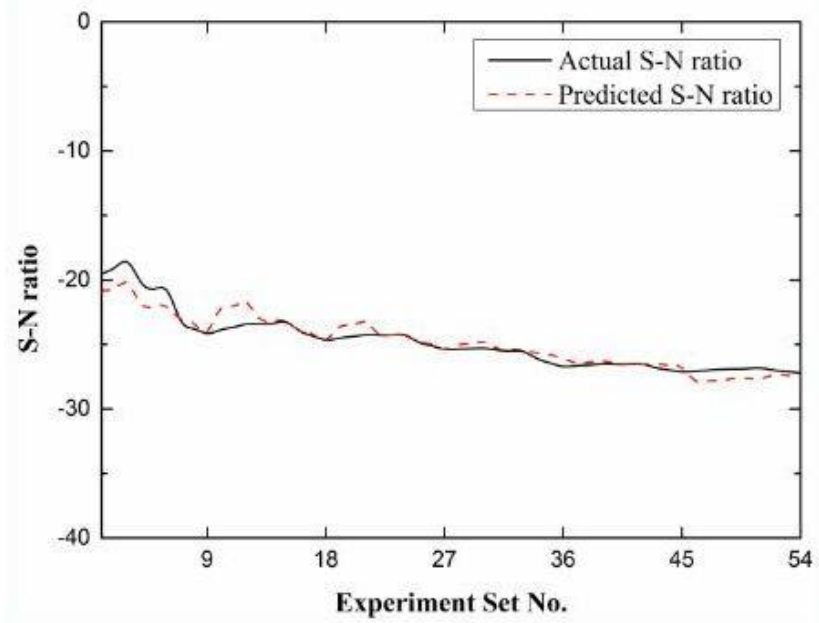

Figure10. Comparison of actual and predicted S-N ratio results for thrust force.

An experimental investigation was performed in order to determine the influence of reinforcing bamboo filler loading, spindle speed and drill diameter on the thrust force. In the present investigation, it is found that with increase in drill diameter, the thrust force increases and the effect of spindle speed is found to be insignificant. The thrust force increases up to $7.5 \%$ filler content and then it gradually decreases due to the weaker bonding between epoxy matrix and bamboo filler. A correlation between drill diameter, spindle speed, filler percentage and the thrust force has been established for predicting the thrust force by using non-linear regression analysis. Coefficient of effectiveness $\left(\mathrm{R}^{2}\right)$ for the regression model is found to be 0.88 and the analysis is carried out at a confidence level of $90 \%$ i.e. p-value $(<0.1)$ indicating the feasibility of the analysis. A confirmation analysis has also been performed to show the accuracy of the developed formula which concludes its ability to predict the thrust force in drilling bamboo filler reinforced epoxy composites.

\section{References}

[1] A. M. Abrao, P. E. Faria, J. C. C.Rubio, P. Reis and J. P. Davim, "Drilling of fiber reinforced plastics: A review,"J. Materials Process. Technol. Vol. 186, pp. 1-7, 2006.

[2] R. Kumar, K. Kumar, P. Sahoo and S. Bhowmik, "Study of Mechanical Properties of Wood Dust Reinforced Epoxy Composite”. Procedia Mater. Sci. vol. 6, pp. 551-556, 2014.

[3] U. A. Khashaba, M. A. Seif and M. A. Elhamid, "Drilling analysis of chopped composites," Compos Part A Appl Sci Manuf, vol. 38, pp. 61-70, 2007.

[4] B. R. Raju, B. Suresha, R. P. Swamy and B. S. G. Kanthraju, "Assessment of Cutting Parameters Influencing on Thrust Force and Torque during Drilling Particulate Filled Glass Fabric Reinforced Epoxy Composites," J Miner Mater Charact Engvol. 1, pp. 101-9, 2013. 

Protection (June $27^{\mathrm{TH}}-30^{\mathrm{TH}}, 2017$, Bled, Slovenia), MeChanical ENGineERING C. Malakar \& S. Bhowmik: Assessment of Optimal Drilling Parameter for Bamboo Filler Reinforced Epoxy Composite

[5] M. Ramesh, K. Palanikumar and K. H. Reddy, "Experimental Investigation and Analysis of Machining Characteristics in Drilling Hybrid Glass Sisal Jute Fiber Reinforced Polymer Composites", presented at the 5th Int 26th All India Manuf Technol Des Res Conf (AIMTDR), Guwahati, 2014, pp. $1-6$.

[6] El. I. Sonbaty, U. A. Khashaba and T. Machaly, "Factors affecting the machinability of GFR / epoxy composites," Composite Structure,vol. 63, pp. 329-38, 2004.

[7] U. A. Khashaba, I. A. El-Sonbaty, A. I. Selmy and A. A. Megahed,"Machinability analysis in drilling woven GFR / epoxy composites: Part II - Effect of drill wear". Compos Part A Appl Sci Manuf vol. 41, pp. 1130-7, 2010.

[8] V. Parashar, A. Rehman, J. L. Bhagoria, and Y. M. Puri, "Statistical and regression analysis of Material Removal Rate for wire cut Electro Discharge Machining of SS 304L using design of experiments" International Journal of Engineering Science and Technology, vol. 2, pp. 1021-1028, 2010.

[9] Jagadish, S. Bhowmik and A. Ray, "Prediction of surface roughness quality of green abrasive water jet machining: a soft computing approach," Journal of Intelligent manufacturing, pp: $1-15,2015$. 
112 10 $10^{\mathrm{TH}}$ International Conference On Sustainable EnERgy and Environmental Protection (June $27^{\mathrm{TH}}-30^{\mathrm{TH}}, 2017$, BLed, Slovenia), Mechanical EngineERING 
$10^{\mathrm{TH}}$ InTERnational CONFERENCE ON Sustainable ENERgy AND EnVironmental Protection (June $27^{\mathrm{TH}}-30^{\mathrm{TH}}$, 2017, Bled, SLOVENIA), MECHANICAL ENGINEERING

J. Krope, A.Ghani Olabi, D. Goričanec \& S. Božičnik

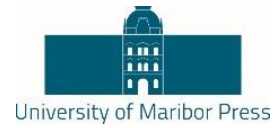

\title{
Domestic Hot Water Consumption in District Heating in Hungary
}

\author{
LÁSZLÓ GARBAI, ANDOR JASPER \& ZOLTÁN MAGYAR
}

\begin{abstract}
The paper presents the methodology for the risk-based dimensioning of domestic hot water (DHW). It is demonstrated that they are stochastic variables. DHW demands are specified on the basis of hot water consumption statistics in Hungary.
\end{abstract}

Keywords: - domestic hot water $\bullet$ stochastic variables $\bullet$ risk-based dimensioning $\bullet$ consumption $\bullet$ Hungary $\bullet$

CORRESPONDENCE AdDRESS: László Garbai Ph.D, Emeritus Professor, Budapest University of Technology and Economics, Department of Building Service and Process Engineering, Müegyetem rkp 3, 1111 Budapest, Hungary, e-mail: garbai@epgep.bme.hu. Andor Jasper, Ph.D., Research Assistant, Budapest University of Technology and Economics, Department of Building Service and Process Engineering, Müegyetem rkp 3, 1111 Budapest, Hungary, e-mail: jasper@epgep.bme.hu. Zoltán Magyar, Ph.D., Associate Professor, Budapest University of Technology and Economics, Department of Building Energetics and Building Service Engineering, Müegyetem rkp 3, 111 Budapest, Hungary, e-mail: Magyar@egt.bme.hu. 
$11410^{\mathrm{TH}}$ International Conference on Sustainable Energy and Environmental Protection (June 27 $7^{\mathrm{TH}}-30^{\mathrm{TH}}, 2017$, Bled, Slovenia), Mechanical ENGineERING

L. Garbai, A. Jasper \& Z. Magyar: Domestic Hot Water Consumption in District Heating in Hungary

Professional literature published abroad so far has not discussed the probability description of domestic hot water and heating demands [1], [2], [3], [4], [5], [6], [7]. The DIN 4708 standard, still applied in Germany today, provides a method for calculating domestic hot water demands on a deterministic basis [8]. In Hungary, this topic was looked into as early as the 1970 s, and the probability theory approach was introduced.

\section{Probability Features of Domestic Hot Water Demands}

Measurement experiences have shown that the quantity and intensity of consumption indicate random and incalculable fluctuations for any group of consumers involving an arbitrary number of apartments at any time of day and in terms of any duration; therefore they can be considered as probability variables and can be described by probability function relationships. In regard to consumption of any duration, consumption is characterized by its density and distribution functions. According to theoretical expectations, the distribution function can be considered as normal, which is determined by its two parameters - namely the expected value and standard distribution - to be specified by measurements. In case of domestic hot water consumption and intensity of any duration, the so-called significant values are sought for. Significant values are characterized by the fact that by definition, it can be expected at a 95 or $99 \%$ reliability rate that no value higher than them will occur in the consumption period examined.

In 2004 and 2005, Budapesti Távhőszolgáltató Zrt. (Budapest District Heating Works Private Company Limited by Shares) measured the hot water consumption of several buildings on an on-going basis and processed the figures yielded. Calculation formulas were developed to determine the duration diagrams of consumptions and consumption intensities (consumption figures per minute) of various durations [9].

\subsection{Examination of DHW demands based on the theory of stochastic processes}

Strictly speaking, the trend of the intensity of daily DHW demands by time of day is a stochastic process. On the basis of both the qualitative examination and exact statistical analyses, two characteristic periods can be discerned on weekdays: the morning peak and the late afternoon peak. In order to determine the significant process of DHW demands and to dimension heat exchanger and storage facilities on the basis thereof - the process of the late afternoon peak must be described.

It is obvious that the development through time of consumption intensity values $V^{\prime}(\tau)$ is interpreted as a stochastic process X_t.

In the present phase of research, the treatment of DHW consumption as a stochastic process is accepted as a reasonable hypothesis. At the same time, as I there was no opportunity to generate multidimensional correlation functions and covariance functions, the problem approach was simplified in certain aspects. Process description is focused on the peak 
$10^{\mathrm{TH}}$ INTERNATIONAL CONFERENCE ON SUSTAINABLE ENERGY AND ENVIRONMENTAL Protection (June $27^{\mathrm{TH}}-30^{\mathrm{TH}}, 2017$, Bled, Slovenia), Mechanical EngineERing L. Garbai, A. Jasper \& Z. Magyar: Domestic Hot Water Consumption in District Heating in Hungary

period. Visually, the process is considered stationary. Average expected values and average standard deviation are defined for the peak period, which are averaged per apartment unit. It should be noted that each of the stochastic processes to describe the DHW consumption of a specific building are different from one another. There is no transformation to homogenize stochastic processes. References made to a so-called unit of apartment approximate processes to each other, but do not make them identical. Stochastically, the DHW consumption of buildings of even an equal number of apartments is dissimilar. Nevertheless, referencing to a unit of apartment will be applied as a working hypothesis, which is allowable in engineering practice.

\subsection{New procedure and model for the probability theory description of DHW distribution and equipment dimensioning}

Typically, there is a morning peak between about 6.00 and 8.00 a.m., when people get up and go to work or school; and there is an evening peak between about 6.00 and 10.00 p.m., when people have a bath or a shower at the end of the day. Consumptions during these two peak periods are characteristically higher than demands measurable during the daytime; however, there are discrepancies as to which period represents the benchmark.

\subsection{Measurement data}

In our study we processed the data series measured by Budapesti Távhöszolgáltató Zrt. in the period 2004-2005. During the measurement lasting several weeks, the DHW consumption measured in 58 different buildings was recorded in a per minute breakdown.

Measurements were performed in the buildings for an average of 19.7 days, meaning that 1104 days of rundown patterns are available in total. 1140 minutes of data were recorded each day. This data set including a total of approx. 1.6 million measurement results was processed in my dissertation.

\subsection{Processing of measurement data}

Tests and measurements indicate that the temporal course of peak period DHW outputs can be considered as a stationary stochastic process with good approximation. This means that the average of intensity values is deemed to be constant in the peak period. Therefore output measurement statistics can be used to estimate the average expected value and standard deviation. Such average expected value and standard deviation deemed to be constant are also characterized by distribution and standard deviation. Empirical density and standard deviation functions can be produced for average expected value and standard deviation. The nature of distribution should be hypothesized. A match test should be conducted to demonstrate the hypothesis. Based on statistics so far, it can be rendered probable that normal distribution or Weibull distribution can be attempted to be applied. Based on the nature thereof it was adjudged that Weibull distribution enables a more accurate description. Completion of the duration diagram of peak period consumption intensities is crucial for dimensioning. Each point of the duration diagram is generated by looking up 
$116 \quad 10^{\mathrm{TH}}$ InTERnATIONAL CONFERENCE ON Sustainable ENERGY AND ENVIRONMENTAL Protection (June 27 $7^{\mathrm{TH}}-30^{\mathrm{TH}}, 2017$, Bled, Slovenia), Mechanical ENGineERING

L. Garbai, A. Jasper \& Z. Magyar: Domestic Hot Water Consumption in District Heating in Hungary

the probability associated with the output value concerned in the distribution function and multiplying the duration of the peak period examined by this value. Theoretically, duration diagrams are different for each building.

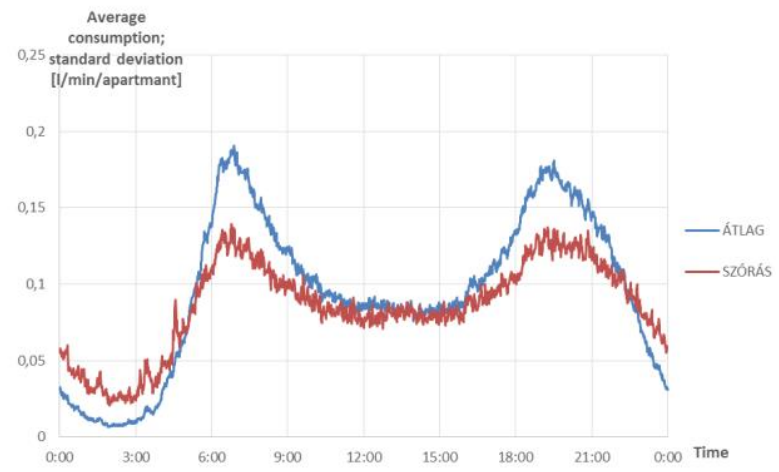

Figure 1. Average consumption and standard deviation "normalized" to the number of apartments as per unit of apartment, broken down to minutes: each point is the average of 1104 pieces of data Paper Layout

Storage and heat exchanger dimensioning should be designed by taking peak period DHW demand rundown patterns as a basis. Figure 1. shows daily consumption intensities averaged per apartment unit based on the number of apartments in all buildings and the standard deviation of intensity values in a per minute breakdown. The figure indicated that there are two peak periods of consumption. The highest probability of the morning peak is the 120 minutes between 6:00 and 8:00 a.m., and the evening peak between 6:30 and 8:30 p.m. It was hypothesized that the daily peak period typically takes place during the evening hours, so this period was investigated, but as shown in Figure 1, the patterns of the evening and morning peaks are similar. Therefore, it would be worthwhile to examine this period as well for the sake of a more complete investigation, but this fell out of the scope of this dissertation.

The average of consumption intensities in each building was specified for each minute of the peak period, together with deviations from the average, that is, the standard deviation of the sample. Taking an average per unit of apartment of these figures based on the number of apartments makes buildings comparable with each other; therefore the average specific consumption intensity and standard deviation calculated for all the buildings can be specified in each minute of the peak period.

Specific consumption intensity can be stated by the following formula:

$a_{i}=\frac{\overline{\hat{V}}_{i}}{n}$ 
where
$\mathrm{n} \quad$ is the number of apartments,
$\overline{\dot{V}}_{i} \quad$ is the average of consumption intensity in minute i, calculated from the data measured on all of the days.

And standard deviation - averaged per unit of apartment on the basis of the number of apartments - can be calculated using the following formula:

$\sigma_{i}=\frac{\overline{\sigma_{l}}}{n}$

The average consumption and standard deviation - averaged per unit of apartment on the basis of the number of apartments - calculated for each minute of the peak period are shown in Figure 2.

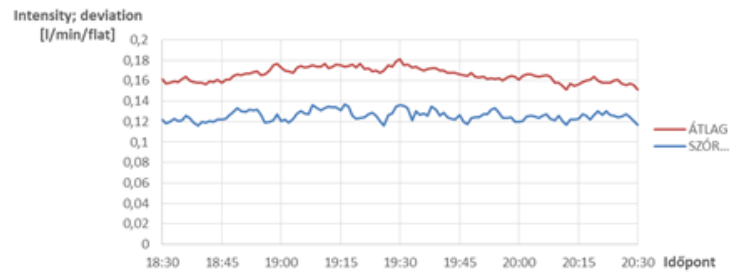

Figure 2. Peak period specific consumption intensity and standard deviation

As shown in Figure 2, both average and standard deviation values - averaged per unit of apartment on the basis of the number of apartments - are within a small interval, therefore, as I mentioned, I applied the simplification that consumption during peak periods can be considered as a stationary process. Then the entire peak period can be characterized by an average consumption intensity and a corresponding standard deviation.

Expected value of the peak consumption intensity of 5085 apartments:

$a=\frac{1}{120} \cdot \sum_{i=18: 30}^{20: 30} a_{i}=0,1660 \frac{l}{\text { min.apartment }}$.

Standard deviation of the peak consumption intensity of 5085 apartments:

$\sigma=\frac{1}{120} \cdot \sum_{i=18: 30}^{20: 30} \sigma_{i}=0,1257 \frac{l}{\text { min.apartment }}$

A duration diagram of normal distribution, characterized by standard deviation a $(0.166$ liter/minute) and standard deviation $\sigma$ (0.1257 liter/minute), is shown in Figure 3. 
$10^{\text {Th }}$ International Conference on Sustainable Energy and Environmental Protection (June 27 $7^{\mathrm{TH}}-30^{\mathrm{TH}}, 2017$, Bled, Slovenia), Mechanical ENGineERING

L. Garbai, A. Jasper \& Z. Magyar: Domestic Hot Water Consumption in District Heating in Hungary

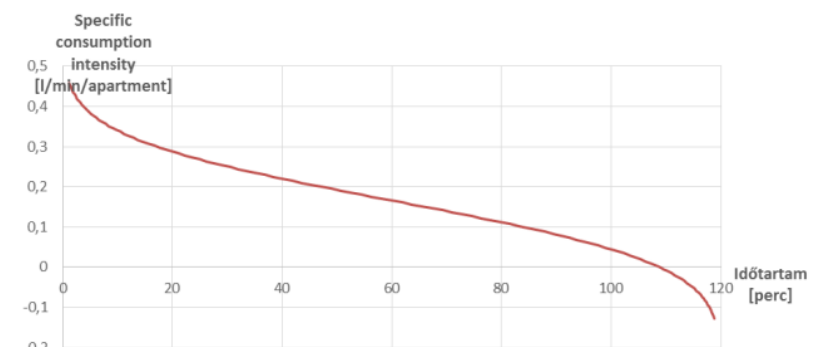

Figure 3. Evening peak rundown pattern based on normal distribution parameters

\subsection{Analysis of peak consumption averages}

The figure to characterize peak period DHW consumption is the total quantity of water used during the given period. It can be used to determine the average per minute DHW quantity utilized in a given peak period if the duration of the peak period is known. The peak period average consumption figures thus yielded can be compared to each other within a building and if averaged per unit of apartment on the basis of the number of apartments, and the entire data set can be managed together as a whole. The empirical distribution of consumption figures can be determined by sorting this mass of data containing the average of 1,104 measurement days, yielded by expressing consumption as average per unit. I previously presumed that in a peak period, both consumption intensity and its standard deviation can be described as a stationary process, and the entire peak period can be characterized by a single probability variable. I assumed that the empirical distribution of peak period consumption average values will approximate a distribution possible to be described mathematically. By arranging consumptions in a histogram, the density function shown in Figure 4. was yielded. Based on the density function, I presumed that distribution was to follow the Weibull distribution; therefore I performed the $\chi^{2}$ test, which verified this conjecture. The approximative Weibull density function is shown by the curve fitted to the diagram.

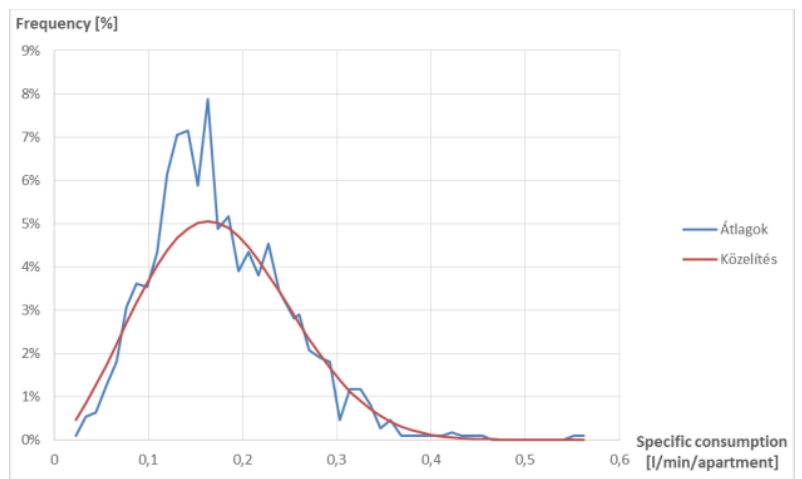

Figure 4. Distribution of peak period consumption averages 
A more suggestive basis for comparison is yielded by Figure 5., showing the empirical distribution curve and the distribution function of Weibull distribution. In order to err on the safe side, the parameters of approximative distribution were selected to yield probabilities at higher consumption levels in case of proper fit than in case of empirical distribution. Graphically, this means that the approximative Weibull distribution curve in Figure 5. is to the right of the empirical distribution curve.

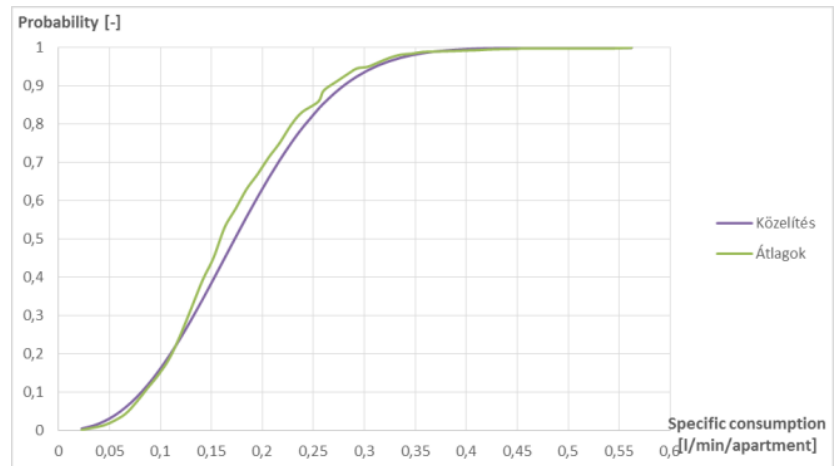

Figure 5. Distribution functions of empirical distribution and approximative Weibull distribution

In the knowledge of distribution parameters, the average consumption value of the peak period can be determined at the desired degree of certainty. The density function of approximative Weibull distribution can be described by formula (5), and its distribution function by formula (6).

$f(x)=\frac{k}{\lambda} \cdot\left(\frac{x}{\lambda}\right)^{k-1} \cdot e^{-\left(\frac{x}{\lambda}\right)^{k}}$,

$F(x)=1-e^{-\left(\frac{x}{\lambda}\right)^{k}}$,

Where

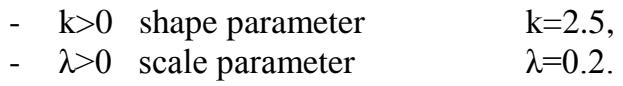

Storage and heat exchanger dimensioning requires an estimate of not only peak period average consumption but of consumption rundown patterns as well. It was stated earlier that the daily rundown pattern of DHW demands follows normal distribution, so this presumption was used for peak period rundown patterns. In order to be able to generate a duration diagram of peal period consumption values, another parameter is required to be determined for the description of normal distribution - the standard distribution of the sample examined. 
$120 \quad 10^{\mathrm{TH}}$ InTERnational CONFERENCE ON Sustainable ENERGY AND ENVIRONMENTAL Protection (June 27 $7^{\mathrm{TH}}-30^{\mathrm{TH}}, 2017$, Bled, Slovenia), Mechanical ENGineERING

L. Garbai, A. Jasper \& Z. Magyar: Domestic Hot Water Consumption in District Heating in Hungary

\subsection{Investigation of the standard distribution of peak period consumption averages}

Figure 6. shows changes in the standard distribution of the average values of peak period consumption as a function of the number of apartments. It can be observed that the addition theorem on the variance of independent probability variables is present, though with a stochastic character, from which

$\frac{\sigma_{1}}{\sigma_{n}}=\frac{\sqrt{n_{1}}}{\sqrt{n_{2}}}$

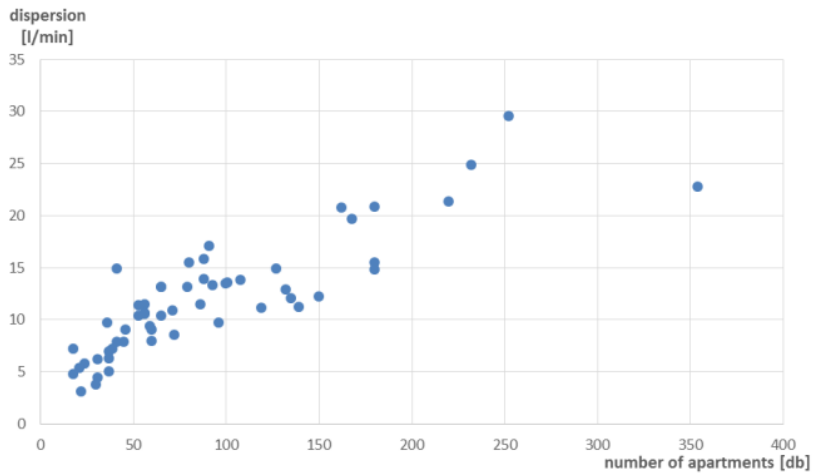

Figure 6. Standard distribution values as a function of the number of apartments

Figure 7. shows how the specific standard distribution of peak period consumption intensities changes as a function of specific average consumption. The relationship is described by linear regression. Specific standard distribution and specific consumption are related value pairs.

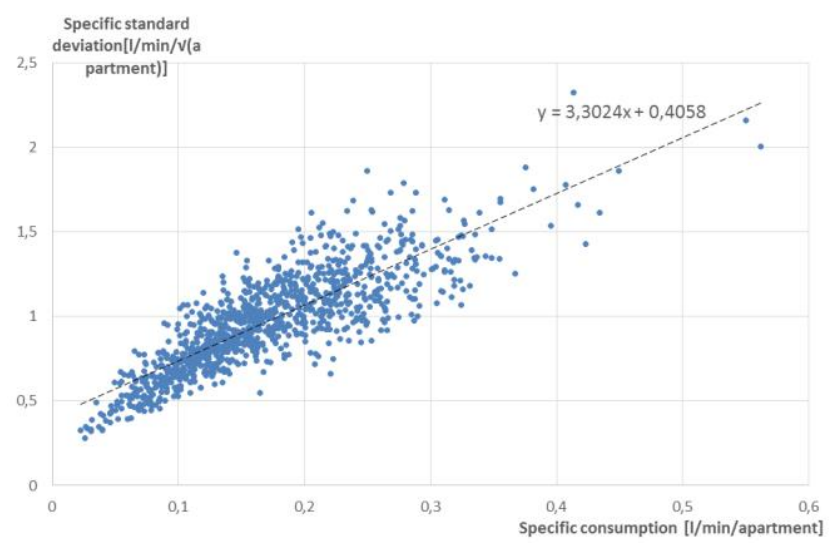

Figure 7. Standard deviation normalized to the root of the number of apartments as a function of specific consumption 
The figure indicates a correlation between specific consumption and standard deviation averaged per unit. A linear trend line is fitted to the points of the diagram, resulting in the dotted line shown in Figure 7.

\subsection{Selection of expected value and standard deviation}

It was shown that average consumption values in the evening peak period follow the Weibull distribution to be characterized by the following distribution function:

$F(x)=1-e^{-\left(\frac{x}{\lambda}\right)^{k}}$,

where

- $\mathrm{k} \quad$ is a scale parameter (value: 0.2 ),

- $\lambda \quad$ is a shape parameter (value: 2.5 ).

The Weibull distribution characterized by the parameters specified was shown by Figure 4. and Figure 6. By substituting $\mathrm{F}(\mathrm{x})$ in the formula describing the distribution function for the desired certainty the specific consumption in the peak period can be yielded:

$a=\lambda \sqrt[k]{-\ln (1-p)}$

Where

- p is the reliability level.

It was shown that standard distributions change according to $1 / \sqrt{n}$ as a function of the number of apartments. Standard deviation per apartment can be calculated as a function of the expected value according to Figure 7.:

$\sigma_{u \%}=3,3024 a+0,4058$.

From the calculated standard deviation, averaged per unit of $\sqrt{n}$, it is possible to calculate the standard deviation averaged per unit of apartment on the basis of the number of apartments:

$\sigma_{f}=\frac{\sigma_{u \%}}{\sqrt{n}}$

The formulas listed above can be used to specify the duration diagram of peak period DHW consumptions for any reliability level and for a number of apartments $n>15$. Table 1 . includes the expected value and standard deviation of specific consumption for several typical cases of dimensioning probability. 
$12210^{\mathrm{TH}}$ InTERnational CONFERENCE ON Sustainable ENERGy AND ENVIRONMENTAL Protection (June 27 $7^{\mathrm{TH}}-30^{\mathrm{TH}}, 2017$, Bled, Slovenia), Mechanical ENGineERING

L. Garbai, A. Jasper \& Z. Magyar: Domestic Hot Water Consumption in District Heating in Hungary

Table 1. Expected value and standard deviation normalized to $\sqrt{n}_{\mathrm{n}}$ of peak period average consumption intensity

\begin{tabular}{|c|c|c|}
\hline $\begin{array}{c}\text { RELIABILITY } \\
\text { LEVEL }\end{array}$ & $\mathrm{a}$ [L/MINUTE/AP.] & $\sigma_{u \%}[\mathrm{~L} / \mathrm{MINUTE} / \sqrt{\mathrm{AP} .}]$ \\
\hline 99.9 & 0.433 & 1.837 \\
\hline $99 \%$ & 0.368 & 1.622 \\
\hline $98 \%$ & 0.345 & 1.546 \\
\hline $95 \%$ & 0.310 & 1.430 \\
\hline
\end{tabular}

The specific expected value and specific standard deviation determined on the basis of equations (10), (11) and (12) can be used to identify the expected value and standard deviation of consumption by the building concerned.

$m=n \cdot a$.

$\sigma=n \cdot \sigma_{f}$

The duration diagram of the evening peak period can be produced using these two parameters. The DHW heat exchanger and storage can be dimensioned in the knowledge of the rundown pattern of the duration diagram.

\subsection{Generation of consumption intensity duration diagrams}

The expected values and standard deviations - determined by the procedure presented in the preceding chapters - can be used to produce the duration diagram of DHW consumption intensities. The distribution functions resulting from measurement data appear to present normal distribution (see: Figure 8.). In order to demonstrate normality, a $\chi^{2}$ test was conducted. As a result of the test it can be declared that the distribution function produced by averaging peak period consumption data measured in the buildings can be approximated by normal distribution.

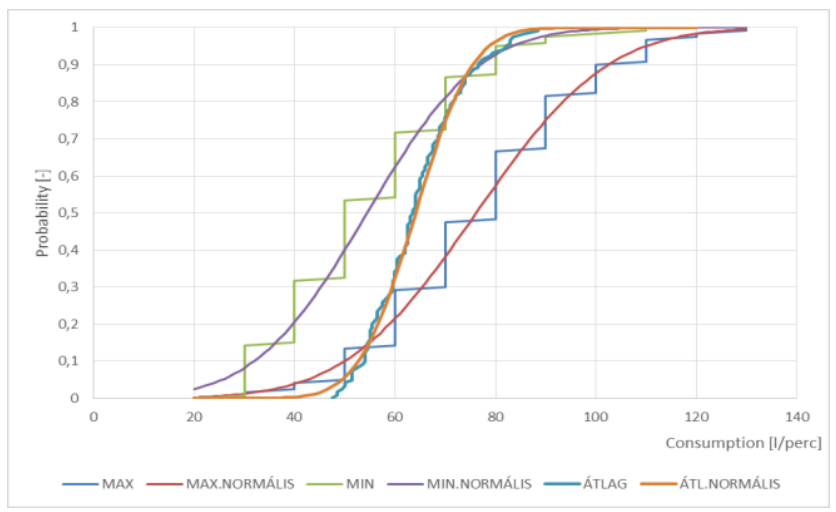


$10^{\mathrm{TH}}$ INTERNATIONAL CONFERENCE ON SUSTAINABLE ENERGY AND ENVIRONMENTAL

Figure 8. Distribution function - empirical and theoretical - generated from the minimum, maximum, and average daily peak period values selected from the measurement data series of a condominium of 252 apartments

As a result of the tests, it can be stated that consumption duration diagrams for peak periods of 120 minutes can be described by the following equation:

$F(x)=120 \frac{1}{\sigma \sqrt{2 \pi}} \int_{-\infty}^{t} e^{-\frac{(x-m)^{2}}{2 \sigma^{2}}} d x$

where:

- $\mathrm{m}$

is the expected value of consumption intensity,

$-\sigma$ is the standard deviation of consumption intensity.

The duration diagram produced can be used for dimensioning the heat exchanger and the heat source at a chosen reliability level, as a function of the discharge time selected by the design engineer.

\section{Conclusions}

We elaborated a probability theory model based on the theory of stochastic processes in order to describe the probability distribution and sorted duration diagram of peak period consumption intensity figures. We designed this model based on measurements conducted by FÖTÁV in 2004-2005. We established that the process of peak period consumption intensities can be approximated by a stochastic process. The expected average value of peak period consumption intensity can be approximated by Weibull distribution. We established that peak period consumption distribution is of normal distribution, and its duration diagram can be derived by normal distribution in function of the number of apartments.

\section{References}

[1] Chen Xi, Lu LIn, Yang Hongxing: Long Term Operation of Solar Assisted Ground Coupled Heat Pump System for Space Heating and Domestic Hot Water, Energy and Bulidings, 43 (2011) pp.1835-1844.

[2] John C. Evarts, Lukas G. Swan: Domestic Hot Water consumption Estimates for Solar Thermal System Sizing, Energy and Buildings, 58 (2013), pp. 58-65.

[3] Jordan, U., Vajen, K. 2000. Influence of the DHW load profile on the fractional energy savings : A case study of a solar combi-system with Trnsys simulations. Solar Energy 69, pp. 197-208. 2001.

[4] U. Jordan and K. Vajen. DHWcalc: Program to generate domestic hot water profiles with statistical means for user defined conditions. In: Proceedings of the ISES Solar World Congress, Orlando, USA, 8-12 August 2005. 
124 10 $10^{\mathrm{TH}}$ InTERnational CONFERENCE ON Sustainable ENERGy AND ENVIRONMENTAL Protection (June $27^{\mathrm{TH}}-30^{\mathrm{TH}}, 2017$, Bled, SLovenia), Mechanical ENGineERING

L. Garbai, A. Jasper \& Z. Magyar: Domestic Hot Water Consumption in District Heating in Hungary

[5] Hendron, R., Burch, J., Barker, G. 2010. Tool for generating realistic residentialhot water event schedules. Proceedings of the Fourth National Conference of IBPSA-USA, Simbuild 2010. New York City, New York.

[6] B.Bøhm: Production and distribution of domestic hot water in selected Danish apartment buildings and institutions, Energy Concersion and Management (67) 2013 pp. 152-159.

[7] R. Spur, D. Fiala, D. Nevrala, D. Probert: Influence of the domestic hot-water daily draw-off profile on the performance of a hot-water store, Applied Energy, 83 (2006) pp.749-773.

[8] DIN 4708-2:1994; Zentrale Wassererwärmungsanlagen; Regeln zur Ermittlung des Wärmebedarfs zur Erwärmung von Trinkwasser in Wohngebäuden.

[9] Lakóépületek mértékadó használatimelegvíz-fogyasztásának meghatározása, Budapesti Távhőszolgáltató Zrt. (összeállította: Dr Szánthó Zoltán, Némethi Balázs), 2005. (in hungarian) 



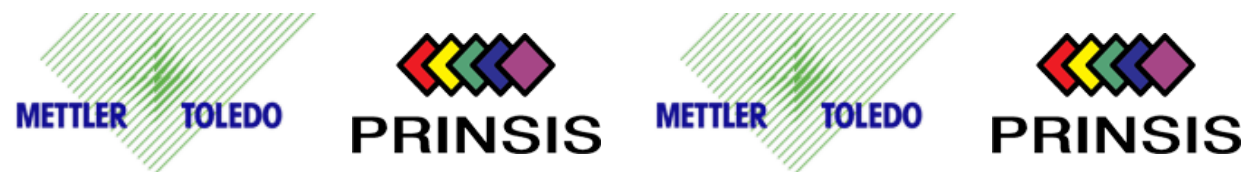

$€$ energetika ljubljana $€$ energetika ljubljana

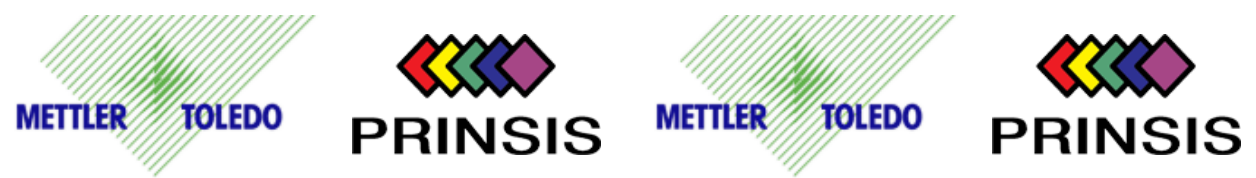

$€$ energetika ljubljana $€$ energetika ljubljana

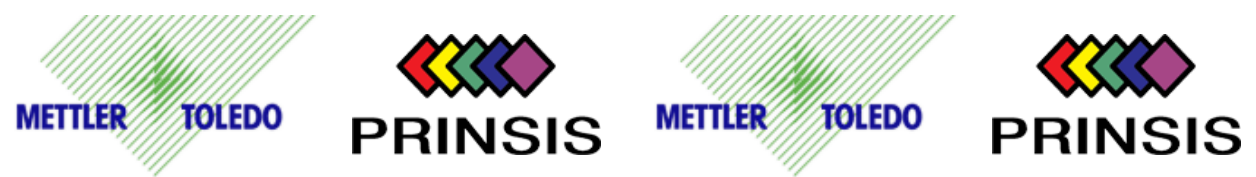

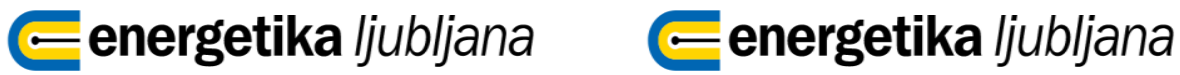

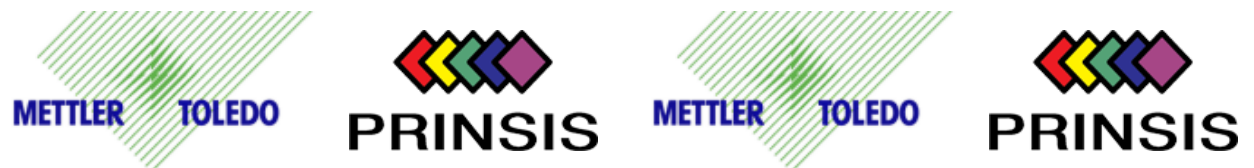

$€$ energetika ljubljana $€$ energetika ljubljana

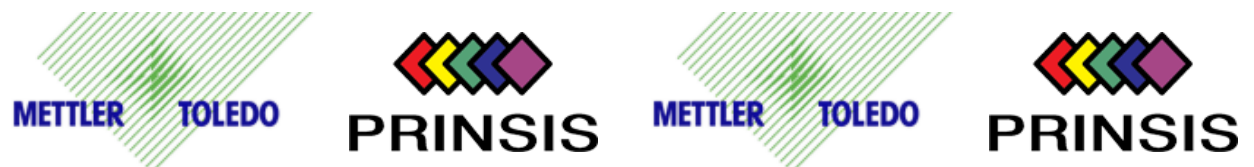

$€$ energetika ljubljana $€$ energetika ljubljana 